COMMON COMMODITIES

\title{
AND INDUSTRIES
}
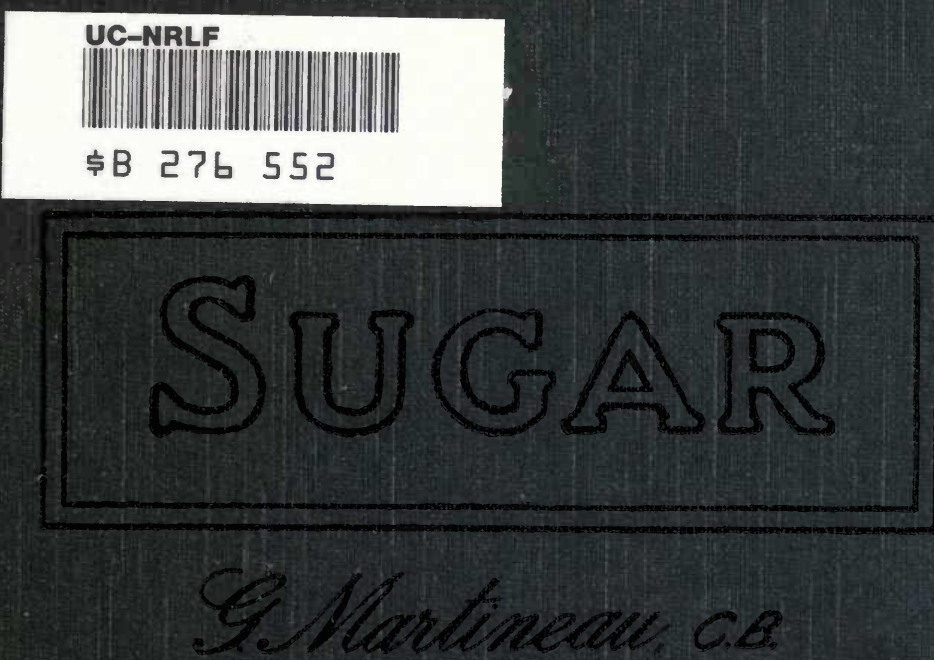

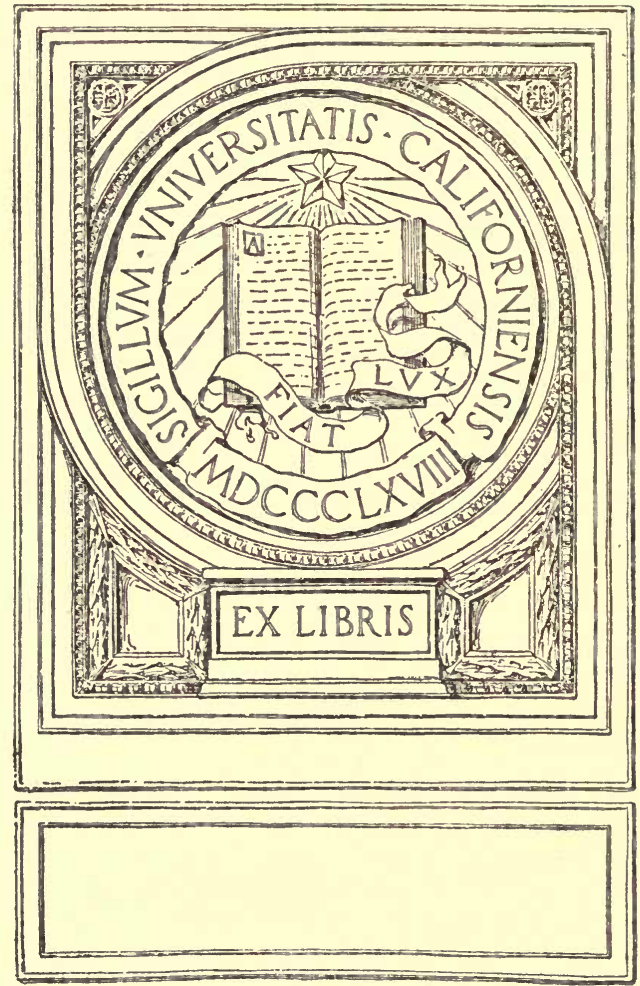


SUGAR 


\section{Common Commodities and Industries Series}

Each book in crown 8vo, cloth, with many illustrations, charts, etc. 2s. net.

Tea : From Grower to Consumer. By A. Ibbetson. Coffee : From Grower to Consumer. By B. B. Keable. Sugar: Cane and Beet. By Geo. Martineau, C.B.

Cotton: From the Raw Material to the Finished Product. By R. J. Peake.

Rubber : Production and Utilisation of the Raw Product. Bv C. Beadle and H. P. Stevens, M.A., Ph.D., F.I.C.

Iron and Steel: Their Production and Manufacture. By C. Hood.

Silk: Its Production and Manufacture. By Luther Hooper.

Tobacco: From Grower to Smoker. By A. E. Tanner. Wool: From the Raw Material to the Finished Product. By J. A. Hunter.

Coal : Its Origin, Method of Working, and Preparation for the Market. By Francis H. Wilson, M.Inst.M.E. Linen: From the Field to the Finished Product. By Alfred S. Moore.

Timber: From the Forest to its Use in Commerce. By William Bullock.

Clays and Clay Products. By A. B. Searle.

Leather : From the Raw Material to the Finished Product. By K. J. Adcock.

Oils : Animal, Vegetable, Essential, and Mineral. By C. Ainsworth Mitchell, B.A., F.I.C.

Wheat and its Products. By A. Millar.

Copper: From the Ore to the Metal. By H. K. Picard, Assoc. Royal School of Mines, Mem. Inst. of Min. and Met.

Paper: Its History, Sources, and Production. By H. A. Maddox.

Glass and Glass Manufacture. By Percival Marson.

Soap : Its Composition, Manufacture, and Properties. By William H. Simmons.

The Motor Industry. By Horace Wyatt, B.A.

The Boot and Shoe Industry. By J. S. Harding.

Gums and Resins. By Ernest J. Parry.

Other Volumes in preparation. 



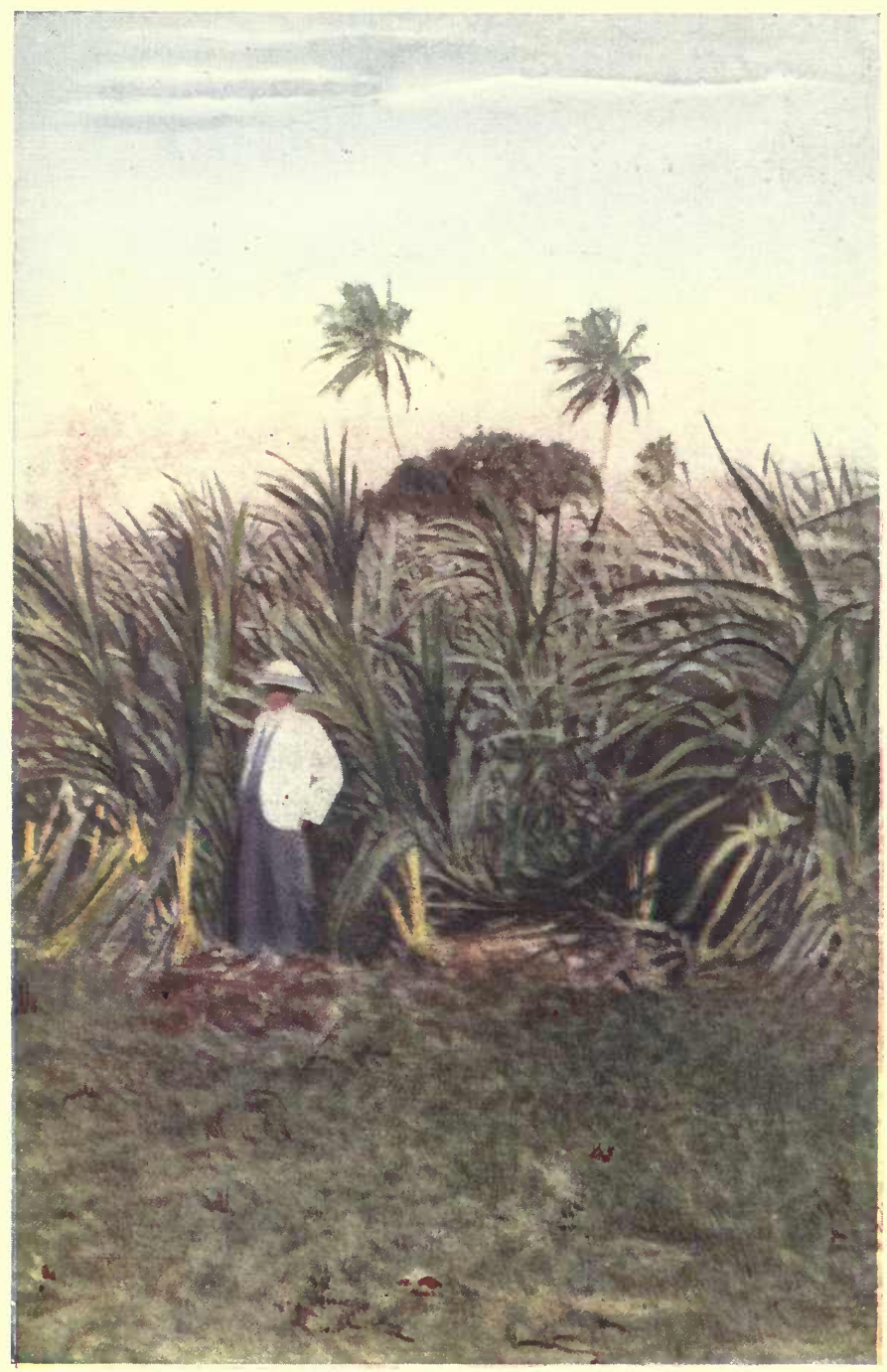

Photo by

N. P. Edwards, Littlehampton

SANTA CRUZ-A FIELD OF SUGAR CANE contun? 


\section{PITMAN'S COMMON COMMODITIES}

\section{AND INDUSTRIES}

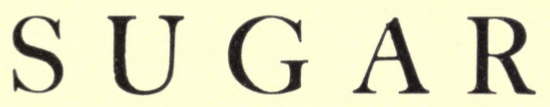

CANE AND BEET

AN OBJECT LESSON

\section{BY \\ GEORGE MARTINEAU, C.B.}

Secretary to the British Sugar Refiners' Committee, I872-92. Adviser to the British Delegates at the International

Conferences of 1875-6-7, I888, I898, and I901-2. Assistant British Delegate on the Permanent International Sugar Commission at Brussels, r903-5

LONDON

Sir Isaac Pitman \& Sons, Ltd., 1 Amen Corner, E.C. 4 And at Bath, New York and Melbourne 


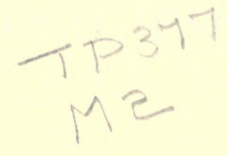

First Edition, February, 1910.

Second Edition, November, 1910.

Third Edition, August, 1914.

Fourth Edition, February, 1918.

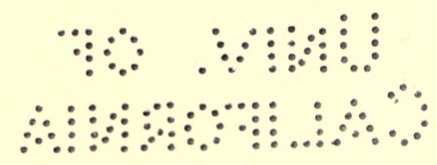

Printed by Sir Isaac Pitman \& Sons, Ltd., London, Bath, New York and Melbourne 


\section{Preface to the Fourth Edition}

THE statistics have been brought up to date, and so have the brief accounts of the various producing countries. The technical progress of the industry has consisted chiefly in the increased size of the factories and machinery. Improvements in the construction and use of the machinery continue to be evolved as time goes on, but do not develop anything sufficiently new to call for special notice in this elementary treatise. The only strikingly new feature is the extension of the system of producing white sugar direct from the cane juice and the perfecting of its methods. By white sugar is here meant fine, dry grocery sugar of the highest quality and whiteness, which will keep for any length of time without deteriorating. No cane sugar factory can produce such sugar without perfection in the arrangement of the necessary machinery, great skill and care on the part of the managers and workmen, and the carrying out of the process by methods recognized as most successful. This was comparatively easy in the case of the beetroot sugar industry; with cane juice greater care and skill are absolutely essential. It remains to be seen how far tropical management and labour will succeed in this new undertaking.

Several new books of very high class have appeared since the first edition of this little handbook. "The World's Cane Sugar Industry: Past and Present," by Dr. H. C. Prinsen Geerligs, published by Norman Rodger, 2 St. Dunstan's Hill, E.C., should be read by every one 
who wants to know all about the history of sugar, without being troubled with its technicalities. Those who desire the technicalities, most interesting and essential to the expert, must read the latest edition (1911) of Noel Deerr's "Cane Sugar," from the same publisher, who has also published " Practical White Sugar Manufacture" (1915), and "Chemical Control in Cane Sugar Factories" (1917), both by Dr. H. C. Prinsen Geerligs. Another book from the same publisher deals again with "Plantation White Sugar and its Manufacture," by Harloff and Schmidt, translated from the second revised Dutch edition by James P. Ogilvie, F.C.S., Technical Editor of the International Sugar Journal. A new book has recently appeared from the United States, "Something About Sugar," by George M. Rolph, a handsome volume, well illustrated, giving first a full account of production and refining, and then a history of the industry.

The diagram in the Appendix is merely intended to indicate that variation in visible supplies is the cause of variations in price. It is not put there for statistical purposes, but it does, incidentally, illustrate what happened at a very critical period in the history of sugar, namely, that the abolition of the bounties, in 1903, had no effect on the price of sugar, which remained rather below the cost of production, except when, in 1904, a bad beetroot crop, which deprived consumers of $1,200,000$ tons of sugar, sent prices up for a few months, until a good crop, in 1905, sent them down again below cost of production. 


\section{Preface to the First Edition}

THE publishers have asked me to write a little book on Sugar. I take this to mean a popular book which shall attract the reader by being, if possible, interesting as well as instructive, and that where technical detail is necessary it shall not be too " dry."

But for those whom I may succeed in interesting, and who may desire to know more and go deeper, I can recommend a few books of a reliable character. One of the greatest sugar experts of the present day is $\mathrm{H}$. C. Prinsen Geerligs, ${ }^{\mathbf{1}}$ who has been doing splendid work in Java for many years. He wrote a little book in 1902, published at the office of The Sugar Cane, Altrincham, on "Cane Sugar and the Process of its Manufacture in Java," which is easy to read and well worth reading. This was followed by a larger work in 1909, published by Norman Rodger at the same office, entitled "Cane Sugar and its Manufacture." It does what it professes, giving in one book all that is known of the chemistry and technology of the sugar cane and cane sugar manufacture. The technicalities relating to machinery it leaves to others, especially to Noël Deerr's work, "Sugar and the Sugar Cane." This book, a very excellent one, published in the same office, appeared in 1905. The most recent work, published by Edward Stanford in 1909, "The Manufacture of Cane Sugar," by Llewellyn Jones, M.I.E.S., and Frederic I. Scard, F.I.C., is also a fine work, profusely illustrated. A new edition, published by Spon, 1909, has recently appeared, of Newlands' portly and expensive volume, "Sugar: a Handbook for Planters and Refiners," bringing things

1 Now Dr. H. C. Prinsen Geerligs. 
up to date. I hasten to express my acknowledgments to all these authors. ${ }^{1}$

The Sugar Cane, now called The International Sugar Journal, published at Altrincham, ${ }^{2}$ is the best English vade-mecum for technical matters and general news connected with sugar. The West India Committee Circular is also well worth reading, full of interesting news and good pictures. The Journal des Fabricants de Sucre, the Paris organ of the French industry, has been one of my constant companions ever since its birth in 1860. It is a mine of accurate information on all matters connected with the world's sugar industry. From America we get the Louisiana Planter, the American Sugar Industry and Beet Sugar Gazette, ${ }^{3}$ Willett and Gray's Weekly Statistical Sugar Trade Journal, and other useful guides to knowledge. There are also German and Austrian sugar journals of a firstclass character for those who can read the language. The inquiring student, when he has read and digested the larger works which I have mentioned, can therefore keep up his knowledge from week to week by reading the journals of the day. If this little popular treatise succeeds in impelling him to further study I shall not have laboured in vain.

1 The following are exhaustive treatises on the beetroot sugar industry : "Beet-Sugar Manufacture," by Lewis S. Ware ; 2 vols., New York, 1905. "Treatise on the Manufacture of Beetroot Sugar," by Paul Horsin-Déon, revised and enlarged by Georges Horsin-Déon; third edition, 2 vols., Paris, 1912. "Treatise on the Manufacture of Beetroot Sugar," by Manoury, Paris.

2 Now 2 St. Dunstan's Hill, London, E.C.

3 Now Sugar. 


\section{CONTENTS}

CHAP.

PAGE

PREFACE TO FOURTH EDITION • • . . v

PREFACE TO FIRST EDITION . . , vii

I. A RETROSPECT $\quad$. . . . . . 1

II. CANE AND BEET . . . . . 13

III. CANE JUICE • . . . . . . . 26

IV. BEET JUICE • . . . . . . 38

V. CLARIFICATION . . . . . 50

VI. CRYSTALlizATION . $\quad . \quad$. $\quad . \quad 64$

VII. SUGAR REFINING . $\quad . \quad$. $\quad . \quad 30$

VIII. THE CANE INDUSTRY $\quad . \quad$. $\quad . \quad$. 89

IX. THE BEET INDUSTRY . . . . 104

X. COMPEtition . $\quad . \quad$. $\quad . \quad$. $\quad$. 117

XI. DIPLOMACY $\quad$ • $\quad . \quad$. $\quad . \quad$. 126

XII. THE SUGAR MARKET . . . . . 137

APPENDIX TO FIRST EDITION . . . . 145

APPENDIX TO FOURTH EDITION . . . 148

$\operatorname{INDEX} \quad . \quad . \quad . \quad . \quad . \quad . \quad . \quad . \quad 159$ 



\section{LIST OF ILLUSTRATIONS}

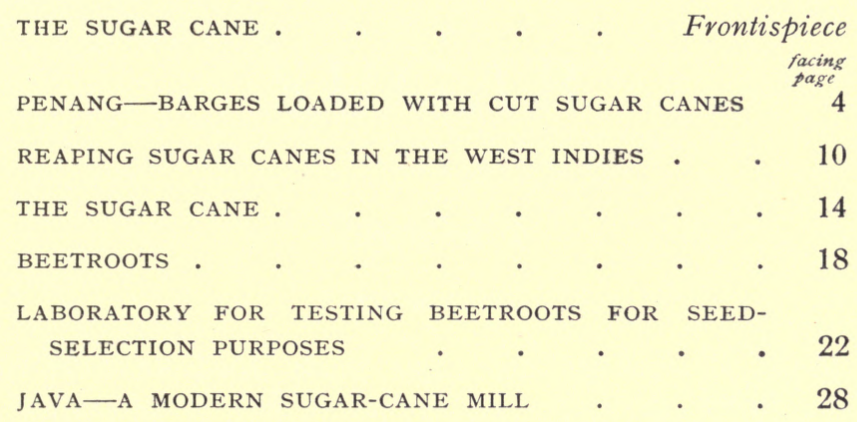

CRUSHING--SHOWING RIPE CANES IN CANE-CARRIERS 32

UNLOADING A CARGO OF BEETROOTS . . . 40

TRANSPORTING BEETROOTS TO THE FACTORY BY

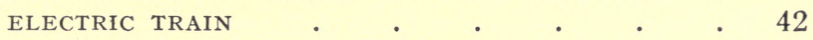

JAVA-SUGAR FACTORY $\quad$. $\quad . \quad$. $\quad . \quad 52$

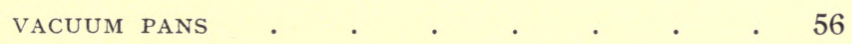

JAVA-DIGGING OUT A CANAL TO PROVIDE A

PLANTATION WITH WATER . . . . 62

A ROW OF CENTRIfUgal MACHINES . . $\quad$ • 72

CARRYING THE CANES TO THE FACTORY IN MEXICO 82

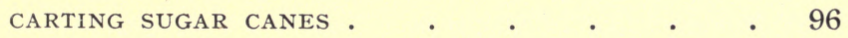

QUEENSLAND-CARRYING CUT CANES TO THE FACTORY 110

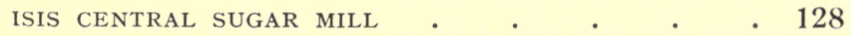

UNLOADING SUGAR CANES AT THE FACTORY . . 138

CHART SHOWING FLUCTUATION IN PRICES. end of book

MAP SHOWING SUGAR-PRODUCING COUNTRIES . , , , 



\section{SUGAR}

\section{CHAPTER I}

\section{A $\cdot$ RETROSPECT}

A POPULAR book about sugar can, perhaps, be made interesting as well as instructive. The dry details of growth, manufacture, distribution and consumption may here and there be flavoured, illustrated and developed by a few historical facts. To begin with, a retrospective glance at what sugar was in this country sixty years ago compared with what it is now will best enable the reader to realize at the outset the extraordinary development of the world's sugar industries since the middle of the last century-development not merely in the technical details connected with production and manufacture but also in the much more interesting, because more human, process of keen competition between the various and constantly changing sources of production. This will lead up to a yet higher kind of interest when we come to examine to what extent and in what manner the Governments of various sugarproducing States have stimulated production and influenced, for good or for evil, the natural course of supply and demand. Here will arise many fascinating questions of international relations, political controversies, and the conflict of economic facts with economic theories.

Thus it will be seen, at the end of the story, that the 
subject of sugar is not only a technical one of the highest importance both from the practical and the scientific point of view, but also has an international, economic and political side which furnishes a unique and striking object lesson for those who take an intelligent and inquiring interest in the economic questions of the day. But rightly to learn this lesson the reader must bring to the study an open mind, unwarped by preconceived notions founded on theoretical dogmas unsupported by the practical experience of actual work and daily experiment. In natural science it is necessary to begin in the laboratory in order to arrive at the facts on which to construct theories. In economic science this process is equally necessary, but unfortunately is seldom followed. The history of sugar will show that the practical experience of that great laboratory called industry does not always bear out the conclusions to which learned professors may arrive in the comfortable repose of their armchairs.

To begin at the beginning, let us cast a retrospective glance at sugar in this country sixty years ago, just before great changes began, and first of all to I.ondon, at that time the largest centre of importation. The actual figures of proportional imports were, in 1860 : London, 50 per cent. ; the Clyde, 17 per cent. ; Liverpool, 15 per cent. ; Bristol, 10 per cent. ; other ports, 8 per cent. In the year 1900 the figures, in round numbers, were: London, 11 per cent.; Liverpool, 15 per cent.; the Clyde, 7 per cent. ; Bristol, 4 per cent. ; other portsentirely foreign refined sugar-63 per cent. The imports in 1860 were practically all raw sugar; we made all the refined sugar consumed here. In 1900 the imports were, in London, Liverpool, the Clyde and Bristol, raw sugar for refining coupled with a certain proportion of foreign refined sugar. In all the other 
ports - 63 per cent. of the total-they consisted entirely of foreign refined sugar. In 1860 the total imports into the United Kingdom were: raw sugar, 434,766 tons; refined sugar, 13,303 tons. In 1900 they were: raw sugar, 661,747 tons ; foreign refined sugar, 962,409 tons. These are eloquent figures and we shall see how the change came about.

In 1860 our supplies of sugar came mainly from our own sugar-producing colonies in the West Indies, Mauritius and India. The Spanish West Indies, Brazil and Manilla were our other principal sources of supply. At that time practically all the refined sugar consumed in this country was the product of our own refineries. Sugar refining was, in those days, a most important British industry, and London was its principal centre. In London was produced nearly all the loaf sugar that the country consumed. The London refiners were men of some importance in the City. Their "sugar houses" were to be found in the East End in considerable numbers and constituted the staple industry of the district. From Whitechapel eastward to Mile End, and southward through St. George's-in-the-East to the gates of the London Docks, their chimneys were to be seen on all hands. The London Docks and the East and West India Docks were full of raw sugar destined for these various refineries. A refinery in those days was considered to be a good-sized one if it dealt with three or four hundred tons of raw sugar in a week. This may sound ridiculous to the reader of the present day, but he must recollect that the consumption of sugar only arnounted then to about $34 \mathrm{lbs}$. per head of the population. It must also be remembered that in those days, from the time the raw sugar entered the refinery until it left it in the form of loaf sugar, at least a month elapsed. Some of the London loaf sugar producers were at 
that time very much in the habit of working almost entirely the raw sugar that came from the island of Jamaica. Our West India Islands made only what is called muscovado sugar, the nature of which will be explained when we come to the subject of sugar production. The muscovado sugar from Jamaica was very superior to that from most of the other islands, and was much sought after by the more fastidious of the London refiners. But, of course, the time came, as consumption increased, when the refiner had to add some of the inferior qualities and to maintain his average by using higher grades of raw sugar from Havana or Mauritius, and subsequently, when the Dutch monopoly of the Java crop ceased, the fine qualities from that favoured island.

In the streets of the East End could be seen, at all hours of the day, great wagons, drawn by the finest specimens of the cart-horse breed, each containing six hogsheads-about five tons - of British West Indian sugar destined for one or another of the twenty flourishing refineries of the district. A visitor to those busy streets, if he followed one of these wagons, would find himself opposite a large factory, a hive of bustling industry. On one side of it would be a row of similar wagons, their freight of raw sugar being hoisted to the top floor of a lofty building where the refining process began. On the opposite side of the works he would find a much longer line of smaller wagons or carts taking delivery of the refined sugar to go to the consumer. Such was the life of the East End in those days. To-day it is called "The Workless City."

The London refiner made five products: loaf sugar, white crushed sugar, yellow crushed sugar, and a small quantity of very brown sugar, from which followed the final product-treacle. Even this treacle was a nice 


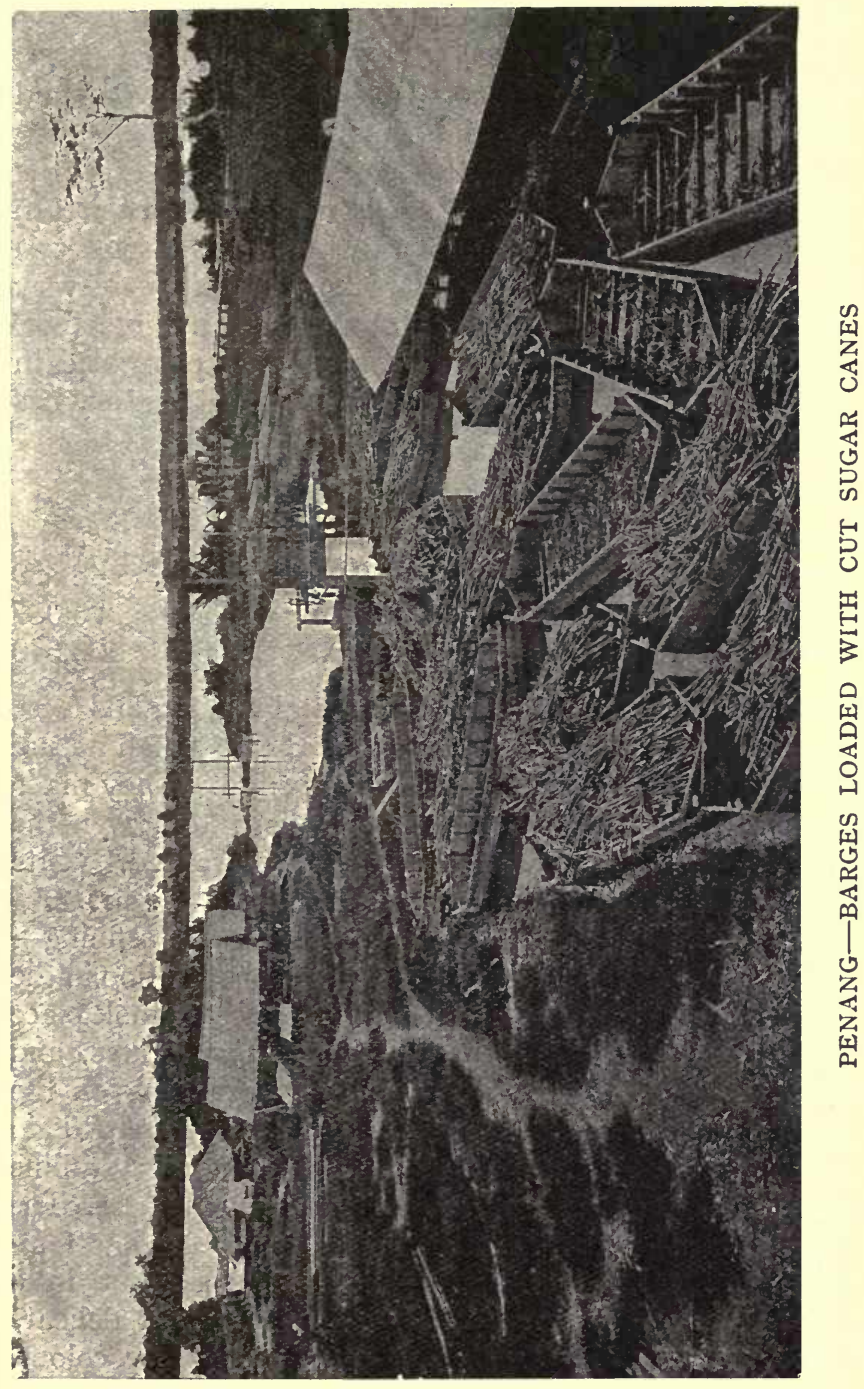


sweet food in those days, with a pleasant flavour and aroma of good West Indian sugar.

Passing to Scotland, the next largest seat of the industry, there were at Greenock, in 1860 , about thirteen refineries, to which must be added four in Glasgow and one in Leith. Many of the Greenock houses were very flourishing and constantly improving their manufacture. The wonderful increase in the raw sugar consumed in the Clyde refineries in the middle of the last century has been stated as follows:

\begin{tabular}{|c|c|c|c|c|c|c|}
\hline & & $\begin{array}{l}\text { West } \\
\text { Indies }\end{array}$ & $\begin{array}{l}\text { East } \\
\text { Indies }\end{array}$ & Mauritius & Foreign & Total \\
\hline Year & & Tons & Tons & Tons & Tons & Tons \\
\hline 185 & & 21,483 & 588 & 12,045 & 14,443 & 48,559 \\
\hline 1860 & & 25,962 & 2,394 & 10,192 & 36,539 & 75,087 \\
\hline 1865 & .. & . 30,645 & 1,000 & 9,032 & 95,863 & 136,540 \\
\hline
\end{tabular}

In the following year, 1866 , the total was 162,368 tons.

These figures sufficiently indicate the go-ahead nature of the industry in Scotland at that period. They made no loaf sugar, but supplied the northern (and even the southern) markets with what they wanted, white crystals and white and yellow "crushed" sugars.

Two vital improvements in the art of sugar refiningimprovements which created a complete revolution in the industry and in the style of sugar produced-took place during the period indicated in the above figures, and fully accounted for the boom in sugar refining on the Clyde. The first was the adoption of the centrifugal machine, by which the sugar in the boiled crystalline mass is separated from the syrup in a few minutes. The second was the boiling of yellow sugars at a low temperature, causing the sugar to be turned out in a uniformly moist state, and with a pale and delicate primrose tinge instead of a dull dark yellow colour. The firm who discovered and perfected this latter 
process made a large fortune in less than seven years, and immediately built a big refinery on the banks of the Thames. Here was a striking instance of the often disregarded maxim, that if you want, in industry, to profit from a new invention you must do it at oncc.

But the importance of the fact in this particular chapter is that it greatly conduced to the remarkable progress of the industry on the Clyde. The increase already stated was sufficiently striking, but the success continued for twenty years. The yearly average for the five years $1877-81$ was 248,429 tons, and for $1882-86$ 240,852 tons. Then came a terrible relapse. The quinquennial yearly averages which followed have been :

$\begin{array}{ll}1887-91 & 228,733 \text { tons } \\ 1892-96 & 170,373 \quad, \\ 1897-1900 & 124,874 \quad,\end{array}$

Thus we see that the first spurt from 75,000 tons in 1860 to 136,000 tons in 1865 reached to 240,000 tons in 1882-86, and then fell away until the average for $1897-1900$ is only 125,000 tons, a figure actually lower than that of the first burst more than thirty-five years before. ${ }^{1}$ This is almost incredible. Consumption in the United Kingdom had gone up by leaps and bounds, the Greenock refiners had constantly improved their manufacture, their sugar was as popular as ever, and they could certainly work as cheaply as any refiners in the world.

1 This lamentable fall in the Greenock sugar refining industry was entirely the result of the new European bounty-fed competition. British markets, and every small port on the coast, were flooded with foreign refined sugar, sold frequently at prices below the cost of production, Since the abolition of the bounties by the Brussels Convention, in 1903, the industry has recovered and now flourishes, as will be seen by the figures given in the Appendix IX. 
Let us pass to the next centre of the sugar refining industry, Liverpool. Here are to be found, even now, some of the oldest names in the trade. Two were well known in the Clyde in the early" part of last century. In 1860 there were nine refineries on the Mersey and two at Manchester. They were, like their brethren in London, men of considerable substance and position in the city of Liverpool, and took a leading part in public affairs. Their raw material came largely from Brazil, Liverpool being the principal goal for ships from that country. They were, therefore, accustomed to work a rather low class of raw material, and consequently turned out a considerable proportion of yellow sugar. There was one exception to this at a later period; another instance of success in seizing on a new invention rapidly, fearlessly and on a large scale. There again a large fortune was made in a very few years, and was immediately followed by the erection of a monster refinery on the banks of the Thames, which has flourished greatly ever since, a notable instance of the survival of the fittest. But that does not concern us at the moment. Golden syrup was a speciality at Liverpool, but has now been superseded by a superior article; again, another instance of inventive genius coupled with bold, unhesitating action.

At present there are only three sugar refineries, properly so called, in Liverpool or its neighbourhood, but there are several refineries of sugar for brewing purposes.

Bristol is the fourth sugar refining centre, and historically the most interesting. In the eighteenth century, Bristol was largely engaged in trade with the British West Indies. There were nearly a hundred firms in the sugar trade, and about twenty refineries in operation. Many of the inhabitants of the town 
were owners of West Indian estates, and importers of sugar. Even as late as 1811 sixteen refineries were at work. But when, shortly afterwards, the vacuum pan superseded the older processes the industry became concentrated in fewer hands and, in 1848, the number had been reduced to five. In 1863 only two remained, afterwards increased to three.

One of these, an old-established firm, was for many years a leading feature of the Bristol sugar refining industry, and carried on the work on a larger scale than any of its competitors in England or Scotland. It was the first to adopt the centrifugal machine on a large scale, and to turn out large-grained crystallized sugar. Of this trade it had for many years almost a monopoly, and a well-deserved celebrity. The family of Finzel were quite the sugar kings of that day, and were as celebrated for their munificent charities as for their fine sugar, of which they turned out more than a thousand tons a week. But, alas, this most successful firm, and their large fortune, disappeared, squeezed out by foreign competition, and by newer schemes and discoveries. The West India sugar, which was the original basis of the Bristol industry, disappeared from the market, and Bristol refiners had to seek their raw material in other and less convenient quarters.

Our brief retrospect of sixty years comes to this. At the beginning of the period we made all our own refined sugar for home consumption. At the end of it we import nearly a million tons of foreign refined, but still manage to produce about 700,000 tons at home. Big refineries have taken the place of small ones. In London, where there were twenty, there are now two, both on the banks of the Thames. But there are also two large refineries and one or two small ones where sugar is refined for the use of brewers. 
As to refineries on the Thames, a few words may be not altogether out of place. The first monster building to appear there was built, as has been already stated, about the year 1864 by the Greenock firm who made a rapid fortune by quick and extensive adoption of a new process. The I.ondon house was carried on by James Duncan, one of the partners. He was the prince of sugar refiners in his time, and never ceased to keep himself informed of all that was going on in the great beetroot sugar industry of Europe. His enterprise was unbounded, and his success undisputed. The whole region round about the Victoria Docks benefited, not only from the great industry which he established in its midst, but also from his constant munificent, though silent, assistance to all good works in the district. Though he had a beautiful estate on the banks of the Clyde, he was never an idle man. Always at work, always thinking out some new scheme, he soon distanced his competitors. But when the crisis of 1884 arrived, with all its disasters, he had a hard struggle and, in 1886, his great works at Clyde wharf, Victoria Docks, were closed. At one time he is said to have turned out two thousand tons a week. He lived for many years in happy retirement. $\mathrm{He}$ was for years Chairman of the British Sugar Refiners' Committee during their long fight against unfair foreign competition.

Then came another man, the late Sir Henry Tate, who made a rapid fortune by quick and bold adoption of a new process. While others talked he acted. He was lucky in one respect. He came to London in 1877 to make loaf (cube) sugar, just at the moment when the French Government, goaded by our persistent exposure of the vast profits made by Paris refiners out of the sugar duty, at last abolished the questionable practices and set matters on a more even footing. 


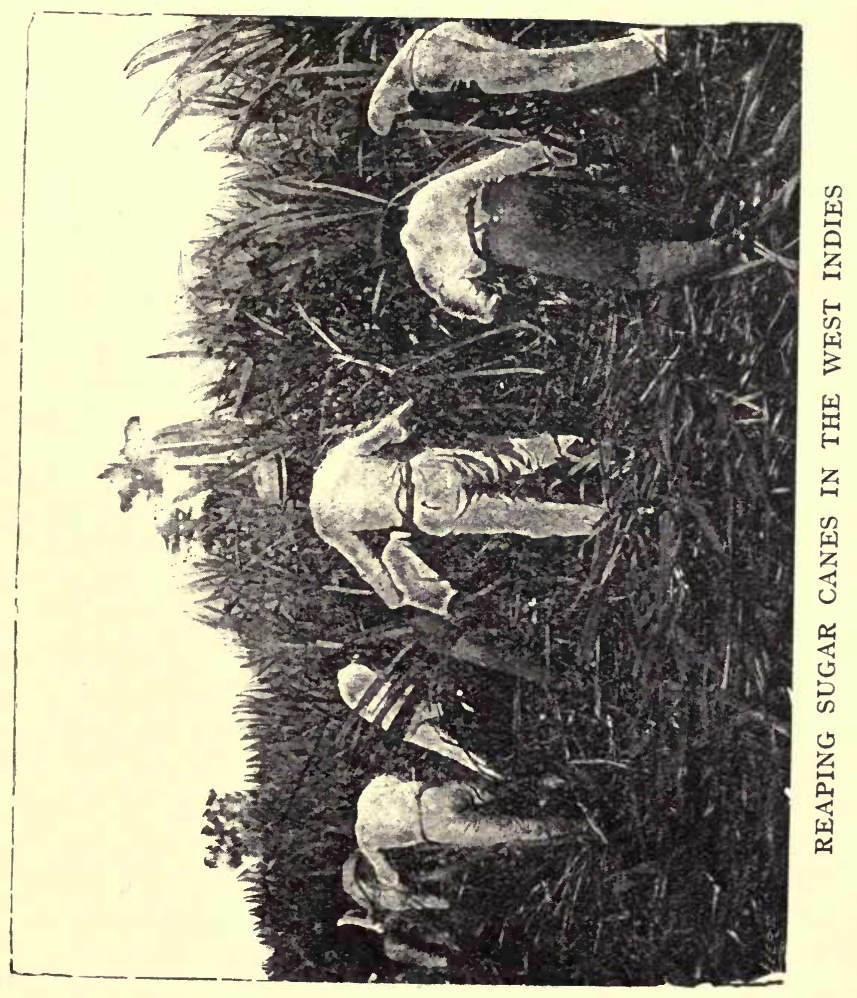


In Scotland, where there were eighteen refineries, there are now five, with one for brewers' sugar. Lancashire, which had eleven refineries in 1860 , now has three, together with several makers of brewers' sugar. Bristol is now a blank.

These great changes are the result of many causes, some natural and inevitable, others artificial, injurious both to our industries and to our consumers, and not only much to be deprecated but also, curiously enough, easy to overcome. And yet they were permitted, for more than thirty years, to create such a disturbance of the natural course of production throughout the world, that it will take some years to restore matters to their normal state. The history of this part of our subject will come at a later stage, and we must now plunge into the more technical details of sugar production. 


\section{CHAPTER II}

\section{CANE AND BEET}

IMAGINE a great thicket of sugar cane in the full vigour of growth before it is ripe. Stems six to twelve--even to twenty - feet high, clothed from foot to head with great tropical leaves, and crowned at the top with a final wide-spreading bunch of the same. Imagine the field again when the canes are ripe. Except the bunch at the top the leaves are gone. The slender elegant cane, of various hues, curves up to the sky, shining in its waxen skin, variegated with rings at regular intervals where the lost leaves had sprung out, and where still nestles the bud or germ which under wild conditions would, when the cane falls exhausted, throw out roots and spring into a new cane. From the bunch of leaves at the top has now shot out a long slender arrow with silky grey tassels of feathery flower at the end of it. The cane is ripe, and full of good sugar juice nearly up to the top. It is cut down, the top joints removed, and the rest of the cane piled up on wagons to go with all speed to the factory. No time must be lost, for the sugar begins to deteriorate with great rapidity.

In the good old days, when fortunes were made out of sugar without much trouble, there was plenty of loss before the cane got to the mill, and plenty more after it got there. But now all this is changed. There is little hope of making a decent living unless everything is done in the best way; and this "best way" it has taken many long years and much science, skill and perseverance to discover and carry out. The Indian. 
native, the Chinaman in Formosa, or the inhabitants of the Philippine Islands may still be squeezing out the juice with primitive rollers, boiling it in iron pots till it solidifies, and then selling it for what it will fetch, but this is not sufficient to supply the world with eight million tons of cane sugar every year. The growing of the cane and the making of the sugar have now become industries of the very highest scientific perfection. Accurate chemical knowledge of the constituents of the cane, of the constituents of the soil where it happens to be growing and, consequently, of the nature of the manures necessary to maintain in the soil the various foods required for the healthy growth of the plant, are the first requisites for the successful cane farmer. He must also know which particular kind of cane-for there are many-is most likely to flourish in his soil and climate. As to cultivation, the ordinary rules for good ploughing, good drainage, and careful hoeing during the early growth, are just as imperative in the tropics as in the European fields of sugar beet or any other crop.

The sugar cane is planted, not sown. A bit of cane, long enough to include two or three of the rings, is laid lengthways, or stuck in in a slanting direction, along a furrow running the length of the field, or in holes dug at regular intervals. When the trench is planted the pieces of cane are lightly covered with earth. In a few weeks they show growth above ground. The germ-bud at the ring has begun to shoot out into young cane, and the ring at the same time has thrown out rootlets into the soil. The parallel trenches must leave room between them to enable the labourers, when the wide-spreading canes, double the height of a man, are getting ripe, to reach between the rows and remove the dying leaves which cumber the ripening 


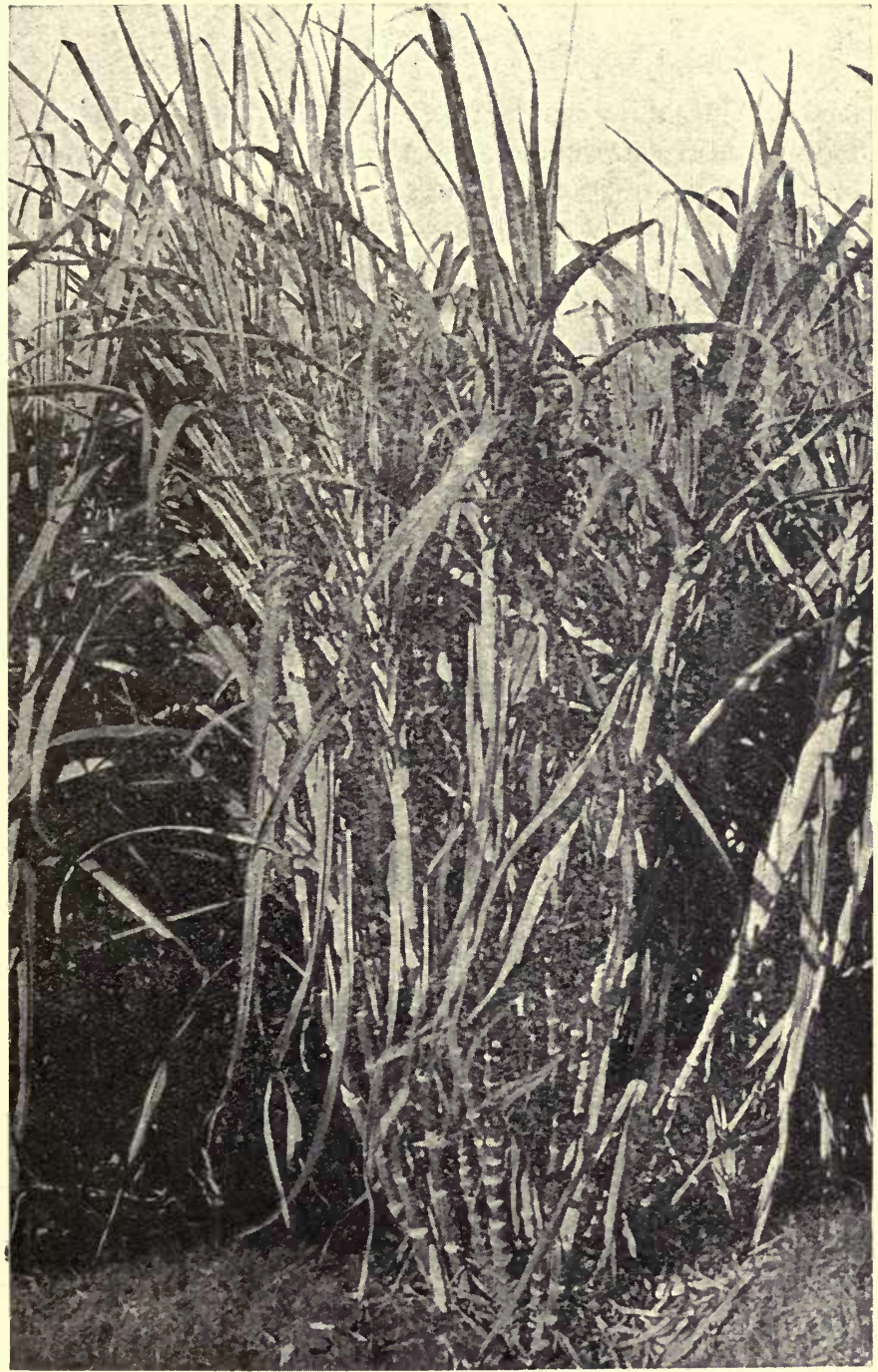

By p:rmission of the Q.teensland Governincut 
cane. The falling leaves take with them much valuable food to return to the soil, and the naked cane has better opportunity for good ripening.

This ripening of the cane is a very ticklish matter. If the cane is cut before it is quite ripe some of the sugar which it contains is not in a crystallizable state. On the other hand, if the cane gets too ripe some of its crystallizable sugar goes back into the uncrystallizable state. This must often be a sad trouble to the manager of an estate and factory. Again, if the central factory is supplied with canes from a multitude of small farmers they may be all wanting to send their canes in at one time. To the factory this is an impossible situation. The manager must, consequently, be content to have canes which are not always at the exact point of ripeness which might be desired.

The growth of the cane, lasting about 15 to 18 months is an interesting study. When it is at maturity the rind is of a very strong consistency, and is protected on the outside by a waxen covering. The inside of the cane consists of the cells containing the sugar juice, and of long bundles of fibres which convey from the ground the water and food necessary for helping to carry on the process of development. These fibres call at each ring of the cane in order to deliver the particular food required for the growth of the leaf, and the sustenance of the germ-bud. To the top of the cane they bring those things which are necessary for the growth of the cane, the arrow and the flower. The leaves in their turn do a most important work. While the internal fibres are bringing food and water from the ground, the leaves, helped by the sunshine, are collecting carbonic acid from the air, and it is the carbon thus consumed by the plant which, combining with the water from below, forms the substance which we call sugar. 
It is the same with the sugar-beet, that little modest plant of northern climes, with its small bunch of leaves close to the ground, spreading out like a toy parasol to keep the ground moist underneath, and to suck in the rays of sunshine from above. It is a little bulging root, tapering to a slender tap-root which thrusts its way far down to find water and food, while the leaves and the sunshine make the sugar. It is curious to think that this humble root, weighing only two pounds, at one time gave to the world as much sugar every year as the lordly sugar cane, and that the beetroot factory should actually extract a greater percentage of sugar from the little root than the cane factory wins from the rich cane. But it must not be forgotten that, under favourable circumstances, the cane can produce twice as much sugar to the acre as the beetroot. Which will win the race?

Up to 1903 the beetroot had the great artificial stimulus and assistance of paternal Governments. In some places the cane is now beginning to receive something of the same kind. The United States gives preferential treatment to Cuban sugar, and Cuba consequently goes ahead by leaps and bounds. But the United States does more than this. It admits its own sugar, from the cane fields of Louisiana and the beet fields of the Northern States, free of duty. Those industries therefore flourish. It also admits, free of duty, the cane sugar from Porto Rico, the Sandwich Islands and, recently, the Philippines. The two former have consequently doubled and trebled their production. It remains to be seen what the slow moving inhabitants of the Philippines will do. Japan has also come into the field as a paternal Government. Their newly-acquired island of Formosa has always produced sugar in the Chinese way. Bad canes badly 
cultivated and crushed in stone mills driven by buffaloes, have produced a rough, dirty, nearly black sugar, and the Chinaman has been satisfied. He gets less than half the juice from the cane, and half the sugar from the juice. But Japan means to substitute for this state of things a first-class sugar industry, and has set about it, as usual with the Japanese, in a business-like way. They began by learning their lesson and finding out how sugar is grown and how it is made in the very best factories, whether tropical or European. They then told the people in Formosa how they should grow their canes, what canes they should plant, and what manure they should use. They told them, further, that central factories would be established which would buy the improved canes from the farmers at a much better price than what they got out of their whole process of growing and sugar-making. It took some time to move the naturally conservative ideas of the native producer, but they are succeeding. Factories are being erected and the growers are beginning to fall in with the new ideas. If success comes it means that in a few years Japan will make sugar enough to supply the Japanese consumer with all the sugar he wants; and as the sugar receives preferential treatment in Japan, and therefore fetches a high price, there will be a great stimulus to Formosan production, and the final result may very likely be that Japan will become an exporter of refined sugar. In 1901-2 Formosan exports to Japan were 46,893 tons; in 1910-11 256,950 tons. The crop in 1916-17 is estimated at 338,997 tons.

The methods of growing cane sugar vary in different countries. In our West Indian colonies the first planting may give an average yield of thirty tons of canes to the acre. This is called the plant-cane crop. The "stool" left when the canes are cut down will, if permitted, 


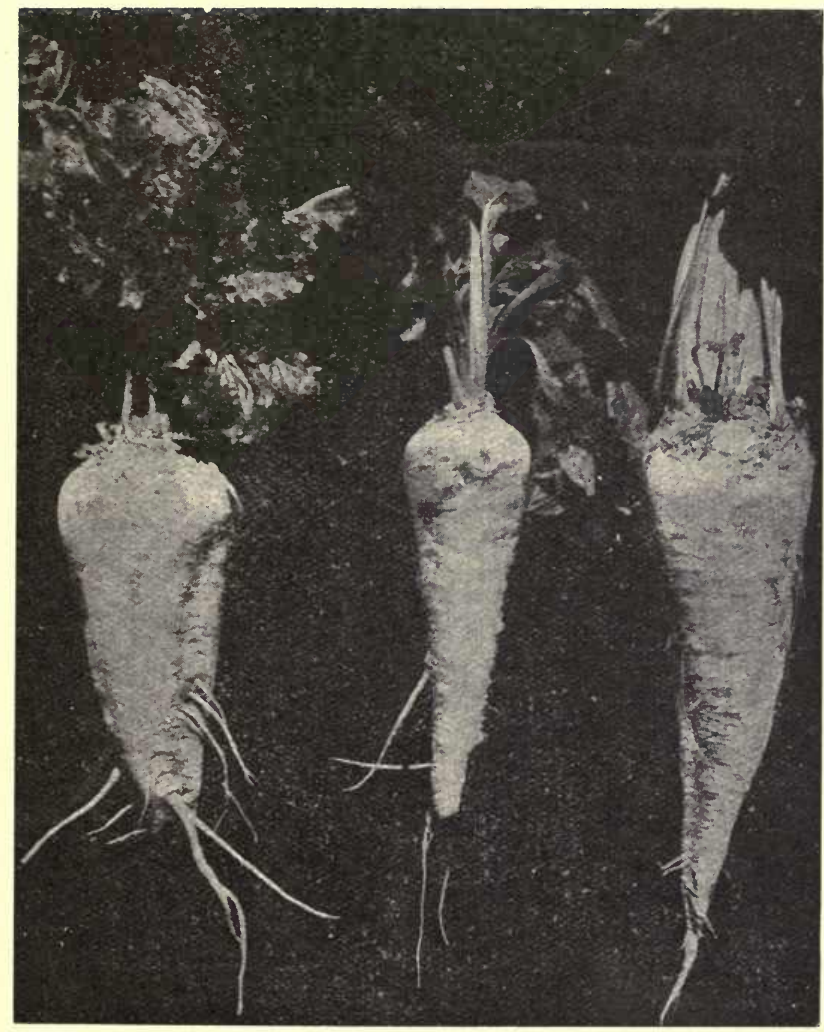

BEETROOTS 
throw out another but inferior crop of canes. This is called the "ratoon" crop, and may amount to about twenty tons of canes to the acre. In the West Indies, and in other parts, several ratoon crops are sometimes grown; but in countries like Java, where labour is plentiful and cheap, the crop is freshly planted every year. In Java, sugar is, in fact, a rotation crop, other crops being grown in alternate years. This is a governmental regulation which must be observed. This system, coupled with great perfection in cultivation and manufacture, has had the result of realizing, as the average crop for the whole of Java, the almost incredible quantity of more than four tons of sugar to the acre. This means that many of the best estates and factories turn out at least five tons to the acre, a truly marvellous performance when we recollect what was considered a good yield in the West Indies fifty years ago. Two hogsheads of muscovado sugar to the acre was considered in those days a thing to boast about. As a hogshead weighed from sixteen to eighteen hundredweight this was only a yield of a ton and a half to the acre, about the average yield of the European beetroot.

There is another important variation in the agricultural system of different cane sugar countries. The sugar cane must have water, if it is to grow properly and give its customary yield. Very often it gets too much water and, therefore, good drainage is essential. In British Guiana, where the cane fields lie below the level of the sea, the superfluity of water has sometimes to be pumped off the land. But, on the other hand, there is often a terrible spell of dry, hot weather, and then water has to be pumped on to the land. Many countries have to grow their canes almost entirely by irrigation. Peru is the most remarkable case, for in 
that country there is practically no rain. Fortunately there are splendid means for easy and effectual irrigation. Where this is the case some of the heaviest crops in the world are produced under a system of thoroughly scientific irrigation. In the Sandwich Islands, for instance, it is known, and has been recorded, that crops of more than fifty tons of cane to the acre have been produced. Here we have the wonderful crops of Java easily eclipsed.

There is one more detail about the sugar cane which must be noted. The wild cane produces seed, but the cultivated variety has become so accustomed to growing from cuttings that it has, as a rule, forgotten how to produce seed. It has been discovered recently that seed can be found, and that it will produce canes. These seedling canes come up in very various qualities, some perhaps better than the existing kinds. Men of science have set to work to select from these seedlings and endeavour to produce a cane that will possess a maximum of good qualities, each selection to be the one most suitable to a particular soil and climate and, especially, to be the most powerful in resisting disease. The growers of cane sugar have thus at last found an opportunity of following the example of the beetroot industry.

In the European beetroot countries the process of selection has been going on for generations. The roots used to yield five to six per cent. of sugar; now they yield thirteen to fifteen per cent. In 1908, a very exceptional season, the average yield for the whole of Germany was nearly seventeen per cent., and for Bohemia even more. This is a truly wonderful advance, entirely thanks to the producers of beetroot seed. By constantly selecting the richest roots for planting in their seed nurseries they have gradually advanced year $3-\left(1_{4} 63\right)$ 
by year to this pitch of perfection. The beetroot flowers and seeds in its second year, so there is every opportunity for this process of selection.

The beetroot plant is sown as early as possible, but not so soon as to run the risk of late frosts. The ground is prepared in the most thorough and scientific way because the crop, to be successful, must have clean land, well broken up, and in good heart as to the right kind of richness. To keep it clean during the growth of the young plant you may see, on a first-class farm in Germany or Austria, a band of labourers hoeing between the faint green lines of the baby plant long before weeds are visible. This is the real way to stop weeds. The germs are turned up and left to die in the hot sun of May and June. If the crop has a nice moist spring, plenty of sunshine in the summer, and a good long autumn, it will be a good one. A dry spring, wet summer, and short, cold autumn, will give a short crop. But, worst of all is drought all through spring and summer, such as they had in 1904. That means a deficiency of more than a million tons of sugar in the European beetroot crop. We want great increases in the cane crops of the world to defend us against such disasters in the future.

The roots begin to be ready for the harvest in late September and early October, and they are all gathered in by the middle of November. Those that do not go direct to the factory, have to be pitted till the factory is ready for them. The pit is constructed in a scientific way, with proper ventilation, and a good covering. But the factories are so big now that they make short work of it, and have generally finished with their roots by the end of the year. The delivery of the roots to the factory was at one time a sad source of disputes and friction, but habit has pretty well overcome this 


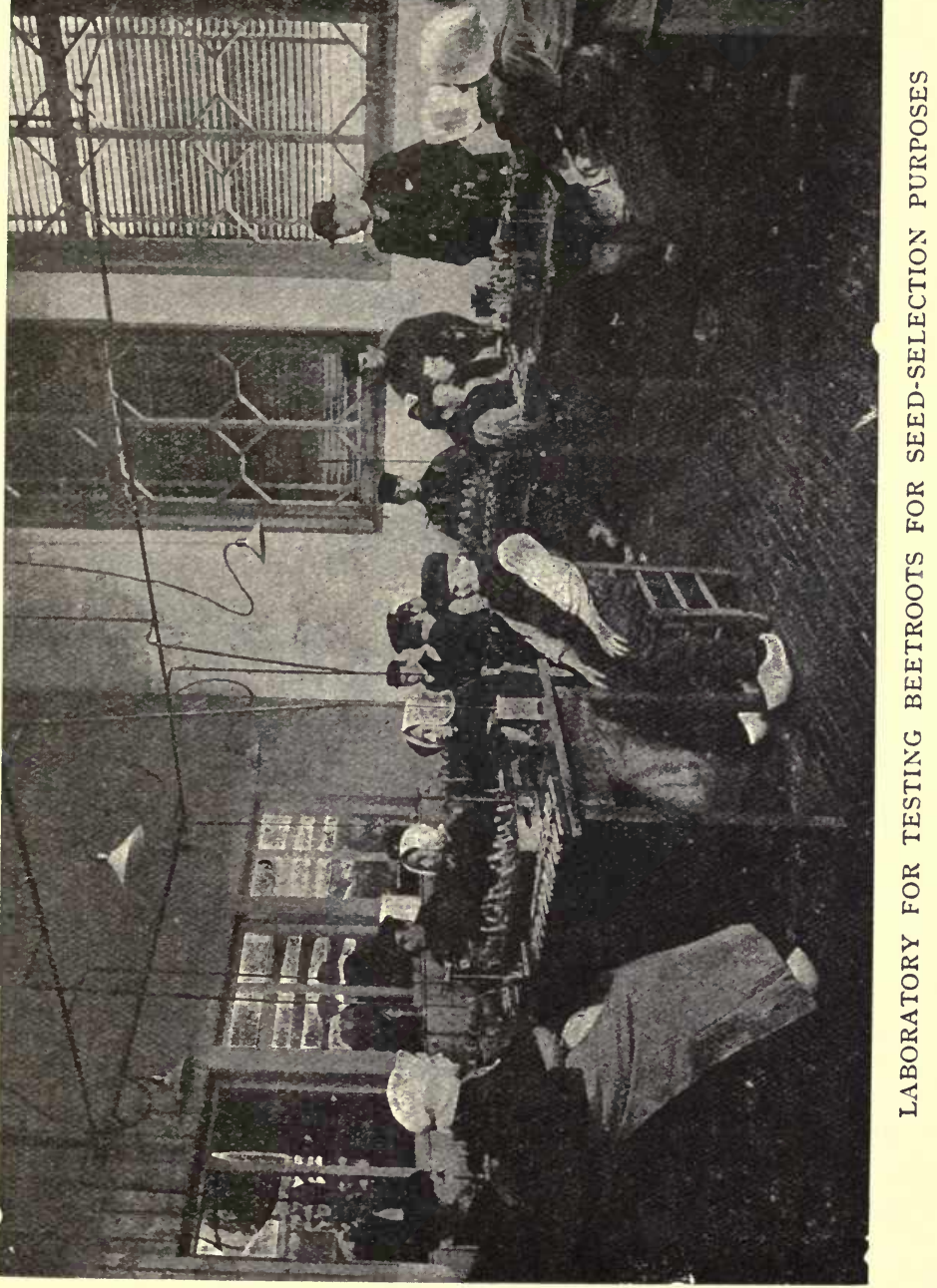


difficulty. The farmers and the factory now understand each other better. The farmer is bound by contract to use the best seed, and the right kinds of manure, and to deliver the roots clean and well trimmed. If Germany in a good year can make an average yield of nearly seventeen per cent. of sugar, it is certain that nothing but first-class roots have been delivered. The weight of roots to the acre varies in different countries. Germany averages between ten and fourteen tons, Austria much less. Russia cannot get beyond six to seven tons.

The cane crop fortunately takes place at very various times in different quarters of the tropical regions, and thus does not flood the markets of the world with all its sugar at once. But Cuba, stimulated by the United States' preference, now makes 3,000,000 tons of sugar, and as it naturally sent its sugar to the market where at one time it enjoyed a preference of about 1s. $6 \mathrm{~d}$. per cwt., the American markets were flooded with Cuban sugar during the crop season. This led to the curious and abnormal fact that in the early months of the year the price of sugar in America was often 1s. 6d. per cwt., and even more, below what is called the world's price. The preference has now been reduced to $1 \mathrm{~s}$. $2 \mathrm{~d}$.

It may be interesting to note the dates at which the various crops of cane sugar begin. All the West India islands begin in January, except Cuba, which is a month earlier. In the United States the cane sugar districts of Louisiana and Texas begin in September. Mexico, like Cuba, begins in December. In South America, British Guiana has two crops, May and October, while the Argentine gets to work in June. In the East, Java, a most important crop, begins in 
May; Formosa and the Philippines in December, and British India about the same time. Egypt works in January, and Mauritius in August. August is also the crop time in Natal. In Australia and the Fiji Islands June is the month. 


\section{CHAPTER III}

\section{CANE JUICE}

WE now begin the main part of our subject, the extraction of the sugar from the cane or the beetroot. With the cane the first thing is, with all speed, to get the juice out of it and to get as much of it as possible. In primitive days -or even now in primitive countriesthey crushed the cane between two vertical rollers of wood or stone, driven by bullocks or by hand. By this method they did not get half the juice, but the remains of the cane made good fuel for boiling the juice. In course of time iron rollers were substituted for wood and stone, and were set horizontally. The driving power for this more powerful mill was wind or water, as in the case of the old flour mill. The island of Barbadoes is not, like its neighbours, mountainous, and is, therefore, well suited to the use of windmills, especially as it has a fairly breezy climate. Many of these windmills may still be seen driving the sugar mills in that fertile, industrious, successful and well-populated little colony.

But a great revolution has taken place in most tropical sugar-producing regions. Extended cultivation soon required new implements capable of dealing with large quantities of cane in an expeditious and economical way. The three-roller mill, driven by steam power, soon became the rule. This machine consists of two rollers placed side by side but with a space between, and another above them nearly touching them. The engine drives gearing which reduces and regulates the speed of the three rollers to the required pace. The 
lower rollers revolve in the same, the upper one in the opposite direction. A travelling band or "carrier" conveys the canes to the mouth of the mill, care being taken that they are so evenly distributed as to form a constant and uniform feed. The canes enter between the front roller and the upper one, only just space enough being left between the two rollers to permit them to catch hold of the canes, and draw them through. Between the two lower rollers, just below the centre of the circumference of the upper roller, is a metal plate which causes the crushed cane to turn towards the space between the back roller and the upper one, where it is again drawn in and crushed a second time. These rollers are placed much closer together, because the already partially crushed cane can now be forced through a narrower entrance. This double crushing may, if well done in a sufficiently powerful mill, extract sixty per cent. of the juice in the cane. This had to be improved upon if cane was to compete with beetroot. The arrangement now is a combination of three of these three-roller mills set tandem fashion, with carriers to convey the crushed cane from the first to the second and from the second to the third. It might be imagined that when the crushed cane, called megass-or, in French, bagasse-issues from the third mill it has lost all its juice. Unfortunately, this is not so, and therefore other expedients have been adopted to still further reduce the quantity of sugar left in the megass. The rollers in the second and third mill are placed closer together in order more completely to squeeze the now attenuated strips of crushed cane. Those mills are also driven at a slightly slower speed. But important additions have of late years been made. It was found that the first of the two crushings in the front mill did not do much more than break the outside rind of the 
cane, and that a larger quantity of cane could be worked with the same power if the cane could be cut or torn up to a certain extent before entering the first rollers. Cane cutters or "shredders" were, therefore, introduced in front of the triple arrangement of mills. Another and perhaps better contrivance was afterwards adopted, a pair of rollers with $\mathrm{V}$-shaped corrugations, which slightly break the canes, and thus enable them to be more thoroughly and quickly crushed in the first mill.

But still there was too much sugar left in the final megass. The next scheme, therefore, was to pour water on the carriers between the first and second, and the second and third mills. This water, if properly sucked up by the megass, dilutes the juice and, therefore, the juice in the final megass, being thus diluted, contains less sugar. Dilution of the juice is, of course, objectionable, because it involves the consumption of more fuel in the subsequent evaporation. Very careful calculations are, therefore, necessary, based on the value of sugar and the cost of fuel, in order to arrive at the point where saving of sugar costs more than the value of the sugar saved. To reduce the dilution as much as possible it is now customary to use the diluted juice from the last mill to wash-" macerate " it is called-the megass on its way from the first to the second mill. A careful note of the density-specific gravity, tested by the hydrometer-is taken at the last mill in order to maintain uniformity of maceration, and to make sure that the dilution does not exceed the calculated maximum to be permitted.

The exhausted megass goes straight to the boilerhouse for fuel. The great improvement in special boiler furnaces for the consumption of megass now generally enables cane sugar factories to raise all the 

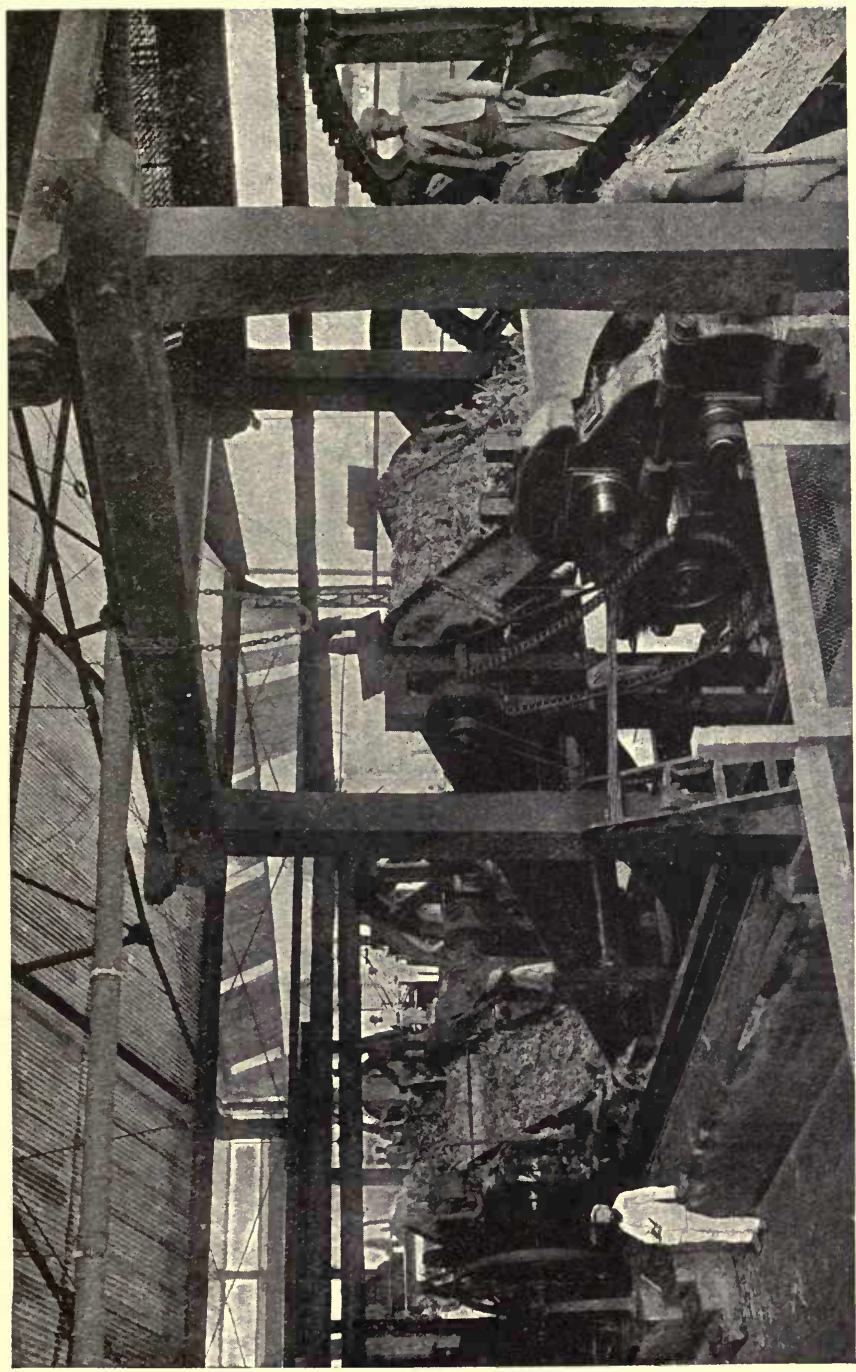

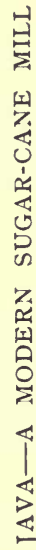


large quantities of steam required for evaporation and driving without the use of any other fuel-a great advantage for cane over beet.

The juice is caught in a trough below the mills and flows to a vessel where it is roughly strained from the quantity of finely divided cane fibre which falls down with it, and is then pumped up to the clarifiers.

Cane juice is a substance of somewhat complex character. The juice from the first mill is comparatively pure, limpid and of a light colour. But the continued crushing in the second and third mills brings more inpurities into it. The colouring matter from the rind of the cane gets into it; so do the organic salts, gums and albumen, all of which make it more and more viscous and quite impossible to filter or evaporate without previous very careful and complete clarification, a matter for consideration in a following chapter.

A good ripe sugar cane contains, on the average, about seventy-five per cent. of water, twelve to fifteen per cent. of crystallizable sugar, one to one and a half per cent. of uncrystallizable sugar, ten per cent. of fibre, less than one per cent. of incombustible matter-called "ash," -and less than one per cent. of organic acids, gums and albumen. The ash consists of very varying proportions, according to the nature of the soil and of the manures, of silica, potash, lime, magnesia and soda, mentioned in the order of their importance, silica and potash being the main ingredients. The silica exists mostly in the form of silicates of an alkaline base. The alkaline bases, mostly potash, are also in combination with organic acids, which disappear on incineration, or with phosphoric and sulphuric acid, and chlorine, all of which constitute part of the ash.

It is now necessary, before going further, to explain the nature of the three kinds of sugar contained in 
the sugar cane, one crystallizable and two called " uncrystallizable." These are only rough and ready expressions for which more accurate words have now been substituted. But an explanation of the difference between the three kinds of sugar, and of their proper names, requires a brief preliminary description of the way in which the quantity of these sugars in cane juice, or any other sugar solution, is determined.

The polariscope is an interesting instrument, and its use in every sugar factory or refinery, and also in every commercial transaction in raw sugar, is now universal and essential. Its construction is based on two facts. The first is that when light passes through certain crystals, calc spar for instance, if the crystal be properly adjusted the light is divided into two rays one of which, has become " polarized." This means that the light ceases to be diffused equally in all directions, but only shines in one plane. The second fact is that if this ray of polarized light be passed through a solution ot crystallizable sugar its plane will be deflected to the right.

The business of the polariscope is to measure the extent of this deflection, and thus detect the quantity of sugar contained in the solution, a very ingenious and complicated process. The general facts can, perhaps, be given without too many technicalities. If light were made to pass through a properly adjusted crystal and thus converted into a polarized ray, and if this ray were then intercepted by another similar crystal, similarly adjusted, the polarized ray would pass freely through the second crystal. But if, between the two crystals, were inserted a tube containing a solution of sugar the light would no longer pass through the second crystal because the plane of the ray would have been deflected by the sugar. The second crystal 
would have to be turned until it arrived at the angle to which the ray had been deflected. When the light had fully reappeared, the angle through which the crystal had been turned would indicate the amount of deflection. An instrument could be imagined in which the scale should be so adjusted, and the parts so constructed that the zero should be the point where, with pure water in the tube, the two crystals coincide and the light passes through; and the one hundred point should be that to which, with a fixed weight of pure sugar dissolved in a fixed volume of water in the tube, the crystal would exactly arrive in order to transmit the full light of the deflected ray. In practice, it is necessary to adopt a more complicated arrangement in order to secure accuracy. Between the tube and the second crystal is inserted a "compensator" constructed of two wedge-shaped crystals, which can be shifted across each other by means of a screw until they exactly compensate or neutralize the deflection caused by the sugar, and allow the ray once more to pass through the second crystal. The screw at the same time moves a vernier scale on which the operator can read off the percentage of sugar contained in the tube. But this does not give absolute accuracy because the exact point of maximum light or maximum darkness is difficult to detect. Behind the polarizing crystal, between it and the tube, is therefore inserted a plate of quartz, made of two plates joined together side by side, with their axes opposed, the one from right to left and the other from left to right, the join being a perpendicular line in the centre. The eye of the operator now sees, when the ray is not deflected, a field of uniform colour. But when the ray is deflected by the sugar he sees the field divided by a sharp perpendicular line into two different colours. As he moves the 


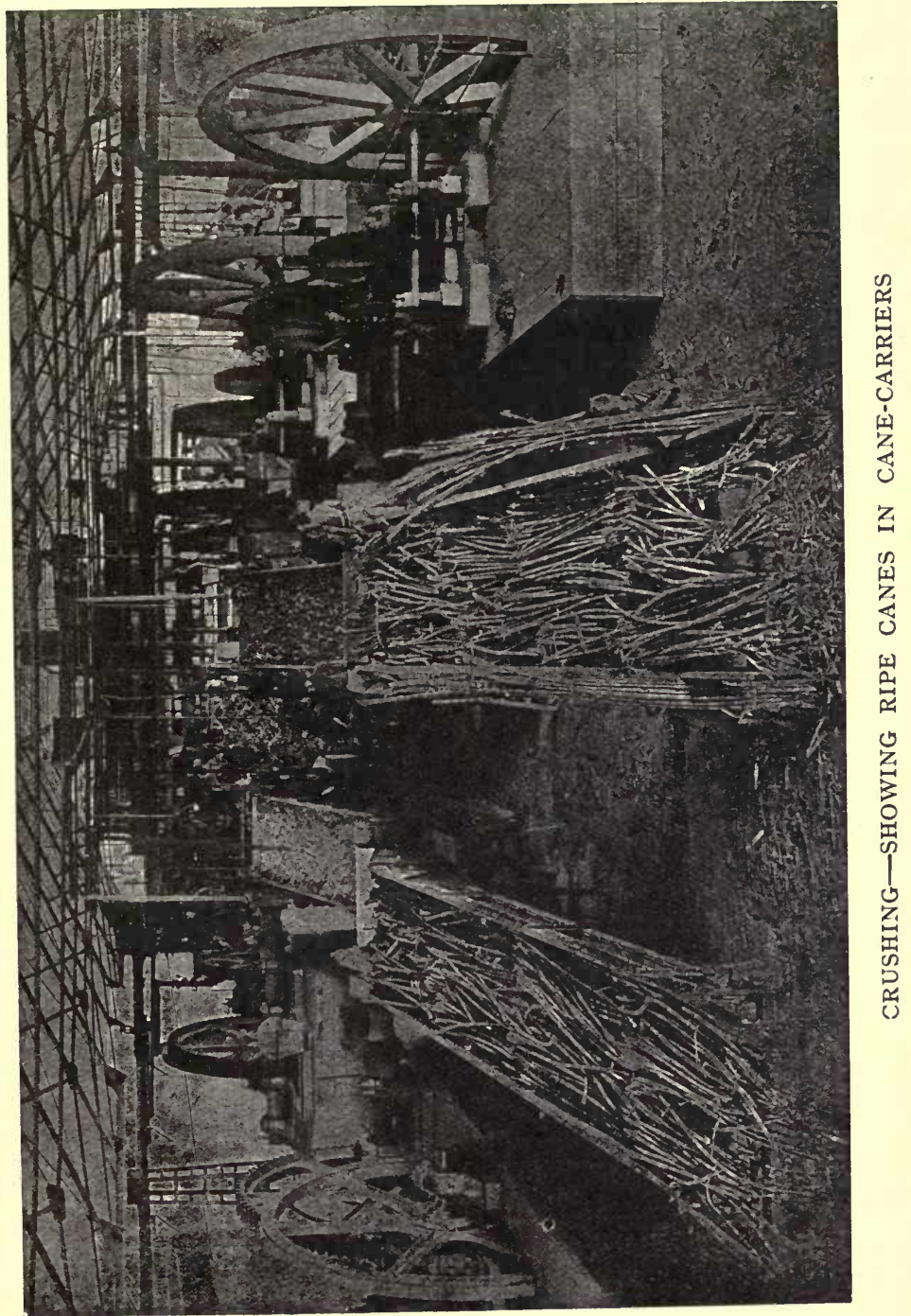


compensator the colours become more uniform, and when an absolute uniformity of colour has been restored he reads off on the scale the percentage of sugar. This method gives great accuracy, but the instrument has now been superseded-perhaps in the interest of those who are colour blind-by one in which shadow is substituted for colour, which is said to be still more accurate.

Thus is the quantity of crystallizable sugar accurately determined in the laboratory. The other varieties of sugar, called uncrystallizable, have an avidity for oxygen ; their quantity is therefore determined.by measuring the quantity of a standardized solution of oxide of copper (cupric oxide) which is "reduced" by the sugar solution to the insoluble form of cuprous oxide, which contains less oxygen. The uncrystallizable sugars are therefore called " reducing sugars." They generally exist in the form of equal quantities of dextrose and levulose, which mixture is created by the action of acid and heat on the crystallizable sugar, which is now called sucrose. This mixture is called " invert sugar" because it deflects the polarized ray to the left instead of to the right.

But dextrose and levulose also exist separate in varying small quantities in the sugar cane. Dextrose is so called because it deflects the ray to the right, but not so much as sucrose. Levulose is so called because it largely deflects the ray to the left. Dextrose is produced in large quantities for industrial purposes by the action of acid on the starch contained in grain, and is called glucose. Maize is generally used for the purpose, and the United States is the largest producer. In that form it is a dull greyish white viscous substance with a sickly-sweetish taste. It is also produced in a solid form. Levulose is also called fructose or fruit sugar. 
It does not appear ini sound ripe canes, but can be found in unripe or overipe ones. Dextrose exists in both ripe and unripe cane, and is also found in many other plants. But the existence of dextrose and levulose as separate substances is a mere nothing compared with the quantity of them produced by the decomposition of sucrose into "invert sugar." This is the "golden syrup " and also the "brewers' sugar" of commerce. If very pure it has the appearance and flavour of honey. Honey itself is invert sugar.

All these sugars are called "carbo-hydrates" because they consist of carbon combined with hydrogen and oxygen in the proportions in which those two elements exist in water. They are formed by the tissues of the leaves of the sugar cane, under the influence of the light of the sun, combining the water of the plant with the carbonic acid of the atmosphere. The stronger the light the more rapid the process. Sucrose is created and conveyed to the stalk. If the process is too rapid during the daytime starch is stored up, and this in the night season is converted into dextrose. Part of the sucrose may also be inverted and thus a little levulose added to the dextrose. The respiration of the plant requires these "reducing sugars," converting them back to water and carbonic acid. Some of the sugars are conveyed to the green top of the growing plant, and further inversion takes place to assist the vigorous growth by vigorous respiration. The reducing sugar also assists in the formation of the fibre of the cane, and some of it combines with nitrogenous substances to form albuminous matter. As the plant ripens and the leaves begin to fall the vigorous respiration slackens, less reducing sugar is required, and the sucrose is stored up in the cells of the pith of the cane. A growing cane, therefore, contains much 
reducing sugar-or invert sugar-used for growing purposes, while a ripe cane contains sucrose with a very small admixture of invert sugars. When the lower leaves die the sucrose is increased only from the action of the leaves which remain at the top, and the time comes when there is no further increase. That is the point of ripeness. After that the heat of the sun has no further creative effect, but would, if the cane were not cut, begin, with the help of the acids in the cane, to convert sucrose into invert sugar.

The contents of the cane juice as it flows from the mill can be stated roughly, but of course it varies greatly according to the quality of the cane, and that is very various in different countries and soils. The variation also arises from the state of ripeness of the cane. Here are figures of the analysis of cane juice which has rather more uncrystallizable sugar than it ought to have if it were perfectly ripe, but they suffice to indicate the proportions of the various constituents of the juice. They also illustrate the impurity of the juice from the second mill as compared with that from the first. They are taken from Prinsen Geerligs' smaller work on cane sugar, published at the office of The Sugar Cane, Altrincham, 1902.

Sucrose, 16.49 per cent.; glucose, 1.98; ash, 0.28; gums, 0.125 ; albumen, 0.025 ; free acid, 0.048 . The density by the Brix hydrometer was $19 \cdot 2$. This hydrometer professes to indicate the total quantity of dry substance in solution. The quantity of sucrose, per cent. of total dry substance, is, therefore, 85.9. This is called "the quotient of purity." This is the analysis of the juice as it flowed from the first mill. That of the juice, without maceration, as it flowed from the second mill gave the following changes. About the same sucrose. Rather less glucose. Ash increased to 
$0 \cdot 41$. Gums increased to $0 \cdot 346$, just three times as much. Albumen increased to $0 \cdot 092$, nearly four times as much. Free acid increased to 0.072. Quotient of purity reduced to 84.4 . The reason why the glucose was less is because the top part of the cane, which contains the largest amount of glucose, and which is the softest part, had been more thoroughly squeezed by the first mill than the harder parts of the cane. The third mill gave a purity quotient of 84 . The colour of the juice from the first mill was light, from the second dark, from the third very dark. The word glucose is here applied to all reducing sugars or invert sugars.

The extraction of juice by the Diffusion process will be described in the next chapter, when dealing with the subject of beet juice. It is one of the most interesting subjects connected with sugar production. 


\section{CHAPTER IV}

BEET JUICE

FoRTUNATELY for the producer of beetroot sugar his raw material, the root, will keep fairly well, so he is able to make sure of a constant and sufficient supply from the day he begins work until his last load of roots comes in. This is of immense advantage in the working of such a delicate article as sugar juice. Interruption of work is a most ruinous proceeding, but it must sometimes happen in the case of the sugar cane.

The roots have to be delivered to the factory as free as possible from soil or stones, and thoroughly trimmed as to the crown and the rootlets. They go straight to the washing machine where they are completely cleansed. Their next visit is to the weighing machine, because in some countries the duty was levied on the weight of the roots. In any case, the manufacturer must know the exact weight of the roots he works, and the knowledge is also necessary for fiscal statistical purposes.

Then comes the extraction of the juice. Fifty years ago this was done by tearing the roots into pulp in a powerful machine, and then squeezing the juice out of the pulp by hydraulic pressure. It was an interesting process to watch. The number of hands it employed was remarkable. There was a constant rushing about of people in a hurry; first to fold up the pulp in cloths and place it on the trays to go to the press; then the carrying of these trays and adjusting them, one above another, on the press. And while this was going on an opposite gang was as busy removing 
the pressed pulp from another press, disposing of the pressed cake of valuable cattle food, and running for more pulp to recharge the second press. And so on for all the row of presses.

The trouble and expense of this method of work soon led to the invention of various kinds of continuous presses, which did the work without all this expenditure of labour and loss of time. Some of these presses did their duty fairly well, and were regarded at the time as the height of perfection.

But a great revolution was approaching. In the year 1860, Julius Robert, sugar manufacturer at Séelowitz in Austria, successfully put into practical form an entirely new method of extracting the juice from the beetroot, called the Diffusion process. His success was complete. All the sugar factories in Germany and Austria gradually adopted it, and in little more than ten years its use had become universal in those two countries. In some parts of a beetroot factory of to-day, instead of pandemonium you would find almost silence. You begin to wonder where the workmen are, and where is the sugar juice. You see a vast room, full of tall cylindrical vessels armed at the top with a complicated regiment of valves, and apparently doing nothing. You hear, indeed, one machine making a slight noise on an upper floor, but you see no one until, perhaps, a solitary man begins to manipulate one or two of the valves. That is the only sign of life which you can, at the first glance, detect in that very important wing of the establishment.

This process of Diffusion is so interesting, and has had such an important bearing on the success of the industry, that it must be described in some detail. It was found, some sixty years ago, that when two liquids of different densities are separated by a 
membranous partition a process of diffusion takes place, the denser passing into the lighter, and the lighter into the denser liquid. This occurs in spite of the fact that the membrane is not a filtering medium. It was also found that if the denser liquid contained in solution a mixture of crystallizable and uncrystallizable substances, the former would diffuse freely into the lighter liquid, while the uncrystallizable would hardly diffuse at all. This phenomenon was called osmosis, or osmose. The diffusion of the crystallizable substances into the lighter liquid was called exosmose, and that of the lighter into the heavier liquid, endosmose. The easily diffusing substances were called crystalloids, and the others, such as gum, albumen, gelatine or glue (colle) were called colloids. If, therefore, there should be on one side of the membrane a quantity of the juice of the beetroot or the cane, containing crystallizable sugar mingled with many gummy and gelatinous substances, and on the other side water, the solution of sugar would diffuse into the water, and the water into the sugar juice until the liquids on each side of the membrane became of the same density. If the water containing the sugar were then drawn off and fresh water substituted the diffusion would recommence, and this process might be continued until the whole of the sugar had passed away in the form of a nearly pure solution, while the impurities would remain alone in the solution which was originally sugar juice. The membrane may be animal or vegetableparchment paper, for instance, answers the purpose.

But in nature the walls of the cells of plants form a diffusing medium. The sugar in the beetroot or the cane exists shut up inside the cells. It was found that it could be extracted in the way described above, by diffusion. 


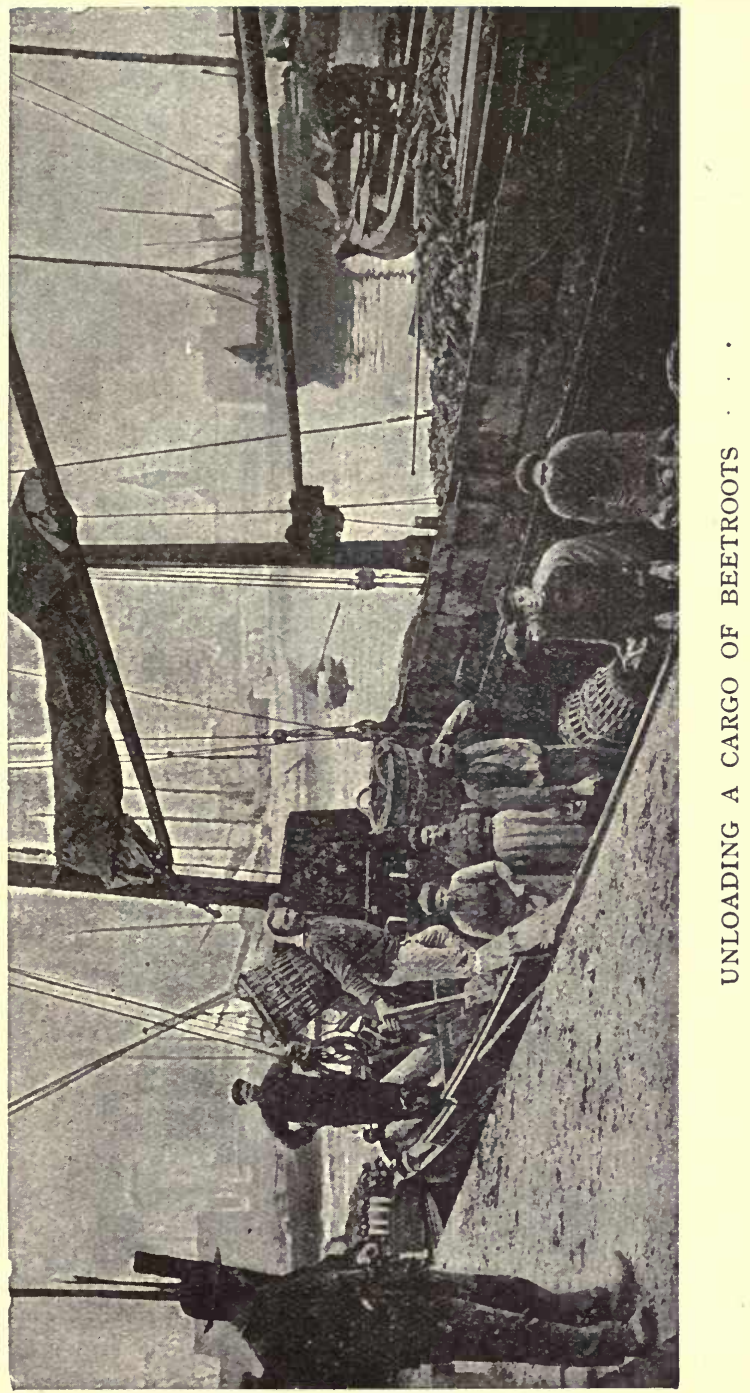


The apparatus for doing so is constructed and worked in the following way. A number of large vertical cylindrical vessels are ranged either in rows or in a circle. They are furnished with a well secured manhole at the tup and bottom, and with pipes which convey hot water to each vessel, and others which convey the liquid from each vessel to its next door neighbour, passing on their way through a heater which keeps the liquid up to a certain temperature. The pipes are arranged so that the liquid can be passed from one vessel to another either at the top or the bottom, or can be drawn off when the process of diffusion is completed. On the floor which commands the top of this battery of vessels are the valves by which the man in charge is able to conduct the operations. On an upper floor is the machine which cuts the roots into slices, all of the same size and shape, so that they can lie in the vessels without getting jammed together, but leaving room for the water to flow freely round them. If the battery is arranged in a circle the slices from above can be directed by a revolving shoot into any one of the vessels. On the upper floor is also the hot-water tank, situated sufficiently high to give the necessary pressure for the circulation of the liquid through the vessels of the diffusion battery.

Let us suppose that all the vessels $(8,12,14$ or 16 , as the case may be) are filled with slices, and the openings at the top through which the slices have been shot securely closed. Hot water from above is then turned on to the first vessel until it is full. Diffusion of the sugar takes place, and the density inside and outside the cells begins to approach to uniformity. Before the diffusion seriously slackens its pace the water-now a weak solution of sugar-is passed on to the second vessel, after traversing the intermediate heater, and 


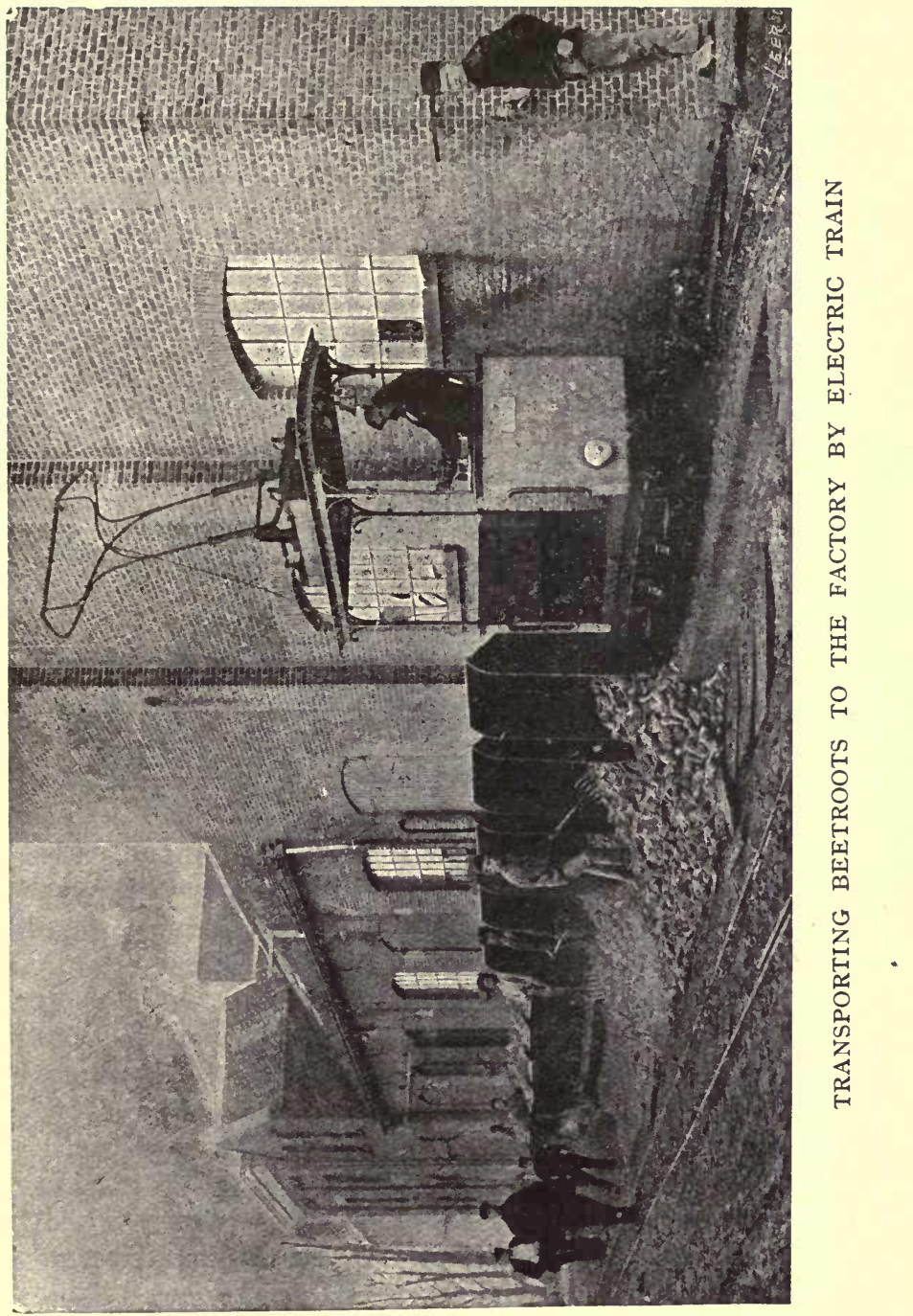


meets with fresh slices. Here the density of the juice in the cells exceeds that of the weak sugar solution, and diffusion goes on briskly. The process is continued through about half a dozen vessels. The solution of sugar when it has travelled so far is so nearly of the same density as the juice in the cells, that diffusion practically ceases. The sugar solution-called diffusion juice-is, therefore, drawn off, and goes to a measuring tank, and thence to the clarifiers to commence the defecation process. We now have six vessels of the diffusion battery of which it may be said roughly that in the first the slices have lost nearly half their sugar, in the second they may have lost about a quarter, and so on up to the sixth where very little sugar has been diffused out.

When the weak sugar solution left the first vessel fresh water was turned on, and followed in the round. A fresh exhaustion of the slices results, the process will finish at the seventh vessel, and again the contents of a vesselful of diffusion juice will be measured and go to the defecation. We can imagine the process continued until the whole battery of vessels is at work. The liquid is circulating under pressure the whole time. but when the moment comes that the slices in No. 1 are exhausted all its connections are turned off, the pressure is transferred to No. 2, the man-hole below in No. 1 is opened and the exhausted slices are shot out by means of compressed air. If the battery is circular there is a pit in the centre towards which the opening at the bottom of each vessel is directed, and which receives the wet exhausted slices. That the slices may be loosened, in order to be more easily ejected, the last charge of water to that vessel is directed from the bottom upwards. The vessel is at once refilled with fresh slices, and becomes the last instead of the 
first of the series. This is, roughly, the method of working the diffusion battery; but the rate at which it works, how often each vessel is filled and emptied, and how quickly the diffusion juice is passed from one to another, are matters which require most accurate regulation and supervision.

The diffusion juice is, of course, much purer than the cane juice which, as we have seen, is sadly spoiled by the violent crushing to which the cane is subjected in powerful modern cane mills. The diffusion juice contains the sugar and some portion of the salts of the beetroot. It may also contain small traces of the gummy and albuminous impurities, but the bulk of them remain in the cells of the exhausted slices. Of course, in the process of cutting the slices a certain number of cells are broken, and from these broken cells the impurities must find their way into the diffusion juice.

The superiority of this process over the crushing of the cane, as described in the last chapter, is so striking, that it may well be asked why cane mills have not been superseded by diffusion. Many cane sugar manufacturers have asked themselves the same question, and some have answered it by putting up a diffusion plant. But it cannot be said that the experiment has been altogether satisfactory. The cutting of the cane into slices is not a very easy operation, but that objection might perhaps be waived if other things went well. Diffusion involves dilution of the juice to the extent of at least twenty per cent. Maceration between the mills of a triple cane mill ought never to create a dilution of more than ten to fifteen per cent. This extra dilution in the diffusion process is a serious thing with a canesugar factory which relies on its megass for the whole of its steam-raising fuel. Moreover, the megass left 
from the diffusion battery of a cane sugar factory is very inferior to ordinary megass as fuel, and requires pressing and drying before it can be used. This is a rather fatal objection. Again, a beetroot factory need never, or hardly ever, stop for want of roots; but a cane factory may often have to suspend work for want of canes. With mills this is easily done, but with diffusion it involves considerable loss. Suddenly to stop a diffusion battery for want of raw material means that all the juice in the battery, most of it very thin, must be worked up as it is or a considerable loss of sugar incurred. A diffusion battery requires great regularity in the quality of the raw material. But a cane mil] is obliged sometimes to work up a large extra quantity of damaged cane in a hurry. With mills this can be done, but it would be impossible with diffusion.

Diffusion can, under favourable circumstances, extract ninety-five per cent. of the sugar in the cane. Mills are now so much improved that, with all recent appliances, they can get more than ninety per cent. of the sugar in the cane. The reason for adopting diffusion is, therefore, not so strong as it was some years ago, and is more than counterbalanced by the disadvantages.

There are several cane sugar factories in various countries that have tried the diffusion process. The most remarkable instance is the late Mr. Minchin's factory at Aska in Madras. The writer of these lines made an extended tour of the European beetroot districts with Mr. Minchin as far back as 1871, and on that occasion they paid a visit of several days to Mr. Robert, the inventor of the diffusion process, at his home at Séelowitz in Austria. Mr. Minchin knew him well, and had already been working the diffusion process at Aska for some years. As the process was only 
invented in 1860 Minchin must undoubtedly have been the earliest pioneer of that invention in the cane sugar industry. He stuck to it bravely for more than thirty years, and possibly it may be still working.

The exhausted beet slices from the diffusion battery are, of course, saturated with water which has to be pressed out. They are then either at once delivered to the farmer for cattle food or stored in pits till wanted. In the latter case they ferment, and are said to be preferred by the cattle in that state. Recently various methods of artificially drying the pulp have been adopted and will, no doubt, become general. The pulp makes a very good cattle food if judiciously mixed with chopped straw or hay. The writer has seen it mixed with the molasses of the factory, which seems a very natural and reasonable plan, and also a good way of utilizing a by-product which fetches a very poor price in the market when sold for distilling or to the special factories which extract its sugar by chemical process.

The well-known inventor, Steffen, has suggested the idea of extracting less than the maximum quantity of sugar from the roots, and drying the resulting pulp, rich in sugar, which ought to obtain a high price for cattle-feeding. The suggestion has not yet been adopted on any considerable scale.

A combination of crushing the sugar cane in the usual way and then treating the megass in a diffusion battery, called the Naudet process, has recently attracted some attention. Sixty-five per cent. of the juice is first extracted in the mill, and the megass is then loaded into the diffusion battery. The juice, heated and mixed with lime as if it were going to the clarifiers, is then poured on to the megass, and transferred from vessel to vessel as in the diffusion process. This process 
dispenses with the elaborate clarifying and filtering operations.

The following analysis of the beetroot is given in Horsin-Déon's book of 1894, "Le Sucre et l'industrie Sucrière." Water 80 per cent., sugar 15 , cellulose and woody fibre 1 , gummy matters $0 \cdot 6$, albumen and other nitrogenous substances $1 \cdot 6$, other organic substances 1 , mineral matters 0.8 per cent. Since then the average percentage of sugar has risen in many countries 2 per cent. Even the sugar actually extracted has risen in some favoured districts to more than 16 per cent. in a good season. This beats cane sugar hollow. But then the beetroot farmers only produce on the average, in the most favoured countries, 10 to 14 tons of roots to the acre, whereas the sugar cane is produced at the rate of twenty to forty tons to the acre. The sugar cane in Java, that most successful sugar-producing country, cannot be said to contain, on the average, more than 12 to 15 per cent. of sugar, and the quantity actually extracted does not, on the average, exceed $10 \frac{1}{2}$ to $10 \frac{3}{4}$ per cent. But, as has been already stated, they produce in Java, on the average, more than four tons of high-class sugar to the acre. The average production of European beetroot sugar is well under two tons to the acre.

There is one peculiarity of the beetroot juice which is of great importance: it contains no uncrystallizable sugar. Good raw beetroot sugar, therefore, is entirely free from what is roughly called glucose. The juice, moreover, is not acid and, therefore, does not become inverted so rapidly as cane juice. Here beet has a great advantage over cane. But in some of our sugar colonies, Jamaica and Demerara for instance, the final product, molasses, which of course contains, among other things, the invert sugar existing in the cane and largely 


\section{CHAPTER V}

\section{CLARIFICATION}

THE speed with which canes should be brought to the mill to be crushed, so as to avoid the danger of rapid changes in composition, is still more important with the juice itself after its extraction from the cane. It contains many kinds of impurities, and the more complete the extraction the greater is the amount of impurity. Among other things there are the germs of fermentation which would at once commence if the juice were not speedily subjected to the operations of clarification and defecation.

To go back again to primitive methods, such as still exist in primitive countries like British India, China, the Philippines, and even some parts of Brazil, the juice is at once poured by the small native grower into an iron pot over a wood fire; wood ashes and lime are added, which create scum. This is skimmed off the top until it ceases to rise, and the clear juice is then allowed to boil until it reaches the point where it will crystallize when cooled. When cold the crystalline mass is removed, and is ready for the market. In India it is called Gur or Jaggery ; in the Philippines, Taal or Zebu, or Ilo Ilo, according to the district from which it comes. In Brazil it has many strange names, but here it was called by the name of the port of shipment, Pernams (Pernambuco), Bahias, Maceios, and so on. Those from India, Manilla, and China are dark brown masses of sugar and impurities mixed up together. These sugars, and those from Brazil, used to come to this country in considerable quantities from time to 
time when prices were good, and formed no small part of the raw material of some British refineries.

In our West Indian Colonies the process of clarification was carried on, and still continues in some places, in a similar but much superior fashion. The "Copper Wall" was universal sixty years ago in the West Indies. It is simply a row of copper basins, with a blazing fire underneath them going the whole length of the row and then up the chimney. The juice, much purer than that from the powerful modern mills with all their appliances, contained nevertheless much albuminous and gummy matter which must be removed. The copper wall combined clarification and crystallization. In the first copper milk of lime was added, and the scum skimmed off ; in the succeeding coppers, to which the juice was ladled from No. 1, a further skimming or brushing took place, and when the juice reached the last of the six coppers it had become thick enough and pure enough to crystallize when cool into an excellent raw sugar, called muscovado, the principal raw material of the British sugar refiner sixty years ago.

But new appliances, in the course of time, took the place of the copper wall. The vacuum pan was invented for carrying out a more perfect kind of crystallization. Then came the European beetroot industry, which introduced many varieties of clarification and defecation. Capable men took up the subject and gradually developed a really scientific system of dealing with sugar juice. Lime was still the basis of the system, but it was no longer used in a haphazard or rule-of-thumb manner. Lime is absolutely necessary, especially with cane juice, which is naturally acid; but though it removes impurities it is liable to create more than it removes by forming lime compounds very detrimental to the subsequent crystallization. The beetroot factories 
proceeded to get over this difficulty by introducing carbonic acid gas into the defecating pans, which precipitated the excess of lime in the form of insoluble carbonate. The cane sugar manufacturers are learning the lesson from their European competitors, and are now beginning to practise, in countries where science reigns supreme, as complete a system of defecation by lime and carbonic acid as can be found in the most up-to-date beetroot factory.

We must skip over as lightly as possible the intermediate processes which preceded the perfected methods of to-day. The copper wall was superseded by an operation completed in one vessel, where the juice was heated by steam, the lime scums removed from the surface and partly allowed to fall to the bottom of the vessel, from which they were subsequently removed, the clear juice being run off for concentration in the vacuum pan. Another method was to heat the juice in a special juice heater and then, when the air bubbles had thus been removed, run it into the defecating pan where lime was added, the lime and impurities all falling to the bottom in the absence of air bubbles, and the clear juice being decanted.

In all these various processes the important point is to hit off the exact quantity of lime necessary. Too much lime would be worse than too little. But even when exactly the right quantity is used it does not remove all the impurities. Many modifications were introduced, continuous defecators were invented, new methods of heating the juice before entering the defecator were adopted, but no really satisfactory results are likely to be obtained until the lessons taught in the beetroot factories are learned and applied. The preliminary heating of the juice before defecation not only drives out the air bubbles but, what is much more 


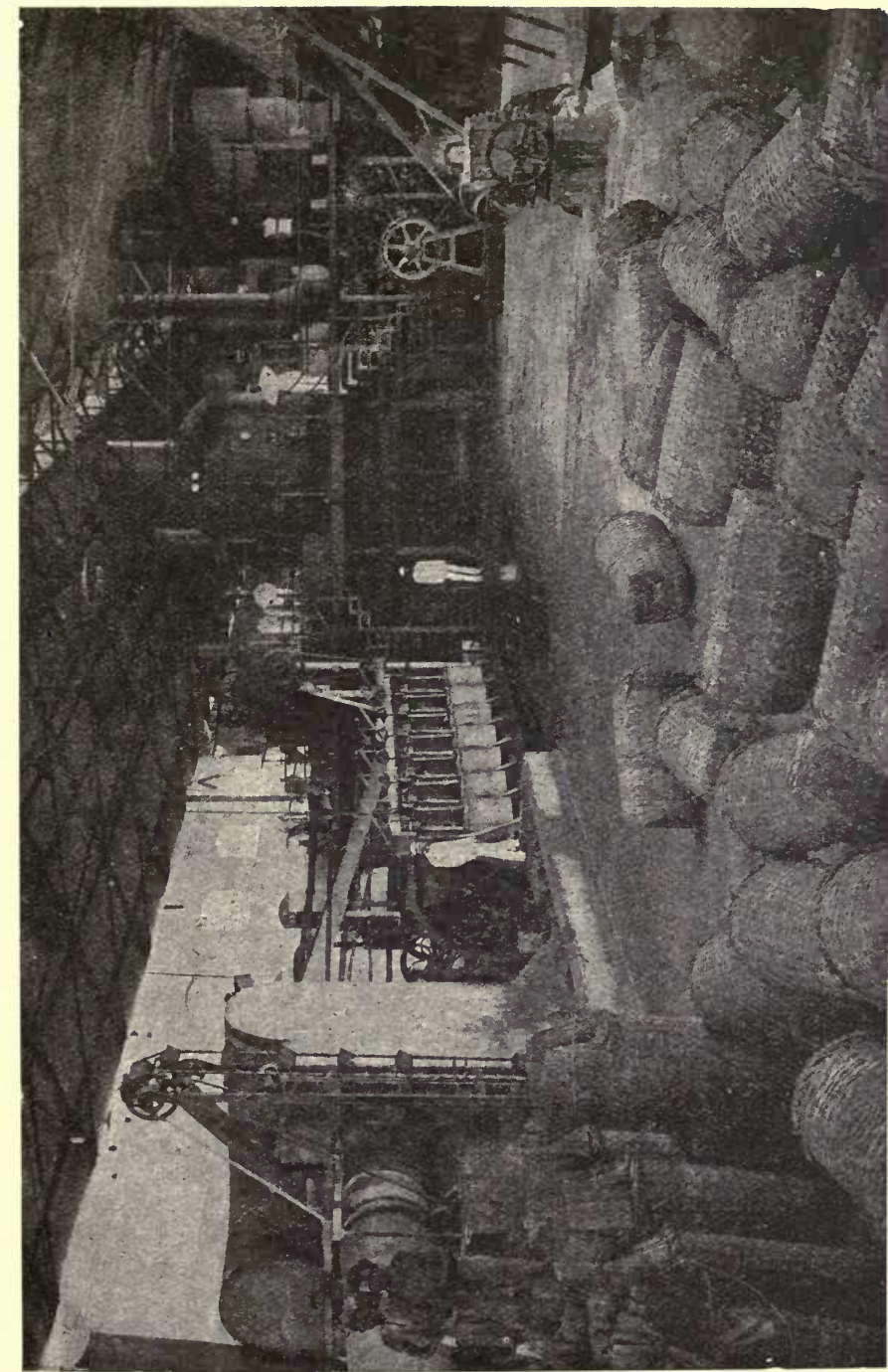

告 
important, coagulates the albumen. The addition of lime in the defecating pan not only neutralizes the acidity of the juice but also combines with the albumen and creates flocculent precipitates which carry down with them a portion of the gummy impurities and also all suspended substances, such as fibre, wax, colouring matter, and the dirt which had adhered to the canes. The albumen is almost if not entirely removed. The gums and pectine, a gelatinous substance akin to gum, are reduced to about half their quantity, and the quotient of purity is raised about two per cent.

But great skill and care are necessary in this process of clarification. Too little lime fails to carry away all the acids, albumen and gummy matters, and the precipitation is imperfect and slow. Too much lime, on the other hand, attacks the glucose, combines with the resulting organic acids and forms viscous substances very injurious not only to the subsequent crystallization but even to the body of the sugar itself. The exact point of right quantity can be ascertained by rough experiment easily carried out, but it all depends upon the operator that this shall be done correctly. In making raw sugar for the refiner the object of the operator is to keep the juice as nearly neutral as possible, but with a slight tendency towards alkalinity. This secures that the resulting sugar, when crystallized, shall not be acid and, therefore, shall not deteriorate in quality.

But there is much sugar made now, roughly called "Demerara sugar," which is intended to be consumed in the form of raw sugar. Large quantities of sugar were, in former days, consumed in the raw state. They were the superior kinds of muscovado sugar, from Barbadoes, Jamaica and Porto Rico. It was only the lighter coloured varieties with a yellowish tinge which were good enough for the grocer. They were 
sweet and fragrant, with a pleasant flavour of the sugar cane. But when the home refiners produced yellow sugar with a pale primrose tint the poor old muscovadoes were thrown rather into the shade. Then came the new raw sugars from our colony of Demerara which soon cut out all competitors. They were crystallized in the vacuum pan and had a large bold crystal of a pretty yellowish tinge. Trinidad followed the example of its neighbour, then came St. Lucia, and now many more imitators.

There is no secret now as to the method of preparing the juice for making this sugar. A few words are sufficient to give the general reader an idea of the special preparation of the juice when "yellow crystals" are to be made. There is a gas called sulphurous acid, the product of burning sulphur, which has the property of bleaching vegetable substances. In the days when sulphur matches existed boys used to light one and hold a flower over the smoke to see it turn white. The cold juice from the mill, heavily limed, is pumped to the top of a tower or vertical box, where it runs down the inside over a series of perforated trays which scatter the juice in a shower. Sulphurous acid gas is introduced at the bottom under pressure, so that the juice and the gas thoroughly mingle. While the juice is descending the gas is rising to the top of the tower. An alternative system is to blow the gas through perforated pipes into the bottom of a tank full of cold limed juice. The effect of these processes is to nearly neutralize the lime with sulphurous acid. The viscosity is greatly reduced and the subsequent work of crystallization and "curing" greatly facilitated. The juice must not be heated until neutralization is nearly complete. The action of the acid on the cold limed juice is to bleach it, and to break up the organic soluble salts, substitut ing 
insoluble sulphites. The resulting juice, being now acid, is bright in colour, but in order to maintain this colour up to the time of crystallization it is necessary to keep it rather on the acid side of neutrality. If there is any fear of alkalinity, phosphoric acid is used in the defecator, which precipitates any excess of lime. Of course, great skill and experience is necessary in carrying out this special process for the purpose of producing bright yellow crystallized sugar, first by maintaining the bright colour of the juice and, secondly, by avoiding the danger of "inversion" in its slightly acid state. When all precautions are properly taken the result is a bright yellow sugar which fetches a fancy price; but if not, the product will be a dingy yellow or even grey sugar, and will not be a success in the market. When there is a poor demand for yellow sugar the factory goes back to the ordinary defecation process and makes "refining centrifugals" for sale to refiners. The cost of production is less, and the yield of sugar is generally rather better-and there is always a market. In some factories it appears that the treatment of the cold juice with the acid precedes the liming of the juice, apparently a still more dangerous process. It is said that yellow crystals are more difficult to produce now that more powerful mills produce a juice of less purity.

We now turn to the clarification and defecation of the beetroot juice, and must enter on a brief review of the processes which led up to the present perfected system of what is called "carbonatation." The juice of beetroot, like that of cane, contains certain impurities which have to be removed before the juice is fit for filtration, evaporation and, finally, crystallization. Fortunately it contains no glucose and, therefore, there is no creation of those inconvenient and injurious organic acids which are produced in cane juice when 


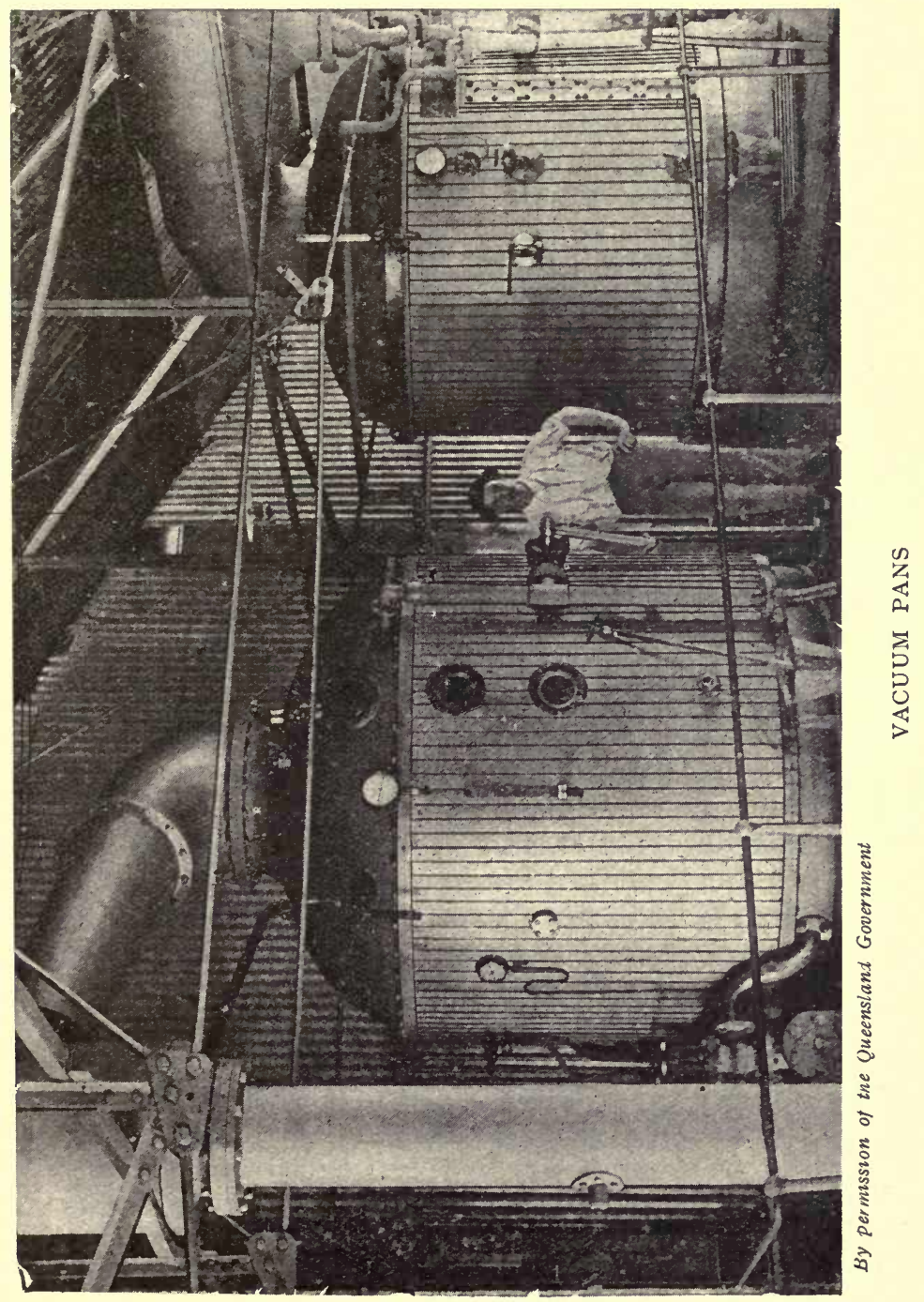


the lime attacks and decomposes some of the glucose. In the beginning the beetroot factories followed the example of their brethren in caneland; they added lime, the scum at the top was removed, the heavier impurities sank to the bottom, and the intervening clear juice was drawn off. That was simple clarification. The juice was then boiled in open pans, and allowed to crystallize as it cooled ; the result was a very excellent raw sugar which can still be recollected and praised by those who go back to the sixties. Very little of the raw beetroot sugar is as good as it was then. It is a curious fact that the modern agent, sulphurous acid, was tried with beetroot sugar more than a hundred years ago ; but science was not sufficiently advanced in those days to make it a safe experiment. They even tried sulphuric acid as a means of throwing down the excess of lime, and with some success. This method was practised more or less up to $\mathbf{1 8 4 9}$, when the idea of using carbonic acid gas made its practical appearance. It was called the Rousseau process. The juice, after decantation from the defecating pan, was saturated with the gas until the whole of the excess of lime was thrown down in the form of insoluble carbonate. Ten years later Périer and Possoz introduced double carbonatation, which is now the universal system. The name of Jelinek is attached to this system in Austria. New industrial methods and new scientific ideas have a habit of springing up simultaneously in various quarters.

Among the gummy impurities is included pectine, which, if the raw juice were left to itself, would rapidly decompose into gelatinous substances converting the whole mass into a sort of jelly. Other fermentations would follow and attack the sugar itself. Lime throws down this pectine as well as the organic acids, and coagulates the albumen in a hot juice. But in a hot 
juice the lime, if not neutralized, would form with the sugar various sucrates (or saccharates) of lime, some soluble but some, unfortunately, insoluble. Here would be a great loss of sugar because the insoluble sucrate would disappear in the scum. Hence the absolute necessity for some acid to neutralize the lime and to set free again the sugar from its unstable combination. There is another combination of sugar with lime, discovered or defined by Boivin and Loiseau in 1868, which is interesting for other reasons. They called it the sucrate of the hydrocarbonate of lime. It is a gelatinous body but is broken up by further addition of the gas.

It is clear from these facts that it is necessary to saturate the limed juice thoroughly with carbonic acid in order to make sure that no sugar finds its way into the scum, and to commence the saturation before applying heat. But if the saturation were carried too far part of the precipitated carbonate, which had carried with it not only the impurities but also the colouring matter, would become soluble, and the decolorized juice would again become coloured. In the double carbonatation the saturation is stopped before this danger-point is reached, the decolorized and purified juice is drawn off, and a second operation commenced. More lime is added, and the juice is again saturated with the gas up to the point where it is nearly but not quite neutral.

The details of the operation may now be briefly described. Milk of lime is added to the cold juice directly it comes from the beetroot. This operation is preferably performed in a separate vessel with a mechanical stirrer. The limed juice then goes to the carbonating vessel and the gas is injected while the juice is still cold, Great frothing takes place, which is 
kept down as much as possible by various means, and a cover to the vessel is necessary to keep back any overflow, and to allow superfluous gas to be carried off up a chimney. When the action is in full force moderate heat is applied through a steam coil at the bottom of the vessel. The frothing begins to slacken and tests are applied to samples of the juice to detect the right point of alkalinity, nearly approaching to neutrality. At that point it is found that a sample of the juice in a glass indicates a quick and steady precipitation of carbonate of lime, leaving a clear bright juice above. It is now ready to go to the second carbonatation. Decantation of the clear juice has, of late years, been given up, as it is found difficult to prevent some admixture of sediment. The machine called a filter press was invented, through which the juice and the precipitate are forced by pressure. The clear juice flows out, and the lime precipitates are retained in the chambers of the press in the form of flat cakes containing the lime and the impurities of the juice. A perfect regiment of these filter presses forms an important part of the plant of a beetroot sugar factory. The clear, bright juice goes to the second carbonating .vessel, more lime is added, the gas is passed through the liquid until the lime is completely saturated the heat being raised higher than in the former vessel, and the operation is finished. The juice again goes through other filter presses, and is ready for evaporation and then crystallization.

This was the process when the juice was extracted in the old way by hydraulic presses. But now that diffusion has become universal, even in France, and furnishes a much purer juice, there is not so much necessity to operate in the first instance on cold juice. The juice from the diffusion batteries is already hot, 
and it is found that if this heat be kept up, and even increased, the defecation goes quicker, and with the purer juice also goes safely. Less lime may also be used, but not to the extent of making the first carbonatation imperfect, which would impede the filtration.

In Java, where a large quantity of white sugar is now turned out fit for direct consumption, the carbonatation process has been adopted in many factories, and at one time it seemed probable that its use would go on increasing. In cane juice there is a small quantity of glucose. In the ordinary defecation, at a high temperature, the lime attacks the glucose and forms dark coloured, viscous substances which are most inconvenient. But when working at the lower temperature of the carbonatation process these lime salts are partially insoluble, the rest being colourless and innocuous. The juice becomes clear, light in colour, and easily filtered and evaporated. Much more of the gummy matters are thrown down than in the ordinary defecation process. A second carbonatation is just as necessary with cane as with beetroot juice, and for the same reason. The first filtration must take place while the juice is still alkaline, otherwise part of the precipitate would be redissolved, and the juice would become coloured. Considerable quantities of lime are necessary in order that the viscous precipitates may be mingled with sufficient lime to make the filtration go well. It is rather difficult to secure absolute neutrality in the final juice and, therefore, a further saturation with sulphurous acid is sometimes found advisable, which also improves the colour of the juice.

This carbonatation process is evidently a more expensive operation than ordinary defecation, but if white sugar is to be made direct from the cane juice 
it was considered essential. ${ }^{1}$ In the case of the beetroot, it has enabled well-managed factories to produce excellent refined sugar. Even as far back as 1871 the present writer saw loaf sugar produced direct from the beetroot juice, and, at a later date, Langen, the inventor of the process for making cube sugar, produced fine cubes in his own beetroot sugar factory.

These are some of the wonderful results of science applied to sugar production, and point to a great development in the future. But this country, the largest consumer, cares for none of these things.

1 As to white sugar in Java, a change has taken place in the method of manufacture which may, in the future, have important and wide-reaching results. The carbonatation process, as has been explained, is an expensive process requiring great skill and care. It requires a large mass of special machinery, including lime-kilns for the production of lime and carbonic acid ; and those kilns require fuel. In tropical countries, limestone and fuel may be difficult to obtain. But a still stronger objection to the carbonatation process in Java is that frequently a factory may find it necessary, for market purposes, to go back to the production of raw sugar when the demand for that sugar is stronger than the demand for white sugar for India. His carbonatation process would make it too good. The planters, therefore, tried experiments, and found that neutralizing the lime by sulphurous acid, a simple process, would, if properly carried out, clarify the juice so well that white sugar quite as good in every way could be turned out. More than half of the Java crop is now white sugar of excellent colour and quality. 


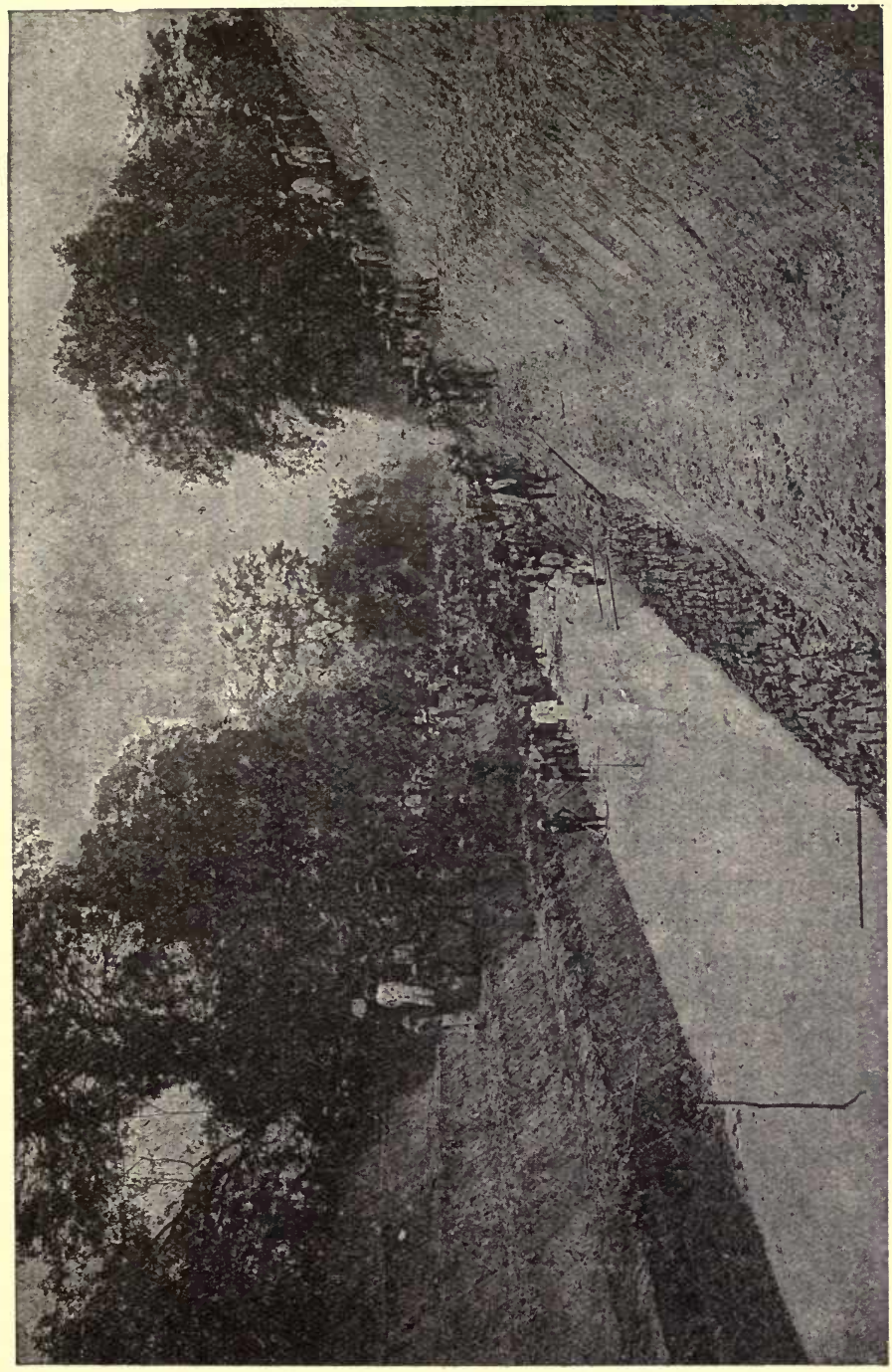

委

恣 


\section{CHAPTER VI}

\section{CRYSTALLIZATION}

HAviNG clarified and purified the cane juice, the next step is with all speed to evaporate the water until crystallization takes place. This, as we saw, was done in the last coppers of the copper wall. But the great waste of fuel and the excessive heat spoiling the sugar, soon led to search for better methods. They cannot all be enumerated, much less described, in a popular treatise, but a few are worth a passing notice. Alfred Fryer, the Manchester sugar refiner, to whom reference has already been made as a man not only of ingenuity but also of ready wit, maintained that the proper way of making sugar in the tropics was to do so as quickly as possible, and at a minimum cost, and to send the rough raw material home to be converted into refined sugar. $\mathrm{He}$, therefore, about forty years ago, invented, constructed and worked (in the West Indies) a simple apparatus called Fryer's Concretor. The clarified juice is run, in a thin stream, over a long sloping platform of metal divided by trays into a series of lanes from side to side, along which the thin stream of juice slowly meanders in a zigzag direction. Heat is applied underneath, and the thin film of juice evaporates so rapidly that by the time it arrives at the other end of the platform it is nearly ready to crystallize. The evaporation is finished in a cylindrical vessel fitted with plates which slowly revolves, hot air being at the same time injected. This finishing process exposes the juice to further heat, and completes the evaporation. The juice is then run out, and allowed 
to crystallize at its leisure into solid blocks, which Fryer very appropriately called concrete. This ought to be a very cheaply produced article of commerce, and the idea appeared to be sound. But unfortunately the concrete never "caught on" in the market. In these days of Brewers' sugar there might be a better demand.

Another method of rapid evaporation of juice in the form of a thin film was introduced about the same time, called the Wetzel pan, the principle of which was to heat the juice in a long trough in which slowly revolved a long cylindrical wheel armed with a series of discs, which constantly exposed, in its slow revolution, a thin film of juice to the air, and thus set up a rapid evaporation. Another form was to heat with steam the wheel instead of the vessel containing the juice, or to make the wheel to consist of a series of steam pipes, placed either lengthways or round the circumference. This method involved the expense of an engine to drive it. At that time some of his brother sugar refiners were one day explaining to Fryer the new method of the Scottish refiners in boiling their yellow sugars at a very low temperature, which not only improved the colour but also enabled them to sell more water in combination with the sugar. "Ah!" said Fryer, " that must be the wet sell process."

The Aspinall pan was another early system of evaporation by steam heat. The steam passed into a chamber in the pan, through which the juice circulated through a series of vertical brass tubes until it was ready to crystallize, when it was drawn off. Many modifications of 'this' were introduced, but all had the serious defect of over-heating the juice. Also, when the juice thickens evaporation goes on with great difficulty because actual ebullition, at the temperature necessary for that 
operation, would be fatal. Hence the introduction of the vacuum pan, where the thick juice can be boiled violently at a perfectly safe temperature. ${ }^{1}$ It is, if we look at its original form of fifty years ago, a slightly flattened sphere of copper provided inside at the lower part with a coil of steam pipe, and also with a steam jacket. An air pump creates a partial vacuum, and a condenser, through which the steam from the boiling juice passes on its way to the air pump, by rapidly condensing the vapour greatly helps to increase the vacuum. The juice is always boiling more or less violently, even when thick, and, therefore, throwing off its vapour freely. This pan in its complete form appeared about the year 1830, and about thirty years afterwards began to be used in the tropics as a useful adjunct to the preliminary evaporation of the thin juice. The vacuum pan, in fact, finished the operation. But it did more than this, it enabled the factory to produce a more distinctly crystalline form of sugar than the old muscovado kind, which comes from the confused crystalline mass formed by the spontaneous crystallization of the thickened juice when, on cooling, it crystallizes of its own accord. But the use of the vacuum pan did not become extensive for many years. Mauritius and the French West Indian Islands were the first to use it on any considerable scale ; then came Demerara, Berbice and Trinidad. Now it is used everywhere, except in primitive countries.

The vacuum pan puts the finishing touches to the thickened juice, but a great deal of evaporating has to be done before the juice arrives at that state. Another

1 A solution of sugar must be heated above $212 \mathrm{~F}$., the boiling point of water, before it boils ; but in a partial vacuum it boils violently at $160 \mathrm{~F}$., and at even a lower temperature in a more perfect vacuum. 
kind of vacuum apparatus has been invented as best suited to that earlier stage. The French call it the Triple-effet, and that is now its name. It is a very ingenious and successful contrivance, and came from France, at that time the leading country in the production of beetroot sugar. The inventor, Rillieux, had to pass many long years, as inventors generally do, before he could procure a good trial of his new idea. In the old days of open pans and the heat of a naked fire the French manufacturers had to burn 400 kilogrammes of coal for every ton of roots worked. When steam was substituted for fire heat, and the steam engine was allowed to enter the factory to drive an air pump for the vacuum pan, they managed to do the work with 250 instead of 400 kilogrammes of coal to the ton of roots. Rillieux proposed to make a further great reduction in the cost of fuel by evaporating the greater portion of the water in the thin juice in a double or triple arrangement of pans, where the steam from the boiling juice in the first should heat the second, and so on. This began to be accomplished about the year 1852. By 1882 it was brought to a fair degree of perfection, and the amount of fuel per ton of roots was reduced to 80 kilogrammes.

The apparatus may be roughly described as consisting of three vertical cylindrical vessels with dome-shaped heads, ending in a wide neck which turns over and downwards carrying the vapour to its next destination. The lower part of each vessel is divided into three parts, a small space at the bottom, then a much larger space enclosed by two horizontal iron plates forming the "steam drum," fitted with vertical copper pipes permitting the juice, which enters at the small space below it, to pass through the steam drum into the large open space above it. The juice is allowed to rise 
above the top of the steam drum, but not far enough to incur the danger of boiling over. The final vessel of this triple-effet is connected with the air pump and condenser. Low pressure steam enters the drum of the first vessel, the thin juice boils and begins to thicken. It is transferred to vessel No. 2 ; vessel No. 1 being charged with fresh juice. The steam from the evaporation of the juice in No. 1 goes into the steam drum of No. 2, and boils the partially thickened juice. There is a slight vacuum in No. 2 ; and even in No. 1 a slight vacuum is created by the rapid condensation of its steam in the drum of No. 2. In No. 3, the vessel nearest to the pump and condenser, the vacuum is greater. The still thicker juice in No. 2 goes into No. 3 ; No. 2 is filled from No. 1, and fresh thin juice goes into No. 1. The triple-effet is now in full work, which goes on continuously. The steam from the boiling juice in No. 2 goes into the steam drum of No. 3, and not only boils the juice there, but improves the vacuum in No. 2 by its rapid condensation. The transfer of juice from vessel to vessel, and from the thin juice tank to the first vessel, takes place every time that a charge of sufficiently thick juice is drawn from No. 3 to be cleaned and go to the vacuum pan. The arrangements for drawing off the water of condensation, and the precautions against loss of sugar by the carrying over of bubbles of juice in the steam, need not be detailed, nor the cleaning of the copper tubes, and many other necessary operations connected with this complex apparatus.

Here we have not only a great saving of steam, but also a complete method for avoiding, as much as possible, any injury to the sugar when the juice becomes thick and, therefore, more sensitive. But the juice, which was perfectly clear and bright when it entered the tripleeffet, loses its brightness as it passes through the process 
of thickening, because many substances which were soluble in the thin juice, become insoluble as it thickens. These substances make the juice turbid, and also deposit themselves in the tubes, which, therefore, require constant cleansing. In the case of cane juice, phosphate, sulphate, carbonate, silicate and oxalate of lime, oxide of iron, silica and a few organic impurities are found in this deposit. For this turbid, thickened juice, a further clarification is necessary. If it has been through the double carbonatation there will be no difficulty in the filtration, but in the case of cane juice from the ordinary defecation it must be treated again in the defecating pans, and neutralized, if necessary, with sulphurous or phosphoric acid, or, if acid, with soda. These help the settlement of the precipitate. Acidity in thickened cane juice may come from fermentation. The only way to avoid this fatal trouble is cleanliness. That must be the first rule in every sugar factory or refinery. The triple-effet is now used universally in all large sugar factories, and has sometimes become a Quadruple-effet. Many modifications have appeared but need not be described here in detail, though they are interesting and instructive. Some are film evaporators, and some substitute horizontal for vertical pans.

The thick juice, after filtration, goes to the vacuum pan, and its treatment there depends on the kind of sugar to be made. It may be boiled into large grained yellow crystals, as in Demerara; or into still larger grained sugar which is afterwards washed white, as in France; or into small grained sugar, afterwards washed white, as is the practice in Germany, Austria, and Russia, in making "granulated" ; or into a superior crystalline raw sugar for the use of sugar refiners, as is the case in Cuba, Peru, St. Domingo, Java, and many other progressive cane sugar countries, and also in most 
of the beetroot sugar districts of Europe; but seldom in the United States, where "granulated " is almost universal. This kind of refining sugar is called "centrifugal" to distinguish it from the lower classes called muscovado. The "mother liquor" from the first crystallization is either boiled into a second product or taken back into the pan to mix again with the boiled mass.

The vacuum pan, which used to be quite a small, nearly spherical vessel, is now made of an enormous size for the use of factories where large quantities of juice have to be dealt with. These large pans, instead of having only one steam worm, are armed with a series of them, the steam being first turned on in the lowest, and then into each in succession as the pan gets fuller. The process of boiling and crystallizing sugar in the vacuum pan is quite a fine art. It must suffice to describe it very roughly in this popular treatise. Moreover, there are infinite varieties of treatment, dependent upon the purity or impurity of the material operated upon, and the kind of sugar the operator desires to produce. For instance, the loaf sugar which we see in a Paris restaurant, a dull white lump of sugar without any sparkling grain, is not crystallized at all in the pan. The liquor is boiled down to such a thickness that it will crystallize of itself while cooling. It is run into the loaf-moulds where it rapidly crystallizes as it cools. It forms a dull granulated mass. On the other hand, the sparkling loaf or cube sugar used in this country is made by most careful and skilful crystallization in the pan. The liquor, as it covers only the lowest of the steam coils, is brought to the crystallizing point, and then comes the skill. Not only can the boiling liquor be looked at through a window in the pan, but samples can be taken from the hermetically sealed pan, with what is called a proof-stick. The pan-man 
carefully watches the appearance of the minute crystals and allows just enough liquor to flow in to prevent a confused mass of crystals being suddenly formed. He thus maintains what is called an even grain-grains all of one size. It is his business to maintain the even grain from that moment until the pan is full, and the boiled mass in an exactly fit state to go out, either to the centrifugal machines or to the sugar moulds. He allows the grains to come closer and closer together as time goes on, and if he has done his work well it will be found, when the contents of the pan goes down into the receiver below, that the boiled mass-the massecuite, as the French call it-contains a very even-sized grain, with as few small grains in between as possible. This is most important in making crystallized sugar which is to be washed white in the centrifugal machines, because there would be a wasting of the fine white "first product" if any of the smaller grains found their way out with the adhering syrup, and were thus degraded into the after products. These rules apply equally well in the case of white or yellow crystallized sugar made in cane or beetroot sugar factories. The French white crystals are boiled very large, and with excellent skill. German, Austrian and Russian "granulated" are boiled to a much smaller grain. The pan is filled much fuller before grain is allowed to appear; then the boiling is allowed to go much quicker than in the former case, and the result is a uniform very small grain.

The centrifugal machine requires no great explanation. Drums with perforated walls spin round at great speed. The boiled mass, carefully mixed and stirred in a vessel commanding the centrifugals, is run into them; the syrup flies off through the perforated wall of the drum, and is caught and carried away from the outside of the 
drum, as a second syrup, to be boiled again into a second product, or perhaps to be taken back into the next boiling of the same pan to form part of what, by courtesy, is still called "first products." This is a very important modification in these latter days which must presently be explained.

The stage of finished crystallized sugar is thus rapidly attained. If it is "centrifugal," that is, a kind of superior raw sugar for the use of refiners, it simply goes into bags when cold, is weighed off, and ready for shipment. White crystals, and "granulated "-white crystals with a very small grain-are carefully dried before bagging. Granulated is dried in a heated revolving cylinder. The process is simple and rapid, and the sugar is soon ready for the bag.

The only matters requiring notice are the afterproducts. They used to be considerable, but their quantity is gradually becoming smaller, and, therefore, less important. In Java, where the practice is to take syrups back into the pan, thus swelling the quantity of so-called first products, the low black final product is very small in amount. In some countries the second products are so good in grain and colour that they fetch a satisfactory price in the market. The beetroot factories often turn out an excellent second product, much sought after by the refiner.

A new method of dealing with the after products of the factory is now much employed. In boiling a viscous, impure, second syrup, it is not possible to produce in the pan as much grain as the syrup is capable of forming. But if the masse-cuite, after it leaves the pan, be subjected to a quiet stirring motion the portion of the syrup which was unable, owing to the inert state of the mass, to crystallize in the pan, will begin to deposit a further amount of sugar in the crystalline form, not 


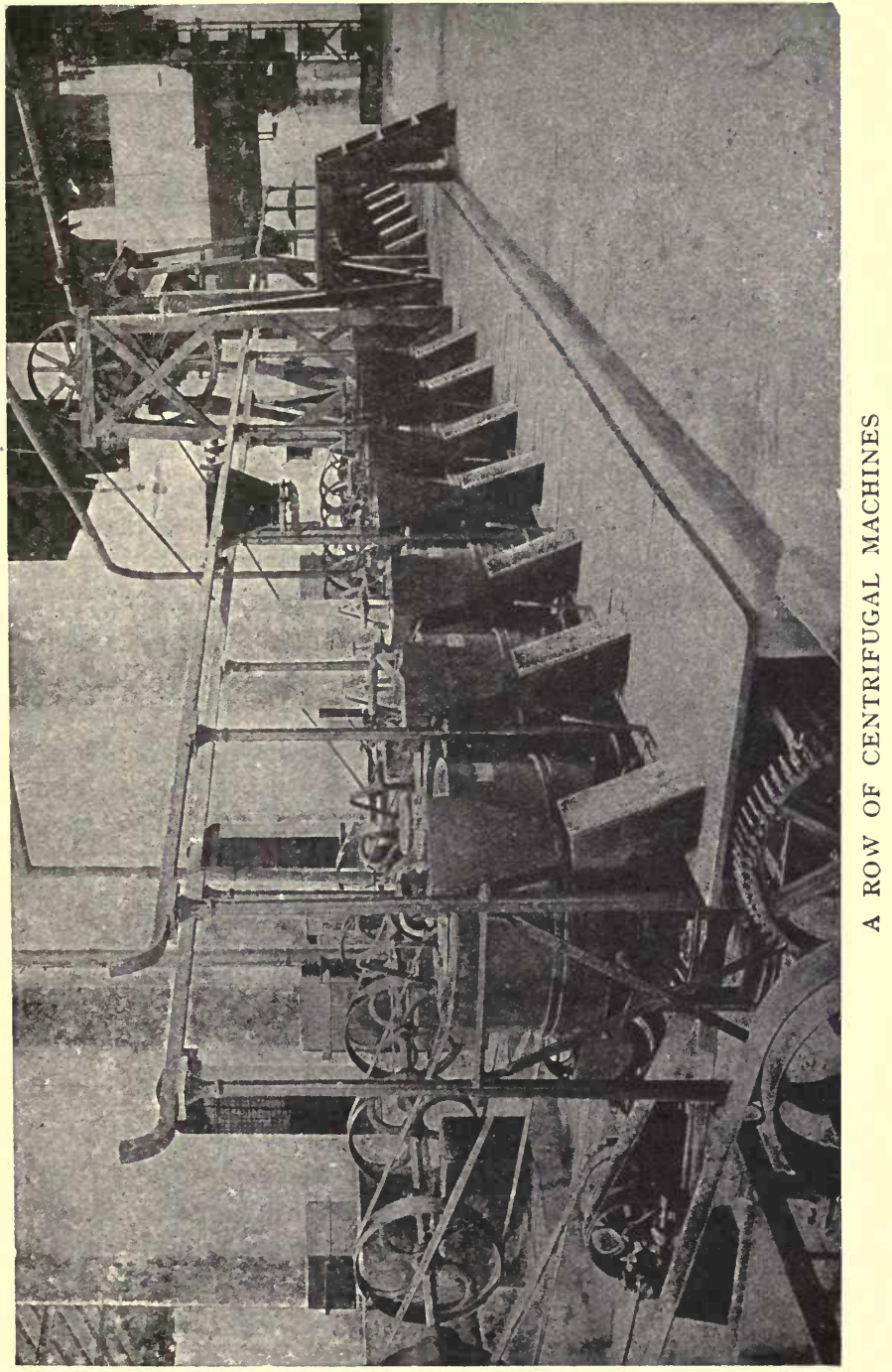


by making new crystals but by building up the crystals already existing in the mass. This has been called "crystallization in motion." The same process may be applied to the so-called first-product, which has been boiled not only from pure juice but also, at the end of the boiling, with an admixture of second syrup. This addition makes the masse-cuite, at the end of the operation, more viscous than it otherwise would be ; but the process of subsequent stirring helps the viscous syrup to deposit more sugar on the grains, and the result is a good imitation of a genuine first product.

The scientific explanation of this method of adding a less pure syrup to the pan nearly full of a first product masse-cuite is worth a moment's attention. As long as the boiling, and, therefore, evaporation, of the crystallized mass in the pan continues, the " mother liquor" in which it moves should continue to deposit fresh sugar on the crystals. But the time comes when the mass is so dense that it is impossible to continue the crystallization, That is the time to introduce some second syrup, that is, the "mother liquor" from the previous masse-cuite, which has been thrown off in the centrifugal machine. This at once makes the dense mass of sugar in the pan more fluid, and enables the deposition of sugar on the crystals to begin again. This further crystallization comes not only from "the mother liquor" in the pan but also from that brought in from the centrifugal machines. The subsequent stirring in the apparatus for promoting crystallization-in-motion adds still more sugar to the grains of crystal, and thus the second syrup is induced to yield a considerable quantity of its sugar in the form of good first product. It looks as if this could only be carried on up to a certain point; but that difficulty can be got over by doing it in two stages. A small quantity of juice is boiled 
to masse-cuite and mixed in the pan with as much of the now nearly exhausted second syrup as will reduce the purity of the "mother liquor" to the desired point. The mass is boiled to a high concentration, let out into the coolers and cooled in motion down to a fixed temperature for a considerable period-several days. The subsequent curing of this in the centrifugal gives a sugar equal to first product "in quality and appearance," and a syrup which is practically exhausted molasses. Dr. Prinsen Geerligs, the eminent Java expert, gives very full details of this most important new departure in the science of sugar production. He declares that, if well conducted, this system will get rid every day of the same quantity of exhausted molasses as enters the factory in the juice in the form of impurities and non-saccharine matter. Those who are sanguine of the result of this new process look forward to the time when there will be only two products of the factory - first products and molasses.

This brings us to molasses, and to some interesting points with regard to it. In places like Jamaica and Demerara, celebrated for their rum, there is no question what to do with the molasses, it goes to the distillery and is made into rum. The sale of rum in these countries is an important item in the account. The receipts from that product can be credited in the final account so as to show a very much lower cost of sugar production. But where rum is not made it becomes a great problem, in cane sugar countries, what to do with the molasses. In some beetroot countries it goes to the ordinary distiller. In Germany it goes to special factories which extract the sugar from it by chemical processes, and actually produce white sugar as their final product. These factories produce in this way about 100,000 tons of sugar a year, which is credited to Germany as part 
of her yield of sugar from the roots. In beetroot sugar there is no glucose, but in the molasses there is some invert sugar, the product of injury to the syrup during the manufacture. The reason why there is molasses is the presence of salts. The theory is that these salts prevent a certain quantity of sugar from crystallizing, and that is the sugar which is held in suspension by the salts in the final syrup, called exhausted molasses. It was much discussed, some fifty years ago, what this melassigenic power, as the French called it, amounted to. The theoretical figure was that one per cent. of ash prevented 3.5 per cent. of sugar from crystallizing. But practically the figure 5 has been adopted as the coefficient. A raw beetroot sugar which contains, by the polariscope, 94 per cent. of sugar, and 1.2 per cent. of ash, as determined by incinerating a weighed portion of the sugar, moistened with sulphuric acid, in a platinum dish, is estimated to yield 94$(1 \cdot 2 \times 5)=88$ per cent. of pure sugar. Beetroot sugar is now bought and sold on this basis of 88 per cent. net analysis, as ascertained by this system, the invoice price being raised or lowered, per degree or fraction of degree, according to the actual analysis of the sugar delivered. On the other hand, cane sugar is bought and sold, basis 96 polarization, that is the actual quantity of sugar, as determined by the polariscope, contained in the raw "centrifugal" sugar. And, in the same way, muscovado sugar is sold, basis 89 polarization; the degrees, up and down, being charged or allowed for in the invoice of the actual sugar delivered.

Cane juice contains a certain quantity of glucose, and this is increased during the manufacture. At one time it was thought that the presence of this glucose, as it may be called roughly, prevented a certain quantity of sugar from crystallizing. This has been shown, by 
Dr. Prinsen Geerligs, to be erroneous. He also shows that a subsequent theory, that the crystallization is prevented by the viscosity of the molasses, is also unsound. His present theory is that there is a chemical combination of the sugar (sucrose) with other constituents in the molasses, forming very soluble bodies, much more soluble than the sucrose or those other constituents when existing in their separate forms. For instance, a solution of common salt dissolves more sucrose than the water contained in the solution would do. Dubrunfaut, a French sugar expert of the middle of the last century, first pointed this out, and many investigations were made at that time as to the melassigenic power of various salts. But the new theory of a chemical combination of salts with the sucrose leads to somewhat different conclusions. The solubility of the constituents is regulated by the solubility of their combinations, and not by the solubility of the bodies in their uncombined state. On the other hand, the presence of glucose does not make the sucrose more soluble. Its presence is found actually to decrease the solubility of sucrose in the presence of salts ; that is to say that, where glucose and salts are present in the solution, the amount of sucrose crystallizing out increases in proportion as the liquid contains more glucose for the same amount of salts.

This is a rather long story, but it is worth putting on record as a definite explanation of the formation of exhausted molasses, hitherto more or less a mystery, but now clearly defined by Dr. Prinsen Geerligs' laborious investigations. He gives seventy-seven analyses of Java molasses with most elaborate details. Finally, he defines an "ideal molasses as a compound of sucrose, salts and water in the approximate proportions of 55,25 and 20 ," and " a factory molasses as a syrupy 
compound of sucrose, glucose and fructose, in varying proportions, in combination with organic and inorganic salts, and holding in solution or suspension gummy and nitrogenous matter, silica, iron and calcium phosphates and other similar bodies."

The use of molasses as a cattle food is making good progress. Mr. Hughes discovered that a mixture of molasses with the pith of the sugar cane produced a substance of a dry mealy consistency which could be transported to consuming countries in bags without losing its dry character. It has been named "Molascuit "-rather a far-fetched and not very attractive word--and is well worth a trial by the dairy farmer. It contains 75 per cent. of good sweet West Indian cane sugar molasses, and 25 per cent. of the dry cellular tissue of the sugar cane, a very nourishing mixture.

In many countries it is difficult to know what to do with the molasses. They have tried it in the boiler furnaces mixed with megass, but it forms masses of coke which choke the bars, and sometimes even combines with the silica of the cane and forms a sort of glass or slag which makes a worse stoppage. But if special furnaceseare made it is found that the molasses, blown in the form of a spray, makes very good fuel. Another use for it is to spread it over the fields and plough it in.

A word or two as to the chemical control of sugar factories and refineries must not be omitted. In these days of scientific perfection, as the only alternative to "going to the wall," this is absolutely essential. In a refinery, the quantity of pure sugar entering the refinery in the form of raw sugar must be compared with the quantity of pure sugar leaving it, whether in the form of pure sugar or of yellow sugars, or shut up in the treacle or golden syrup. Then the value of the unit of pure sugar brought in can be compared 
with that contained in each product going out; thus the profit on each class of sugar produced can be defined and compared to a nicety-a very valuable bit of information. The syrup at each stage of the operations should also be examined in order to ensure uniformity of work. Coal and charcoal must be watched in the same way, and so must scums, charcoal washings and such-like matters. In a cane sugar factory all this must be done, but it is much more difficult. An accurate knowledge of how much sugar enters in the form of cane is almost impossible. Even to weigh the cane accurately is an arduous task; and even then it varies in quality so constantly from day to day that any estimate can, at the best, be only approximate. Nevertheless it is done, and very fair figures are given, in good factories, of sugar coming in, going out, and lost. Cane, megass, juice, masse-cuite, syrups, molasses, waste waters and finished sugars are all weighed or measured, and analysed. The beetroot factories were the first to show the necessity for all these things, and the best way to do them. Cane sugar has learned the lesson, and so have the sugar refiners. 


\section{CHAPTER VII}

\section{SUGAR REFINING}

WE have seen how sugar production, whether cane or beet, grew from small beginnings and primitive processes into the great and highly scientific industry of to-day. Sugar refining has also grown in the same way, but it has also been so much modified from time to time, and so much adapted to the varying requirements of different classes of consumers, that its progress has not been so definitely in the same direction as is the case with cane or beet sugar production.

Sixty years ago sugar refining here was much the same as sugar refining in other countries. But very soon the English and Scottish refiners began to use a much lower raw material than their continental neighbours, and this involved different methods and different results. The essential characteristic of sugar refining, as distinguished from the processes involved in producing sugar from the juice of the cane or the beetroot, is the use, in small or large quantities, of animal charcoal; that is, charcoal made from bones, for decolorizing sugar solutions. The foreign refiners deal with a very high class of raw material, and, therefore, require only a very small quantity of charcoal for filtering their sugar solutions. In Paris, for instance, the greater part of the raw material is white sugar and, consequently, charcoal is only used in a very small way. In Russia the refiners use nothing but white sugar, and make nothing but loaf sugar, the only form in which sugar is consumed in that country. The process of sugar refining is, therefore, in that country mere child's play. 
But still it is very well done, as also in Paris and other continental countries, especially Holland.

In this country, on the other hand, the refiner dealt at one time with very low, brown sugars, from Brazil, Manilla, India, even China occasionally, and also with the excellent medium class of muscovado sugar from our West Indian colonies. To refine these sugars large quantities of charcoal were used, a certain proportion of pure white sugar was turned out, and the rest was yellow sugar, greatly in demand as a cheaper form for consumption among the larger class of the population. This was as it should be, and the yellow sugar produced was a very superior article of its kind, and quite unique in the sugar refining industries of Europe. It was, and still is, a speciality of the British market. The American refiners have learned their lesson from us, and make all kinds for all classes of consumers.

This clearly shows that in studying the art of sugar refining we have to examine two separate industries. Our refiners, working the lower class of sugar, and turning out a considerable percentage of yellow sugar, were content, in the first place, to dissolve the sugar in "melting pans" armed with stirrers, and to run the solution through bags to catch some of the impurities. The clear liquor then went on to the charcoal filters: large, vertical, cylindrical vessels packed with animal charcoal. The liquor, entering brown, came out white at first, then pale yellow, then darker yellow. Numbers of these vessels, containing tons of charcoal, had to be used for the purpose. As soon as the colour of the liquor from the charcoal had deteriorated to a certain point the charcoal cistern was washed out, and the charcoal went to the kilns to be reburned in order to restore to it the power of absorbing colouring matters and other impurities. The liquor was ready for the 
vacuum pan, and the crystallization and subsequent "curing" of the masse-cuite in the centrifugal machines was carried out as already described. The syrups were filtered again and produced, in conjunction with a certain quantity of the lower coloured liquor, the yellow sugars. Roughly described, this was the practice in most British refineries, except those few which made loaf sugar. Mr. James Duncan, the greatest British refiner in the sixties and seventies, in conjunction with his partners in Greenock, hit upon the happy idea of boiling the yellow sugars at a very low temperature, and thus producing a much finer article with a delicate primrose tint, and holding within its granular structure much more syrup than yellow sugars had previously contained. The sugar fetched a much higher price, and the process enabled the refiner to turn out very little treacle, in some cases none at all. This again was a new departure entirely unique and practised only in British refineries. The United States refineries have followed our example, but on the Continent no such sugar is known-sugar for the People is in no demand there. Mr. Duncan introduced the new method to London by building a large refinery on the banks of the Thames, and was king of the industry for many years.

The great fault committed by British refiners was entirely to ignore the value of a defecation process to precede the bag-filtering of the raw brown liquor. They threw the whole burden of the work on the filter bags and the charcoal. Then came the new king of the sugar refiners, the late Sir Henry Tate. He saw the point and looked for some good process of defecation. $\mathrm{He}$ found it in the discovery of Boivin and Loiseau, of Paris, and did not hesitate for a moment. He had been working on the Scotch system in Liverpool; 


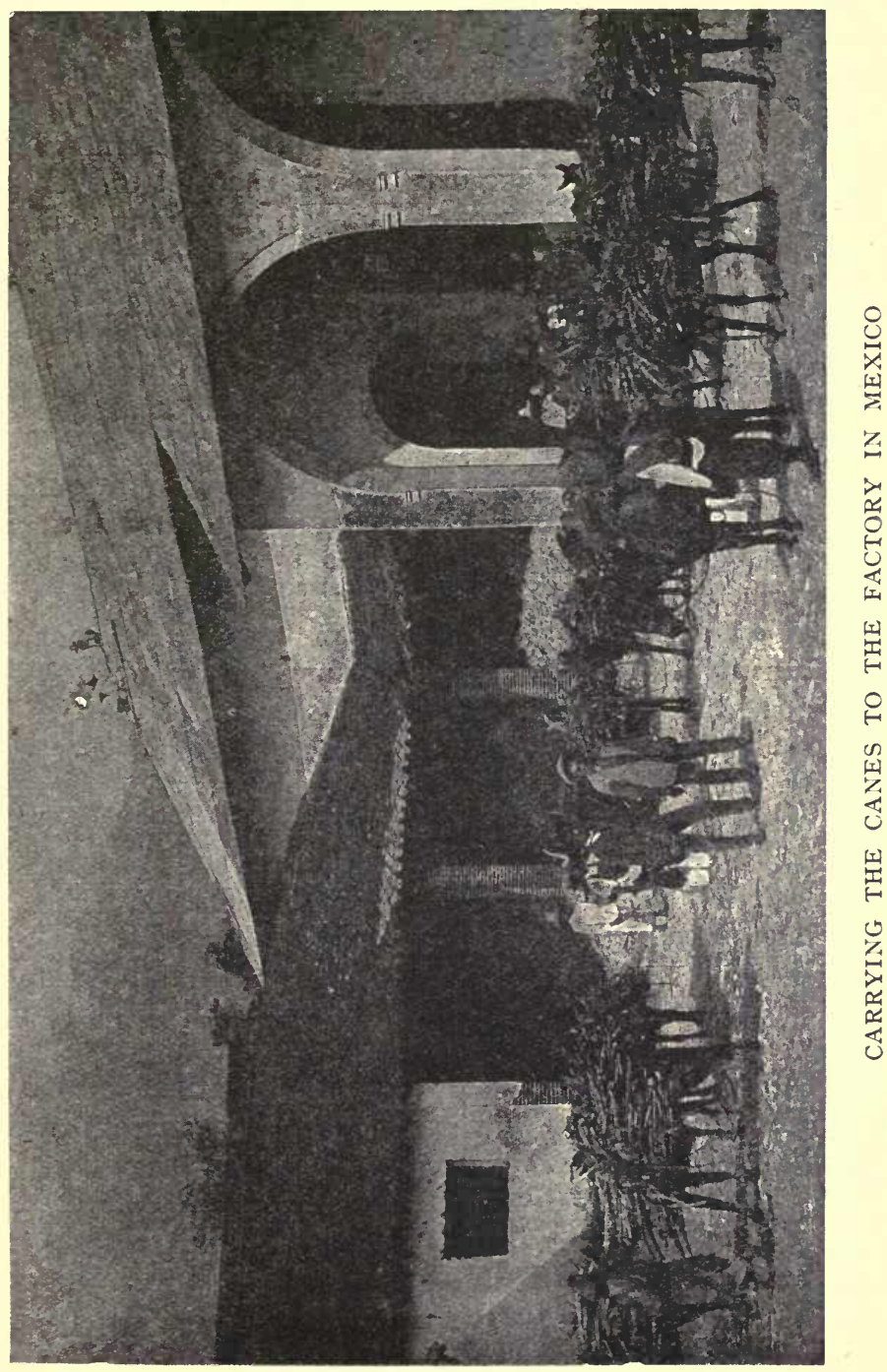


he handed his house over to the Frenchmen, substituted French for English machinery, and at once made his fortune. He got a great increase in the percentage of white sugar and reduced the use of charcoal to such an extent that his loss of weight-an important item in the cost of refining-was reduced to a minimum.

Since then other methods for defecating the raw sugar before filtration have been introduced, lime and phosphoric acid, for instance, creating a precipitate which carries down with it the gummy and albuminous impurities of the sugar.

But we were learning other useful lessons from our continental neighbours. They not only purified their raw liquor before filtering but also purified their raw sugar before melting. The raw sugar was mixed in a stirring machine with syrup, and then went to a regiment of centrifugal machines above the melting floor, where the crystals of the raw sugar were separated from the syrup and impurities which surrounded them. Here again was a system which resulted in the production of a larger percentage of white sugar. In this country the resulting syrup from this preliminary washing would be filtered over charcoal, and boiled into fine yellow sugars. In the continental refineries it was boiled into a good raw sugar which, in its turn, was dried in centrifugal machines and went to the melting pan.

This is only a rough picture of the different methods in different countries, but it is sufficient to indicate in outline the varying ways of refining sugar, and how the demands of the consumer are supplied, whether those demands come from our millions, who consume annually $95 \mathrm{lbs}$. per head, or from those countries who do not consume half that quantity.

In the present day white sugar has become so cheap 
that the million do not demand so much low-priced yellow sugar as they used to do. The consequence is that the British refiner finds it well to use a higher class of raw sugar. For some forty years, up to the outbreak of war, he had an abundant supply of good, strong, and fairly clean raw beetroot sugar, and that is what he has lived upon. So much so in fact, that at one time there were only one or two refineries in the Kingdom who could guarantee that their sugar was "Pure Cane." As far as this country was concerned, beetroot had established pretty nearly a monopoly.

The reader may perhaps wish to know how the Scottish refiners managed to boil their yellow sugars at a low temperature. The vacuum pan has already been described, but the method of condensing the vapour rising from the boiling sugar has not been given in detail. It used to be done by interposing a jet of cold water in the course of the wide pipe which goes from the neck of the pan to the air pump. This condensed the vapour and thus helped to increase the vacuum. The air pump took away the water of this condenser as well as the condensed vapour. This pan would boil at about $160^{\circ} \mathrm{F}$. But to boil at $140^{\circ} \mathrm{F}$ required a much better vacuum. This meant that the pan and its connections must be very air-tight-that is, very well made - that the air pump must be very powerful, and that the condensing power must be greatly increased. This was done by making a condenser with a vertical pipe the length of a column of water held up in a vacuum tube by the pressure of the atmosphere. Under these conditions a larger condenser could receive a plentiful flow of cold water, because the water would flow away down the pipe instead of through the air pump. The water was scattered about the inside of the condenser in such a way as to present the largest possible surface $7-\left(1_{4} 6_{3}\right)$ 
of cold water to the hot steam. The condensation was, therefore, rapid and thorough, and the vacuum greatly increased. With these pans they could boil easily at $140^{\circ} \mathrm{F}$. or even lower, the boiling went much faster, less steam was necessary, and the product was quite a different article. Even the syrup which surrounded the grains of sugar was of a delicate primrose hue instead of a dirty dull yellow. This has now been brought to such perfection that some of the soft yellow sugars are nearly white.

As to the lower yellows, they are not much wanted now, and, therefore, a new method is adopted in some refineries with regard to that stage of the refining process. Instead of going to the expense of boiling and curing these sugars, the syrup from which they would have been made is transformed into "invert sugar" and becomes a "golden syrup " of very superior quality and great beauty. It is of the palest golden tinge and perfectly bright and transparent, so transparent, in fact, that if served up in a cut glass dish the pattern on the bottom of the dish shines out even more brightly than if it only contained water.

There is also a very large sugar refining industry devoted to the production of "invert sugar" for the brewers. The processes of purification are carried out just as strictly as in ordinary sugar refining, perhaps, even more so, and then the whole mass of sugar solution is changed into invert sugar, and becomes a clear, bright syrup, very sweet, and just in fit state for the brewer.

The sugar loaf has disappeared in this country, and "Cube sugar" has taken its place-a very excellent improvement, the only objection being that if you seek in the sugar basin for a smaller lump you have difficulty in finding it. The production of the old sugar loaf was a long, tedious, and expensive operation. The 
boiled mass from the pan was filled into the loaf moulds. When the mass had set firmly the moulds were hoisted to an upper floor where they stood to drain off the " green syrup." There had to be many floors to accommodate these regiments of loaves. When the syrup had drained off, a white saturated solution of pure sugar was poured on to the face of each mould, and this operation was repeated until the loaf became white from top to bottom-a work of some days. The fine syrup from this washing was kept separate from the green syrup as it contained more sugar. The loaves were then knocked out of their moulds and trimmed up, and then came more hand labour in putting them in the stove, a heated chamber running from top to bottom of the tall factory and with doors opening into each floor. Those loaves which had already become dry had also to be handed out of the stoves-nice warm work-neatly enveloped in paper ready for delivery, and stacked up in the warehouse till called for.

Compare with this long and laborious process the making of cube sugar. For the loaf mould are substituted moulds made to fit into the circumference of a large and very strong centrifugal machine. They are divided by plates into a series of narrow chambers the thickness of a cube, and the full depth of the mould. The boiled mass from the pan is run into these moulds and, when the mass has solidified, the moulds are ranged round the inner circumference of the centrifugal machines which quickly throw off the green syrup. The white liquor is then applied, and immediately thrown off, and, behold! the moulds contain large, flat, narrow slabs of white sugar. These slabs are ranged on carriers which travel up through a heated chamber, and come down again dried in a few minutes. They go to the cutting machine where guillotine knives cut them up 
into cubes ready to be packed in boxes and delivered to the buyer. The name of Eugen Langen, of Cologne, the inventor, ought to be immortalized. He was the inventor not only of this great revolution in sugar refining but also of the gas engine. Thus we see that our ideas come not always from our own brains but from those of the Frenchman and the German. It would be possible to describe others which came from the Belgian and the Austrian, but this is enough. To see Langen's beetroot sugar factory at Elsdorf turning out fine cube sugar straight from the beetroot juice was a real treat for anyone who appreciates the pleasure of seeing things well done ; everything clean, everything tidy and handy, no mess on the floors, and a complete chemical control of all the operations, He used to describe any sugar refinery devoid of these virtues as a Schweinerei -pigsty. 


\section{CHAPTER VIII}

\section{THE CANE INDUSTRY}

BEFORE reading this chapter, reference should be made to the table in Appendix I, which gives the production of cane sugar throughout the world-country by country -for the last three years, together with the estimates for the year 1917-18. This table includes the somewhat imaginary figure- of 2,626,000 tons as the production of British India. It is unfortunate that this figure should now be included in the statistics, making comparison with former years misleading and erroneous. The official estimate of the Indian sugar crop is based on an estimate of the number of acres planted, and assumes that an acre will produce $\mathbf{1 . 2 5}$ tons of sugar. But it is well known that a quantity of sugar cane is consumed in the form of cane ; it is also known that the production of sugar in India is of a very primitive kind, and that the sugar produced contains not much more than 50 per cent. of extractable pure sugar. This sugar, in the raw state, is consumed locally by the peasants, and has no relation to the modern kind of sugar imported into India for the consumption of the upper classes. The inclusion of this purely native production in our annual statistics of the world's supplies is, therefore, unnecessary and misleading. It has already led to our present statisticians pointing to the remarkable increase in the world's production of cane sugar at a particular period, forgetting, or not knowing, that the apparent sudden increase at that time was caused by the sudden inclusion of a vague estimate of India's production. This discrepancy can be detected in the table given in Appendix III. 
We will take the countries in their order and say a few words about some of them.

Louisiana is a country not absolutely tropical. They have occasional frosts. In spite of drawbacks the industry is carried on now in a very scientific way and with good energy and perseverance, but it would find it difficult to compete with more favoured districts if left to free competition. It is, luckily, one of the United States, and, therefore, its sugar enters the markets of the United States free of duty, which at present is a nice little bonus of about $5 \mathrm{~s}$. $6 \mathrm{~d}$. per cwt. Concentration of work in Louisiana has been extensive. Small factories have given place to large ones, imperfect work has made way for modern improvements. Before the Civil War, the production reached, in 1861-62, 235,856 tons. During the war it fell, in $1864-5$, to 5,331 tons, and did not show much recovery till 1878-9, when it reached 100,000 tons. In $1893-4$ it got up to its old level, 250,000 to 300,000 tons. In 1904-5 it had the exceptionally large crop of 355,530 tons. The preferential position of the States, Territories, and Protectorates of the United States in the home market has already been explained in Chapter II. The effect of this stimulant, in bringing fresh capital into the industry, was so striking that it soon became evident that before many years elapsed the United States would receive all its sugar supplies from these sources. This forecast came true in 1915, as shown in Appendix XI. This is a remarkable instance of the effect of preferential duties in attracting capital and thus enabling a country to be independent of outside supplies. Louisiana was not, like the others, stimulated to increase her production, but she was kept alive by the preference. That so old established an industry should have kept pace with the times shows that it deserves to be kept alive. 
Porto Rico, in 1898 annexed by the United States, has now free entry into those markets; and, as it enjoys the advantages of a really tropical climate and good soil, it is increasing its production very rapidly, which also means putting in all the latest improvements and doing everything on a large scale. The planters have been investigating matters in Java and Hawaii, being ambitious to get something like the same yields of sugar to the acre. They declare that already their agriculture is superior to that of Cuba. Porto Rico's remarkable progress under preferential treatment is a sufficient object lesson how to attract capital to a home industry. American, British, and French capital poured in, and we see the result. In the Spanish days, Porto Rico's crop was round about 50,000 tons of muscovado sugar. In $1901-2$ it rose to 82,000 tons ; in $1903-4$ to 130,000 tons ; in $1908-9$ to 258,000 tons ; and in $1916-17$ to 448,567 tons-fine centrifugal raw sugar polarizing 96 and above. This remarkable increase will continue. Irrigation is being carried out on a large scale, bringing in large tracts of new land. Labour is plentiful and cheap, and there is nothing to complain of in the climate or the land. This object lesson is not confined to the selfish interests of the country concerned, it confers a world-wide benefitmore land cultivated and more food for the people. We now know, to our cost, that the opposite policylaisser-faire-means less land cultivated and less food for the people.

The Hawaiian or Sandwich Islands have enjoyed a duty free market in the United States for many years and have enormously developed their industry. They grow immense weights of cane to the acre, and as they extract the sugar well their production of sugar to the acre exceeds even the remarkable figure now attained 
in Java. The cultivation is mostly carried on with irrigation and, no doubt, the thing is done in first-class style. They are now millionaires in that happy land. In 1857 the islands produced 313 tons of sugar, and had increased, in 1876 , to 11,640 tons. The reciprocity treaty of 1876 admitted "Sandwich Islands sugars" into the United States free of duty. But it was the annexation to the United States, in 1898, that gave the finishing touch to the feeling of confidence in the future. That year the crop was 229,414 tons; since then it has more than doubled. Perfection in machinery, cultivation and irrigation have done the rest. In 1907 two of the four islands produced an average of $5 \cdot 6$ tons of sugar to the acre. A third got an average yield of about four tons. Hawaii, the largest, was content with the excellent yield of 2.7 tons to the acre. Dr. Prinsen Geerligs tells us that the quality of the cane surpasses that of any other cane-growing country. The juice is the richest and the purest. The cane contains frequently from 16 to 17 per cent. of sugar. The cane mills, as well as the rest of the machinery, are the best that can be had, and they succeed in obtaining 95 per cent. of the sugar in the cane. The sugar yield on 100 of cane is extremely high. Yields of $12 \frac{1}{2}, 13$, even 14 per cent. are quoted, the average being over $12 \frac{1}{2}$. These figures are unsurpassed elsewhere. This is another and still more striking example of what can be done when capital is attracted to an industry by preferential treatment. Its progress since 1910 shows further large expansion. In 1910 the crop was 463,000 tons; in $1916-17$ it was 579,302 tons. The only trouble is scarcity of labour.

Cuba is the place on which the eyes of the sugar world are now constantly fixed. The preference enjoyed by Cuba in the markets of the United States is only 
20 per cent. of the duty, but this has been enough to give a great impetus to its sugar production. American capitalists have been attracted even by this modest bonus, and are exploiting the large and fertile island very thoroughly. Cuba, before the revolution and the subsequent American war with Spain, managed to get up to a million tons of sugar a year; but during her troubles the crop fell off to a comparatively insignificant figure. In 1897 it was under 300,000 tons, but in 1903 had recovered to $1,003,873$ tons. Then the preference in United States' markets began to tell rapidly. In 1909 the crop was $1,521,818$ tons ; in 1913 it reached $2,428,537$ tons ; in 1916, with another great jump, it reached $3,007,915$ tons. The crop of the following year was correctly estimated at over $3,500,000$ tons, but rebellion in the Eastern provinces destroyed the odd 500,000 tons. This wonderful and unparalleled increase in production is an instructive instance of the virtue of even a small and reasonable preference in stimulating the investment of capital in industrial production for the permanent benefit of the country-both producers and consumers. Cuba is undoubtedly the queen of cane sugar-producing countries, though Java runs her very close. Perhaps the most striking point in the Cuban sugar industry is the size of some of her factories. A few hundred tons of sugar used to be considered a fair or even large out-turn for a sugar factory in the tropics, but now we find in Cuba, as shown in Appendix VII, that the majority of the factories turn out from 10,000 to 100,000 tons of sugar per factory in the season. One effect of the enormous crop of sugar in Cuba has been that the rush of sugar to New York during the heaviest part of crop time has frequently depressed prices far below European parity-a curious instance of preferential duties being a benefit even $t_{0}$ 
the consumer. The crop now beginning to be reaped is estimated in some quarters at 3,620,000 tons.

The British West Indies and British Guiana were very hard hit by the beetroot competition, and in some of them sugar has given place to other industries. Barbadoes still holds its own, but is now substituting modern factories and centrifugal sugars for the good grocery muscovado kinds for which it was once so celebrated. Trinidad makes some very good sugar, and will go ahead now that unfair competition has been stopped ; so will Demerara, a British sugar colony which has for long been in the first rank as a producer of choice sugar. Larger factories are now being erected in many of the islands. The first were in the islands of Trinidad, Antigua, and St. Lucia; presently there will be several in Jamaica. There is now one in St. Kitts. The machinery is first-class and comes from British makers, who are now very up to date and know everything that is to be known about modern sugar production. The revival of the industry in our oldest colonies is a matter for much congratulation, especially when it brings a large increase of work for British engineers.

Before leaving the subject of our West Indian Colonies, something more must be said about their condition before and since the great fall in the price of sugar in 1884-5, caused entirely by the over-production of European bounty-fed sugar. Barbadoes and Trinidad seem to have held their ground fairly well : the first on account of the popularity of its fine grocery muscovado sugar and of its syrup, its good soil and climate, and its large population ; the second on account of its very good soil, its prosperity in other respects, and its fairly well-equipped factories, which ought, however, to get a better yield of sugar per 100 of cane than 
they do now. The islands of Grenada, St. Vincent, and Dominica seem almost to have abandoned the crop, and Jamaica to have considerably reduced it. This last island is of special interest to those who, like the present writer, recollect its fine muscovado sugar in the good old days before the flood of bounty-fed sugar set in. The sugar produced by Jamaica was, from the point of view of the British refiner, very superior to any other raw muscovado sugar, except perhaps that from St. Kitts. The juice must have been very pure to produce such sugar, or else the method of manufacture must have been very superior. But now Jamaica is going to launch out into the modern central factory system and to produce the usual " centrifugal sugar, basis 96 polarization." The island's production used to range from 25,000 to 35,000 tons. After the great fall in price in 1884-5, it gradually dwindled down to 18,000 to 20,000 tons. Its future progress will be interesting.

The French West Indies were once in the first rank, but they have not kept pace with the times. They were at one time well equipped, but now their machinery, especially in the evaporating department, is out of date. They have for a very long time turned out a kind of white sugar, the kind for which there is a demand from the refiners in France. Their working expenses are high, and labour is scarce and indolent. They stand still at a production of about 30,000 to 40,000 tons from each island.

The small French island of Réunion, a neighbour of Mauritius, suffers from want of labour. If that could be obtained, the industry would flourish.

The island of St. Domingo seems to be progressing, though not favoured with any artificial stimulus. They made 60,000 tons in $1907-8,80,000$ tons in $1908-9$, 
and 90,000 tons in 1909-10. Since then, as may be seen in Appendix I, the production has increased to 130,000 tons in 1917, and is still increasing. The factories, mostly American, are modern, but not up to date. The great trouble is political unrest.

Mexico is doing well and putting up some first-class factories. They get long prices in their own markets, thanks to an excessive Customs barrier, and do not yet make much of a surplus for export. Here, again, political unrest is the great trouble. The production increased rapidly from 75,000 tons in 1900 to 160,000 tons in 1911. Since then, internal quarrels have reduced the sugar production to 50,000 tons. With peace at home, sugar production will flourish and increase rapidly.

Peru, Brazil and the Argentine are producers on a fairly large scale, but parts of Brazil are sadly behind the times. They can get very good prices at home when they make no surplus, but when they are obliged to export they find it difficult to keep up home prices. They tried to form a combination for that purpose but it broke down. The country could produce a very large crop if it were not that capital and labour are wanting. There are, however, several modern factories in Brazil, trying to reform the industry.

Peru has a great future if all goes well. Irrigation, combined with good soil and climate, and canes which produce rich pure juice, only require up-to-date factories to enable Peru to compete with Java and Hawaii in the amount of sugar produced per acre. The rich land between the mountains and the sea, coupled with the valleys and streams which run from the hills to the coast, give a perfect arrangement for universal irrigation. The climate is almost rainless, so there is no variety of season, and sugar can be produced and 


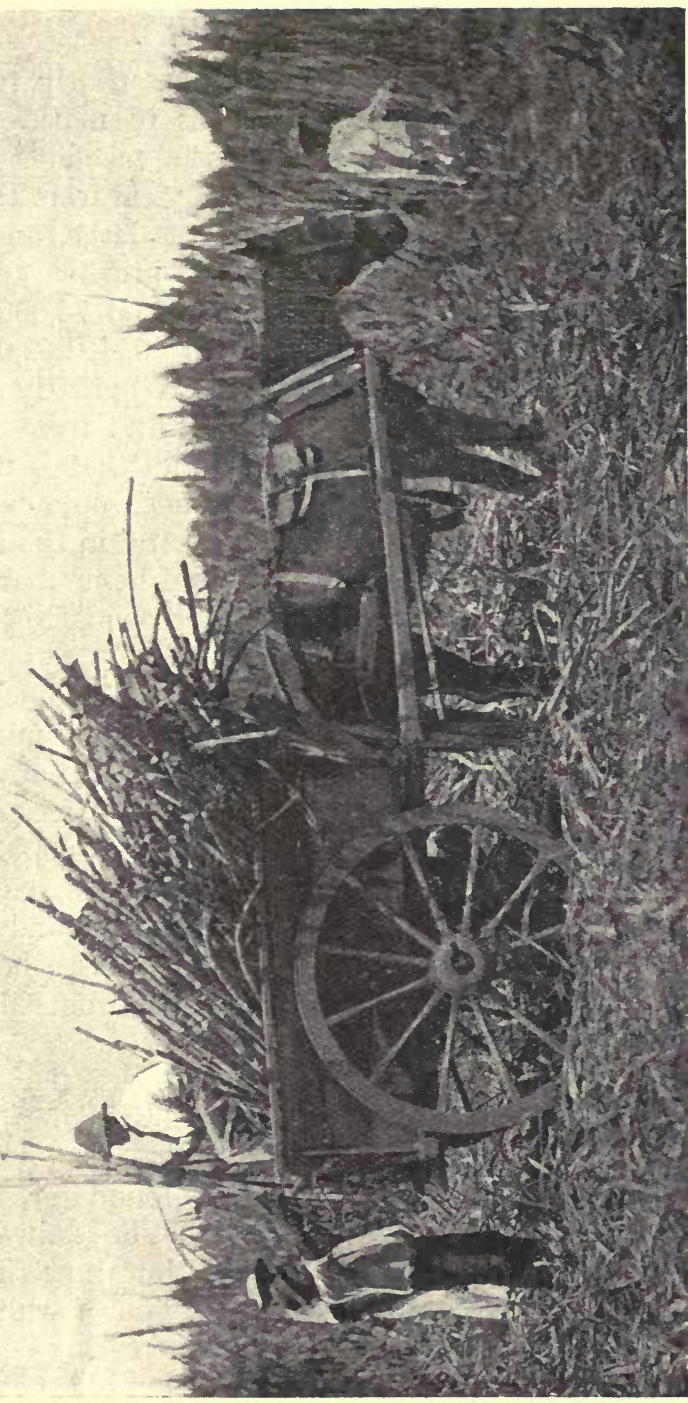

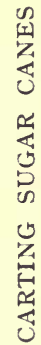

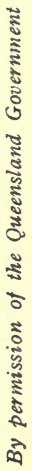


reaped all the year round. It takes nearly two years in this dry climate for the canes to mature. There are many good factories, but the machinery is not powerful enough yet to get a large yield from the canes. The production of canes per acre is large, and 3 tons of sugar per acre represents at present about the average yield. In 1894 Peru produced 74,000 tons of sugar ; in 1904, 156,000 tons; in 1914, 262,000 tons. Previous to 1894 the industry suffered greatly from the European bounty-fed competition, and from war and revolution. Labour is sufficient; all that is necessary for good progress is political rest and some encouragement to the investment of fresh capital in the industry.

Argentina has a heavily protected home market, and is not likely to become an exporter owing to high cost of production.

British India is supposed to produce the official figure stated in the list, but production is so primitive and scattered that it must be difficult to arrive at any definite estimate. It is satisfactory to read, in a recent official report, that "steady efforts are being made by the Agricultural Departments to improve the cultivation and the processes of extracting cane juice and of sugar manufacture." India, in spite of her large home production, is a considerable importer from Mauritius, Java, and even Europe.

Java is a superb instance of success, the result of individual energy and intelligence stimulated only by science and organization. But the island has one advantage which is not always to be found in the tropics, plentiful, good and cheap labour. They have always made the finest raw sugar in the world, but now they have added to this a considerable production of white sugar, for which they find a constantly increasing demand in British India where it competes with our old sugar colony 
of Mauritius, and where it is gradually supplanting the quantities of European beetroot "granulated" which were for many years " dumped" in India.

Dr. Prinsen Geerligs said seven years ago that the increase in the Java crop would go on at the rate of 50,000 tons a year till it reached $1,600,000$ tons. ${ }^{1}$ At one time the Government limited the production in order that sufficient rice and other crops might be grown to feed the people. But since then more land has come under irrigation and continues to do so. This irrigation is now almost universal, and the water from the rivers deposits a fertilizing slime which furnishes sufficient potash and phosphoric acid to the soil. As the cane crop is alternated with rice or other food crops it gets the full benefit of this fertilizing deposit. When the "Sereh" disease threatened destruction to the canes in 1902 cuttings were imported and the "Sereh" was stamped out. Seedling canes were also raised and selected varieties propagated and cross-fertilized, until at last Java has arrived at the remarkable product of 42 tons of canes to the acre, as the average for the whole island.

The increase in the production of sugar per acre is most remarkable. The accurate figures given by Dr. Prinsen Geerligs show that in 1893-4 the average production was $2 \cdot 812$ tons (of $2,240 \mathrm{lb}$.) per acre, quite a remarkable figure in those days. In 1897-8 it had increased to 3.571 tons; in $1903-4$ to 4.058 tons; and in $1910-11$ to $4 \cdot 302$ tons. The only country that can beat that figure at present is Hawaii. Dr. Prinsen Geerligs does not now put any limit to his anticipation of the further progress of the industry. The production per acre is still rising ; cultivation, the selection of

1 In 1916-17 Java produced 1,596,174 tons, and the crop $1917-18$ is estimated at $1,800,000$ tons. 
the right kinds of cane for different soils, improved methods and greater rapidity in juice extraction and treatment, all contribute to this result. The work of cross-fertilization in finding new varieties of cane goes on with redoubled ardour and promises great things in the future. Increase of cane crop coupled with increased richness is what they aim at. It is found that increased quantity of juice in the cane is always accompanied by increased purity of the juice. More juice gives more sugar, and increased purity gives still more sugar. The area in Java, moreover, which will be devoted to sugar goes on increasing. For some time it stood still, because other crops were regarded by the Government as essential to the well-being of the population, but now there is permitted a greater expansion. Fresh ground is being prepared everywhere for the cane crops, together with new systems of irrigation, so that eventually more arable land will be available for the sugar manufacturers, who are quite ready to absorb it. In Dr. Prinsen Geerligs' opinion, therefore, there is every expectation of a steady and perhaps sudden extension of the Java sugar industry.

The history of the sugar industry in Formosa and its probable future have already been described and explained in sufficient detail in Chapter II.

The Philippine Islands are now under the wing of the United States, and the American Government has ordained that 300,000 tons from that country shall be admitted free of duty into the United States markets. Under ordinary circumstances the result would be that American capitalists would exploit this new field for enterprise, erect monster factories, as they have done in Cuba and Hawaii, and create another vast centre of sugar production. But the interest of the United States' own sugar industries in 
Louisiana and in the beetroot districts of the North had to be considered, and it was decided that the preference must be confined to the produce of existing factories, mostly in native hands, and thus the hope for the investment of capital in the new venture was for the moment checked. But now, American capitalists have acquired large tracts of land for the purpose of sugar production on an extensive scale.

Dr. Prinsen Geerligs says : " As regards the prospect of the cane-sugar industry in the Philippine Islands, all forebodings point to gigantic progress in the near future."

In Australia a good deal of sugar is produced in Queensland and a little in New South Wales. The refusal to allow coloured labour to work in the tropical parts of Queensland is a serious drawback to any extension in that direction. In the present sugargrowing districts, where white labour is possible, it is found to be expensive and in other ways difficult. There has been a good deal of Government control, which adds sometimes to the difficulties of the industry. The cost of production is high, and therefore requires liberal preferential treatment to enable producers to make both ends meet. Central factories are now universal, but the cane planting leaves much to be desired. The industry began in a small way in 1864 , and by $1883-4,152$ factories produced 36,000 tons of sugar. In 1910-11, 54 factories produced 207,000 tons. The production is about 2 tons to the acre.

New South Wales produces an average of about 20,000 tons. The total production of Australia in 1914-15 was 246,408 tons.

Our old sugar-producing colony of Mauritius has had many struggles. They made splendid sugar in the old days, only beaten by Java for quality. They do 
still better now because they make a large quantity of white sugar for the Indian market. But machinery which was at one time superior at last became antiquated. Then came low prices, and a great disaster followed. The whole of the cattle were suddenly destroyed by a terrible disease. This deprived them, at one stroke, of their only means of haulage. This, coupled with a destructive cyclone, brought them to the verge of despair. They wanted money for light railways to draw the canes to the mill, and if they did not get it their crop would be lost. The Colonial Office came to the rescue just in time and the danger was averted. Then prices improved, hope began to revive, what the French call concentration of work was carried out, old small factories were closed and large " centrals " established, and they began to breathe again. Irrigation is to be carried out on a large scale, the railways are to be improved, factories are now working on modern lines and things begin to hum. Labour is a difficulty, as with our colonies in the west, and it would be well if capital were more abundant, but, barring cyclones, prospects are good. Labour was originally imported from India, but as the Indians settled down permanently as small planters imported labour became unnecessary. Their production of cane per acre is, however, very inferior to the out-turn of the large planters. The average richness of the cane is a little under 14 per cent., and the yield in the factory about 10.5 per cent. The average crop of cane per acre (30 tons plant and 20 tons ratoon) is about 23 tons, including the inferior crop of the small Indian planter. The canes take from twelve to twenty-two months to ripen, according to the climate of the district. From 1884 to 1897 the crop varied from 100,000 to 150,000 tons. From 1898 to 1912 it ranged from 150,000 to 
250,000 tons. In $1914-15$ it reached 277,164 tons. Sixty years ago we imported large quantities of Mauritius sugar; but when the European bounties were in full operation Mauritius only sent a very small quantity to Europe, mostly after-products. ${ }^{\mathbf{1}}$ India now imports annually 100,000 to 150,000 tons of white Mauritius sugar. During the war, Mauritius has come to the rescue by supplying us with some of her excellent white sugar. Considering the troubles she suffered during the bounty competition, we ought to have been sufficiently grateful to give her, at all events, the full market value. ${ }^{2}$

1 European imports fell to 7,000 tons, but recovered to 50,000 tons after the abolition of the bounties.

2 In 1915 (war time), Mauritius sent us 111,875 tons of raw sugar and 85,118 tons of refined. 


\section{CHAPTER IX}

\section{THE BEET INDUSTRY}

Whether the sugar cane came originally from the East and was carried from one country to another till at last it arrived in the Western Hemisphere, or whether it was indigenous on both sides of the world cannot be definitely decided, but there is little doubt that it was carried from China to India and Arabia, and afterwards introduced by the Arabians into Persia, Africa and Spain. It was the Spaniards who started its cultivation in the West Indies and America. India is said to have produced sugar as early as the seventh century - a rare and costly article in those days.

The date of the first production of sugar from the beetroot, on the other hand, is very definite. A German chemist, Marggraf, in the year 1747, was the first to call attention to the fact that the juice of the beetroot contained sugar identical in composition and properties with cane sugar. But it was not till 1799 that this discovery was put to practical proof on a working scale. A pupil, or follower of Marggraf, Francis Karl Archard, invented at that time a method of extracting sugar from the beetroot. Great interest was taken in this idea for a new agricultural industry, and the King of Prussia gave substantial help in the erection of the first beetroot sugar factory in Silesia. Other factories followed, not only in Prussia but also in Bohemia. In 1811 France took up the new industry and from France it spread to other countries. Bonaparte gave it a great impetus, seeing at once the advantage of producing sugar at home, and voted large sums 
of money and considerable tracts of land for the encouragement of the new manufacture. The blockade had raised sugar to famine prices, so the new French factories flourished. Forty were in operation in 1812 and produced about 10,000 tons of sugar. But when the blockade was raised the price fell and the new venture had a bad time. About 1830 there was a fall in the price of corn and the farmers turned again to sugar beet. By the year 1854 Europe produced something under 200,000 tons of beet sugar. Ten years later the figure went up to over 500,000 tons. In 1871 it exceeded a million tons. Ten years later it was approaching two millions. The cane sugar industry saw itself seriously threatened. The fear turned out to be well founded. The time came when half, and even two-thirds, of the visible sugar production of the world (not reckoning the then unknown production of India) was produced, not from the sugar cane but from the sugar beet.

The way in which this enormous production grew and prospered is a most interesting study. It is dealt with in detail in the writer's paper on "The Statistical Aspect of the Sugar Question," which can be found, for those who may desire the full facts, in the journal of the Royal Statistical Society for June, 1899. Here there is room only for the more salient points.

To begin with a comparison between the progress of France and Germany in the production of beetroot sugar-an instructive chapter in a very remarkable story. In 1871, France was the leader in the industry; she produced 284,444 tons, while Germany produced only 186,442 tons. But while the German Government, as is their practice, began to foster the industry in a far-seeing and rational way, the French Government allowed their great agricultural and industrial sugar producers to shift for themselves. The German 
producer was charged with his sugar tax in the form of a duty on the weight of the roots. The roots were estimated to yield a certain percentage of sugar, and were charged accordingly. This was-and was intended to be -a strong incentive to the farmers to grow richer roots, and to the factory to get more sugar out of them. The system, as usual in Germany, was a great success. The roots grew richer every year and the machinery for extracting and completing the sugar was constantly improved. Scientific methods progressed and flourished because they brought larger profits to both farmer and manufacturer. In France, on the other hand, the factories were under the strictest excise supervision, every ounce of sugar was checked and noted, and had to pay the full sugar duty.

The result of these two opposite systems was that while France produced no more in 1884 than she had done in 1871, the German production had gone up from 186,000 tons to $1,123,000$ tons. The French producers saw that this meant ruin if allowed to continue. The percentage of sugar extracted from the roots had gone up in Germany from 8.28 per cent. to 11 per cent., while in France it remained at the old figure, below 6 per cent. The French Government at last realized their mistake and hastened, in 1884 , to rectify it by imitating Germany. They adopted the system of duty on the roots, and it was a duty based, of course, on a very low estimate of yield. The effect was instantaneous. Better seed was sown in France, better methods of manufacture were.adopted, the diffusion process was substituted for the old hydraulic presses, and the yield of sugar began to rise by leaps and bounds. From 6 per cent. it soon went to 7, 8, 9 and 10 per cent. But as the French producers were allowed the full drawback on exportation, although they were paying only a small 
fraction of the duty on the sugar they produced, the revenue began to show a great and constantly increasing loss. The French Government, unlike the German, had greatly overdone the dose of stimulant, and they had to proceed to take precautions. They found that the sugar industry was making an enormous profit out of the new system. In the first year the manufacturers pocketed $25,000,000$, francs; in the third year, 1886-7, their profit had risen to $91,966,437$ francs, or $£ 3,678,657$. These are official figures. The Government were obliged to check this drain on the Exchequer. In 1887 the legal yield was raised, and the excess yield, instead of going free of duty, was charged with a modified tax. For two years the large profits were slightly reduced, but in 1889 they were again over 90,000,000 francs. There was then another raising of the legal yield and the profit was again reduced, but began to recover as the yield of the factories went on increasing. In 1893 it was $39,000,000$ francs, but in 1896 it had reached 54,000,000 francs. During this period, 1884 to 1896 , the yield of sugar from the roots had gone up from 6 per cent. to 11 per cent., and the French crop had increased from 265,000 tons to 668,000 tons.

Turning again to Germany, the yield of sugar from the roots, which was, in $1871,8.28$ per cent., had risen by 1884 to 11 per cent. They had thus got more than ten years start of their French competitors. But in 1896, when the French managed to reach a yield of 11 per cent. the Germans had reached a yield of 12.66 per cent.

It must be borne in mind that in Germany, as in France, though the duty only struck a portion of the sugar produced, the full drawback was allowed on all the sugar exported. This was an enormous incentive to production and exportation and a serious loss to the 
revenue. The German Government saw that their wise and moderate system had about done its work. In 1888 they took steps gradually to make a transition from the system of duty on the roots to the evidently more rational method of charging the duty on the sugar actually produced. In 1892 this period of probation was accomplished, the factories were under full excise supervision and all the sugar paid the duty. But the German Government were wide awake to what was going on in France, so they presented the manufacturers with a temporary direct bonus on exportation, which was to be abolished as soon as France and other countries ceased to give direct or indirect help to their sugar producers out of the revenue. Here again the German Government were quite wise and reasonable.

The French Government followed suit in 1897 ; but again they made a mistake in overdoing it. They abolished the duty on the roots and levied it, very properly, on the actual sugar. But instead of coming to terms, in conformity with the German friendly overtures, they disregarded the invitation and gave a bonus on exportation just double that of Germany. This, as the French Minister said, was a defiance and a challenge.

The German production had now increased to $1,821,223$ tons, nearly three times that of France. Their revenue from sugar had gone down from $63,249,000$ marks in 1875 to $33,624,000$ marks in 1886 , and $14,677,000$ marks in 1887 . Then they began their reforms and the revenue recovered to an average of about $76,000,000$ marks in the years 1889-92. After that the full duty on all the sugar was secured, and the revenue went up to 84,92 and $99,000,000$ of marks for the next three years. The stimulus had done its work, for not only had the German production gone up to nearly $2,000,000$ tons but their 
exports of refined sugar, which were 5,809 tons in 1871 , had reached, in 1888. when the reforms began, 150,341 tons, and in 1892, when the reforms were completed, 270,607 tons. The direct bonus on export, which was then substituted as a temporary measure, brought the exports of refined sugar up to 503,928 tons in 1897 . The German exports of raw sugar were 491,176 tons in 1883 , and remained much the same till 1894, when they rose to 609,662 tons; in 1896 they were 760,657 tons. This is a striking picture of the progress of an industry under a judicious paternal Government.

France was injudicious, but Austria was still more so ; and yet their system laid the foundation for an enormous and flourishing industry. The Austrian sugar duty was levied in a peculiar way. It professed to be a duty on the roots, but instead of a careful weighing of the roots, as in Germany, the quantity of roots was roughly estimated according to an official supposition of the capacity of the apparatus of the factory. It was, in fact, an estimate within an estimate. The Austrian manufacturers were, therefore, not only stimulated to grow rich roots and to get the utmost quantity of sugar out of them, but also to make the apparatus of the factory capable of working more roots than were estimated by the Government. When the present writer visited the Austrian engineering works in $\mathbf{1 8 7 1}$ he found them full to overflowing with work for the sugar factories, making, among other things, diffusion vessels which should turn out more juice per day than those then in use. There were also, in those days, some factories still working with hydraulic presses. They were a curious sight. The work was carried on at such high pressure speed, in order to do more than the estimated quantity, that the place was a perfect pandemonium, and the floor covered with juice owing to the hurry and bustle of the 
establishment. The Austrian Government were losing revenue to such an extent that it seemed probable that they would soon cease to receive anything from the sugar duty. This proved to be only too true. In 1867 the net revenue was 5,363,159 florins. By 1874 it had dropped to $1,742,324$ florins, and in 1875 , while the gross revenue was $9,337,435$ llorins, the drawback allowed on exports amounted to $9,472,991$ florins, so that the sugar duty produced an actual loss to the Exchequer of 135,556 florins. They remedied this disastrous state of things by insisting on a fixed minimum revenue with a gradual yearly increase. This checked the exports to a certain extent and the manufacturers loudly complained. In 1888, therefore, the whole system was abolished and the duty was levied on the actual sugar produced. The Government followed the example of Germany and gave a temporary direct bonus on exports, to be abolished when a general agreement with the other countries should be arranged. The manufacturers enjoyed the certainty of $9,000,000$ florins per annum and were satisfied. The stimulus to production continued and exports rapidly increased.

Belgium and Holland levied the duty neither on the sugar nor on the roots but on the density of the juice. No one knows how much the manufacturers made out of this, because neither the quantity of sugar produced nor the quantity consumed has ever been discovered.

Russia desired to have a flourishing beetroot sugar industry, and after many vicissitudes hit upon a system which thoroughly answered the purpose of giving the necessary stimulus. The Russian Government, in 1894, took the matter into their own hands. They fixed (1) the quantity of sugar necessary for home consumption; (2) the maximum price to be charged to the 


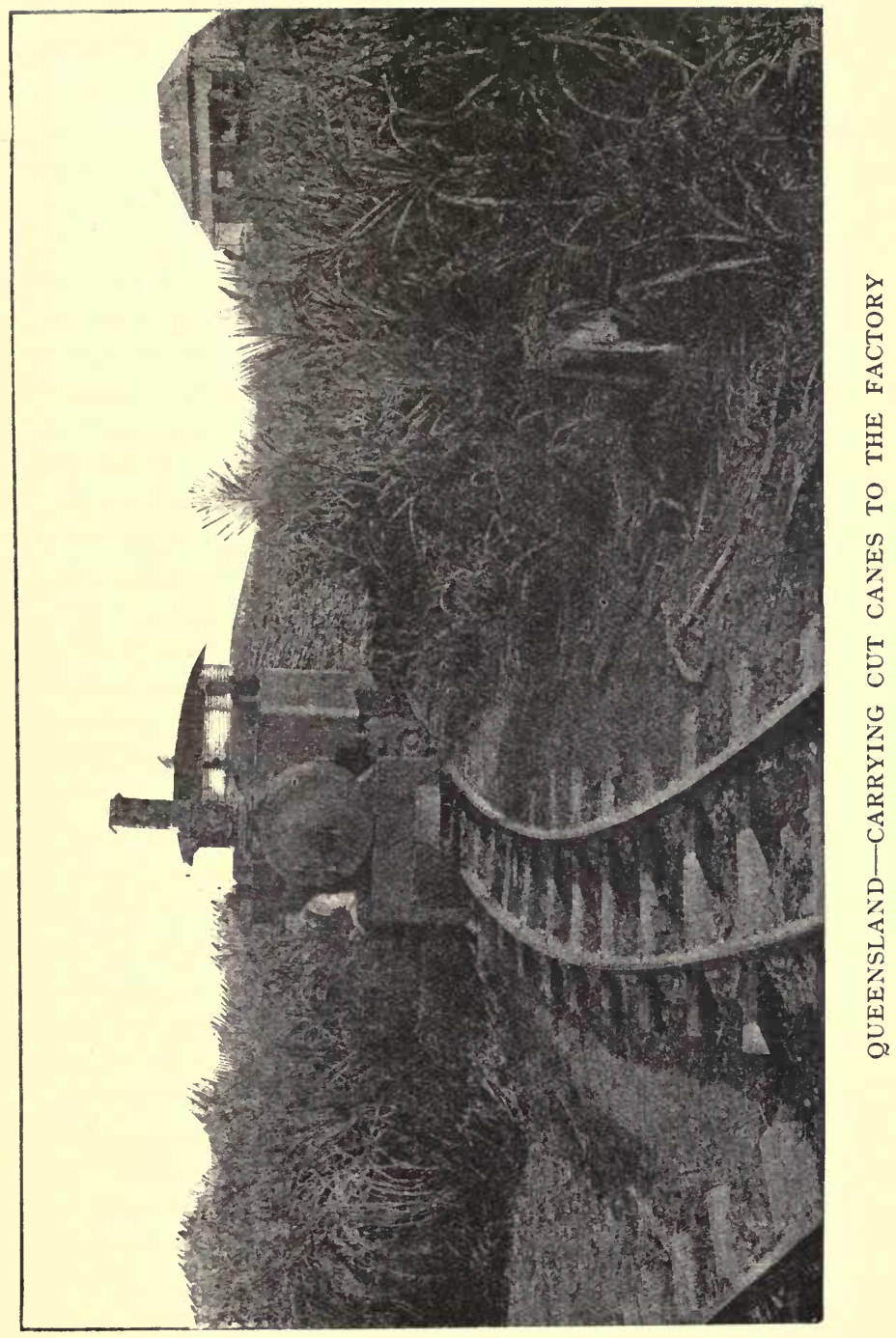


ronsumer, a price, after deducting the duty, about double the price in outside markets; (3) the quantity of sugar to be kept in reserve, a portion of which was to be thrown on the market if prices rose above the fixed limit. Each manufacturer was allowed to send into consumption a fixed quantity of sugar, and then his surplus production was apportioned to the home market in proportion to his total production. Here was not only a security for good profits in the home market but also a constant stimulus to over-production. Fortunately the Russian consumption, in spite of the high price, steadily increases, owing to the constant extension of the Empire eastwards. But at times there is a large surplus to be got rid of, which has to be thrown on the outside markets and sold, for what it will fetch. The high price at home maintains even then, for the Russian producer, a large average profit far beyond the natural level. This is, in fact, a "Combine " or "Cartel," established and regulated, not by the industry but by the Government, and strictly supervised by them. The details have been modified from time to time, but the main features remain. The production in Russia was 159,000 tons in $1875,475,000$ tons in $1885,679,000$ tons in 1895 , $1,127,000$ tons in 1909-10, and exceeded 2,000,000 tons in the two following years. The year before the war, Russia produced $1,750,000$ tons, but by $1916-17$ the production had fallen to $1,160,000$ tons.

During the war the production in Germany, Austria, and France has fallen considerably, as shown in Appendix II.

Turning to the exports from Germany and Austria, the former exported, in 1875, 7,245 tons of refined sugar, and, in 1897, 503,928 tons. Austria in 1875, exported 39,887 tons of refined sugar, and, in $1897,460,154$ tons. The raw sugar exports in 1883 were, from France 42,236 
tons, from Germany 491,176 tons, and from Austria 131,019 tons. From that year Germany kept up a steady export varying between 400,000 and 700,000 tons per annum. The French exports were very fluctuating, as low as 3,000 and as high as 300,000 tons. Austria was also very fluctuating, as high as 180,000 and as low as 31,000 tons. The exports of refined sugar from Austria are very high and very steady, because the profit from the duty or the bonus was so arranged as to give the turn to the production and exportation of refined rather than raw sugar.

This rough sketch of the progress of the European beetroot sugar industry gives rise to many reflections. It has been artificially stimulated, as we see, to a vast extent, and it has now lost its artificial stimulus. The Brussels Convention of 1903 has put a stop to it. During its progress it won the race against cane sugar and became the dominant factor in the sugar markets of the world. What will happen now ? Will it hold its own or will cane sugar win the next heat ? ${ }^{1}$

To answer this question it is necessary to study the cost of production in the rival industries. The yield of beetroot sugar, per acre, is only one-and-a-half to two tons at the best. From the cane, in very favoured countries, as we have seen, the yield per acre can reach four to five tons. Then, as to skill and excellence in manufacture, the beetroot factories were at one time far in advance of the cane. The tropical industry has now learned the lesson from its European competitors, has improved its methods and goes on doing so very rapidly. But the European industry has its market almost at its doors, while the tropical sugar must sometimes travel long voyages to reach the consumer. As to actual figures, it is sufficient to say here that

${ }^{1}$ See Appendix III. 
in the most advanced beetroot country, Germany, the average cost of production is about 9s. to 9s. 6d. per cwt. But Russia, which produces less than a ton to the acre, must have a considerably higher figure. The other countries come between the two. In a first-class cane sugar country, like Java or Cuba, the cost of production might often be a good deal more than a shilling below the cost in Germany. One conclusion can easily be stated. The European producers will continue to make as much sugar as their consumers want so long as competition from outside is excluded. Whether they can maintain their exports on the present scale is doubtful.

The reader may wonder why the United Kingdom, by far the largest sugar consumer in Europe, is the only European country which produces no sugar even for its own vast consumption. The story which has just been told of the European sugar industry is a sufficient answer. As Mr. Robert Lowe told us years ago, ours is not a paternal Government. With a market for $1,600,000$ tons of sugar at our doors, and a good soil and climate, we import it all and read the sugar market report day by day under the cheerful heading of "Foreign Produce." Germany, in the meantime, with a home demand, in 1901-2, of about 800,000 tons, not only supplied all her own sugar, but had, every year, more than a million tons for exportation, half of which was refined sugar. These are curious facts, of which the general public, and even our rulers, know little and care less. ${ }^{1}$

Since the abolition of the bounties, Germany's consumption has risen to $1,600,000$ tons, but she continued to export a million tons.

1 The production of beetroot sugar in Europe from 1909-10 to 1913-14 is given in Appendix II. The increase or decrease for each country from 1903-4 to 1913-14 is given in Appendix IV. 
The United States, after a few unsuccessful efforts in former days, began, in 1890 , seriously to embark in the industry of beetroot sugar production. Clever men made a careful study, in the European countries, of the methods of manufacture; the Department of Agriculture, and especially Dr. Wiley, the chief of its Bureau of Chemistry, rendered valuable advice, and the small beginning soon grew to large dimensions. In 1892 there were six factories, turning out 13,000 tons of sugar. In 1902 there were forty-one factories, with a total sugar production of 218,406 tons. In the season 1908-9, sixty-three factories produced 421,244 tons. In 1912-13, seventy-three factories produced 769,507 tons, expressed as raw sugar. The industry enjoys, like its sister cane sugar industry in Louisiana, the profitable privilege of entry to the home markets duty free. At present the agricultural branch of the industry is not a great success, their average weight of roots to the acre being only 8 to 10 tons. The manufacturing department, no doubt, includes many up-tcdate factories, and the results will probably improve steadily year by year. Up to 1902-3, the extraction of sugar from the roots had increased from 11.4 per cent. to $12 \cdot 8$ per cent. In $1910-11$ it was 14 per cent., and, in $1913-14,14.4$ per cent. Why the farmers do their part of the work so badly is not explained. In many parts, no doubt, the climate is not so favourable as it is in Europe. The industry is, however, very sanguine with regard to the future, and we can only wish them every success in their brave determination to grow and prosper.

Canada is beginning to make her appearance in statistics as a sugar-producing country on a small scale. The history of her attempts to produce beetroot sugar is instructive and a warning. It is very much the 
experience of the United States over again. In 1881 the first attempt was made. We are told in a recent Report that the experiments then made could not prove anything but a failure. In 1901, four factories were started, but suffered from the usual initial drawbacks : insufficient beet acreage and incompetent factory management. The farmers were, of course, inexperienced and discontented with the price paid for the roots. The consequence was that one factory was moved to the States; another gave up the attempt; and the two remaining combined, in 1909, to form the present "Dominion Sugar Company, Limited." The two drawbacks were gradually overcome. The farmer began to recognize the benefits to be derived from the crop; and it became "a known fact that, once interested in beet-raising, he very rarely discontinues." The farmer appreciates the fact that it is a cash crop. Prices have now been arranged on the basis of richness of the roots and, in fourteen years, prices have risen from $\$ 3.50$ to $\$ 5.50$ per ton. No farmer now receives less than $\$ \mathbf{5} \cdot 50$, which shows that he knows how to produce rich roots. Twenty-three shillings a ton is a good price to begin with. The Canadians have now learned the details of the factory work, and can dispense with incompetent imported "experts." It is good to hear that the Dominion Company are now completing the erection of a large beet-sugar factory to do 1,500 tons of roots a day. "The plant is one of the most complete in the world, equipped with the most modern machinery and appliances that science has devised." The Company has evidently learned its lesson and is ready to achieve success. It would be well if some equally intelligent Company were to make its long wished-for appearance in our rural districts. 


\section{CHAPTER X}

\section{COMPETITION}

THE remarkable and sudden growth of the beetroot sugar industry, as related in the last chapter, was stimulated in every possible way, first by a quiet, unseen but well-known system of under-estimate of the duty to be levied, coupled with full payment of drawback on exportation; and afterwards by the payment of a direct bonus on exportation. All this the reader must have thoroughly realized from the facts just described. He must now be led, for a moment, a step further back in the history, to a time in the early sixties when the beetroot industry was still in its youth and the dominant factor in the European sugar markets was the refiner. We made all our own refined sugar in those days and were quite happy. But our comfortable times were to be rudely disturbed. An invitation was addressed to the British Government to join France, Belgium and Holland in an International Conference on the sugar duties. The refiners here got no benefit from the duty and were, therefore, quite willing to have the matter discussed. It was not very clear why the other countries should desire us to join them in reforming their own tariffs. To judge from the result it would almost seem as if they brought us into the discussion in order to get our duties altered. If so, they were entirely successful. Our Government did exactly what they wanted, and kindly did it even in advance of the international agreement. This may have been magnanimity but can hardly be regarded as good business. It would have been better to wait and see how the terms of the Convention were 
carried out. However, it was signed and ratified in 1864, and the only result, so far as this country was concerned, was a constantly increasing supply of loaf sugar from France and Holland. In five or six years the competition became serious. Many of the London loaf sugar refiners retired from business. The rest began to look into the matter and soon found out the cause of this alarming invasion. According to the terms of the Convention the duties on raw sugar were to be levied according to the colour of the sugar. There were three or four classes, paying different rates of duty, the brownest sugar in the lowest class, and so on up to the finest in the first class. The system worked quite fairly in this country, where the refiners used great varieties of raw sugar from all parts of the world. But in Paris the refiners were beginning to use the raw beetroot sugar, the quality of which was not accurately indicated by the colour. They could get sugar classed as yielding only eighty per cent. of refined which in reality yielded ninety per cent. In France the duty was very high and, therefore, the profit on ten per cent. of sugar escaping the duty was very large. The full drawback was allowed on exportation and, therefore, the refiner naturally got the full duty from the home consumer. He, therefore, got a profit of ten per cent. of the duty on the whole of his production. After the Franco-German War, the duty was greatly increased and so was the refiner's profit.

In 1872 our markets were, consequently, flooded with loaf sugar from Paris. A general meeting of British refiners, at which every firm in the kingdom was represented, was held in London, and a Committee was appointed to deal with the subject and induce the Government to obtain a rectification of this gross abuse of the terms of the Convention. The Committee set to 
work with a will, but they little knew that they were entering upon a thirty years' struggle, of which they only saw a small beginning at that time.

The Foreign Office took the matter up very willingly. It was a complicated subject, but they gradually learned their lesson and did their best. Some of the refiners began to add diplomacy to their other labours and the contest went merrily on. There were despatches and counter-despatches without end, but the foreigners were too clever for us.

The refiners, however, found very useful allies in a most unexpected quarter. The French beetroot sugar producers, as related in the last chapter, were under stringent excise supervision and had to pay duty on every ounce of their sugar. If anyone in France ought to have been allowed to "get a pull " out of the duty it was the beneficent agricultural industry of sugar production, not the three or four millionaire sugar refiners in Paris. The country manufacturers were naturally jealous of the favours enjoyed in Paris which they were not allowed to share, and they also saw that large exports of loaf sugar to England robbed them of good customers there and made them more dependent on the Paris monopoly. They, therefore, threw themselves into the fight with great spirit and considerable success. Members of the National Assembly were enlisted on their side and the abuses were well exposed by eloquent speakers.

The remedy proposed by the British refiners, and backed up by their French friends, was that the refineries should be under the same excise supervision as the beetroot factories. If the refined sugar was made " in bond," that is, without any duty having been paid, then the portion which went for export would require no payment of drawback, and that which went for 
home consumption would pay the full duty on leaving the refinery. The cure was absolute and easy. A system which worked without difficulty in hundreds of beetroot factories could be very easily worked in three or four refineries. The arguments were put before the National Assembly with great ability and a law was actually voted for putting the refineries under excise supervision and thus getting the full duty on the sugar actually produced and paying no drawback on exportation.

This was a great triumph, and success appeared to be more than probable. Our Government urged the matter very steadily, an International Conference was held in Brussels in 1875, followed by two more in Paris in 1876 and 1877. But the foreign delegates stubbornly resisted. They proposed a compromise. "Saccharimetry," they said, would be a sufficient remedy. All sugar entering the refinery should be analysed and the duty levied accordingly. The British delegates, very properly, had no faith in this proposal as a sufficient security against clever manipulations, and held their ground firmly. The French Government shelved the Bill voted by the National Assembly for " refining in bond," and showed no great desire to protect their revenue. The Paris refiners were too strong and won the battle. There was only one British loaf sugar refiner left.

During this initial phase of the coming struggle the British Refiners' Committee induced the West India Committee to join hands with them. The West Indians saw that every ton of foreign refined sugar imported displaced an equivalent quantity of their raw sugar. It was also pointed out that new abuses, as described in the last chapter, were making their appearance in Germany and Austria, and that very soon raw beetroot 
sugar, enjoying the extra profit derived from a vicious system of levying the duty, would be invading British markets on terms with which no cane sugar producer could compete. This turned out to be only too true. Not only raw but also refined sugar from Germany and Austria began to pour in, the quantity increasing rapidly from year to year.

The two industries of British refining and Colonial sugar production demanded that a Select Committee of the House of Commons should be appointed to examine the whole question. Mr. Ritchie, then member for the Tower Hamlets, obtained the Committee and presided over it with great ability for two years, 1879 and 1880. The inquiry was carried out thoroughly and was in every way-except practical effect-a great success.

The foreign delegates at the various conferences had pointed out, in view of what was going on in Germany and Austria, that it would be quite impossible for their Governments to agree to any Convention for the abolition of these artificial aids to foreign manufacturers unless the British Government would give them security, by a clause in the Convention, that they should no longer have to compete in British markets with sugar receiving similar advantages from other foreign Governments. This was such a reasonable and necessary demand that it could not be disputed or disregarded. If a foreign producer receives from his Government some gift out of the revenue which enables him to sell his produce below cost price and yet make a good profit, it is not only reasonable and consistent with common sense but also absolutely necessary, if British industry is to survive, that such a direct attack on our industries should be warded off by some defensive action. The amount of the artificial profit thus obtained could, in the case of sugar, be very accurately defined, 
and therefore it would be easy to countervail it by an equivalent duty. The sugar would then enter our markets on equal terms with its British or other competitors. The benefit it received from its Government would be put into our Exchequer for the relief of the British tax-payer, and everyone would start fair. It would be a tax on foreign Government bonuses, not a tax on sugar.

This was the argument, and it was met, not with argument but with violent indignation and heated controversy. The discussion got warmer the longer it proceeded, but the warmth was all on the part of the opponents of a countervailing duty, while its advocates were quite cool and stuck to a pure economic and scientific statement of their case. They had many supporters among real political economists, and a great army of unreasoning opponents whose sole cry was that duty should be levied for revenue purposes only. The case of sugar was sufficient to show how erroneous that curious dogma really was. The Select Committee saw this at once, and the more the witnesses were crossexamined by the dogmatic party the more clear their case became. The Committee reported in favour of a countervailing duty. The minority issued a report, which was defeated by 7 to 5 . Of the five who abstained, four were probably in favour of the Committee's Report. The Report was agreed to without a division.

It would require many chapters to give a full history of this interesting controversy which raged for many years. It suffices to say that in the end many opponents were converted. In 1899 the Indian Government could no longer endure the serious injury to our Indian sugar industry inflicted by the hundreds of thousands of tons of Austrian and German refined sugar which were 
" dumped" there when European markets were glutted with the artificially stimulated over-production in those countries. A scale of countervailing duties was drawn up in India and submitted to Parliament in the Indian Tariff Bill of 1899. A great debate took place, and Mr. Chamberlain made an eloquent and convincing speech, in which he stated the whole case in favour of the duties with remarkable clearness and force. He challenged the House to establish once for all the principle of a duty to countervail such a foreign artificially stimulated competition as this, and the House supported him by a large majority. This was four years before his great pronouncement in 1903. Again, Sir Robert Giffen, who as one of the Government experts had fought valiantly against the sugar industries in his evidence before the Select Committee in 1879-80, made the following handsome recantation at a meeting of the Royal Statistical Society in 1902. Speaking of his evidence in 1879, he said that " he was not sure that he would have taken the same line if he had been able to look forward a quarter of a century and see what the result was to be of allowing these bounties to continue. People became wiser as time went on, and a good many of the assumptions which it was perhaps legitimate to make a quarter of a century ago had been falsified by events . . . but, having had a quarter of a century's more experience, he was satisfied that these bounties must be treated as a great infraction of free trade, and that all the countries affected by them were quite entitled to take exceptional measures to put an end to them. . . Whatever we might gain temporarily in consequence of what foreign countries gave us by these bounties, they were not to be endured, and we should join in this general movement in favour of free trade."

The Report of the Committee fell dead, and the 
question, so far as diplomacy was concerned, slumbered more or less for several years. In 1880 the Government made a feeble effort to reopen negotiations, but were met at once, very properly, by the French Government, who pointed out that they could not consider the matter until the British Government were prepared to give the contracting parties security that they should not have to compete in British markets with sugar receiving similar advantages in other countries.

In 1888 an International Conference met in London and included Germany and Austria. But, though a Convention was more or less agreed to by the contracting parties, its presentation in the House of Commons for ratification was met by one or two speeches which might easily have been answered, but which apparently so frightened the Government that they promptly withdrew the Bill. Great Britain had, on this occasion, to bear the obloquy of rejecting the Convention.

The controversy raged fiercely at that time. The dogmatists had fallen back on the argument that the sale of goods below cost price was such a blessing to the consumer that it was wicked to attempt to stop it. They failed to see that if industries are injured by such competition the consumer also suffers. Production is reduced and prices rise. This is exactly what has happened with sugar. Very low prices have alternated with very high prices at regular intervals. As the late Lord Farrer pointed out, glut is followed by collapse and ruin. The short-sighted dogmatists declare, on the other hand, that they do not mind this ; they welcome ruinous prices as they do sunshine.

Another ten years elapsed, the competition among the various beetroot sugar producing countries had become more and more keen and the weaker ones began to pine for some way of escape from such an artificial 
state of things. Another Conference was called and met at Brussels in 1898. The numbers had multiplied. France, Belgium, Holland, Germany, Austria, Russia, Spain, Sweden and Great Britain were now gathered together and showed some real intention to make the Conference a success. It was an interesting discussion, but all hopes of success were wrecked by Russia. It was agreed that the Russian system was a flagrant case of unfair advantages conferred by the Government on their sugar industry, with the effect of artificially stimulating production and disturbing the natural course of competition. Russia indignantly denied the imputation and the Conference broke up.

At that date Germany exported 760,000 tons of raw sugar and 426,000 tons of refined. Austria exported 377,000 tons of refined, and Hungary 40,000 tons. The average yearly exports from Russia for the period 1885-95 had been 72,000 tons, practically all refined sugar. In 1896 the Russian exports went up to 221,000 tons. An interesting foot-note to the Belgian table of (so-called) statistics says: "The figures relating to the production of sugar are approximative, the duty being based on a presumed yield." This is evidently the case, for on adding the production and imports for 1897 we get the figure of 222,185 tons, while we find the total exports amount to 236,027 tons, leaving a minus quantity for home consumption. 


\section{CHAPTER XI}

\section{DIPLOMACY}

The United States Government were not going to allow their sugar industries to be ruined by the artificial system of forcing production and exportation, now almost universal throughout the European beetroot industry. They were very happy to import the sugar, but it must leave its artificial advantages at the Custom House as it passed through. The practical result of this policy was that not only tens but hundreds of thousands of tons of superfluous European beetroot sugar were imported into the States without hurting anybody, while the American revenue was swelled at the expense of Germany and Austria. The exporters paid the countervailing duty and were thankful to get rid of a good part of their overburdened stocks. The United States thus became the only market where our West Indian sugar producers could escape from this ruinous competition - it was their salvation. The Indian Government followed the example of the United States and gave the same relief to our producers in the East.

Great Britain, in the meantime, gloried in allowing the European producer to enjoy a preferential position in her markets. He was in exactly the same position as if his sugar were admitted free while all other sugar was charged with a duty. That treatment would be rank heresy if bestowed upon British producers; but the other way round it was hailed with delight as the most perfect application of the only true economic doctrine.

Our Colonial Office began to think otherwise, and the 
Foreign Office was quite ready to co-operate in applying some remedy to this crying injustice, rapidly becoming a scandal. They only wanted a mandate and, fortunately, they got one. The Congress of Chambers of Commerce of the Empire met in London in 1900. The London Chamber, with some difficulty, had been induced to take up the sugar question and Sir Nevile Lubbock, Chairman of the West India Committee, was entrusted by the London Chamber with the duty of moving a resolution at the Congress, to the effect that it was time for an International Conference for the abolition of these artificial stimulants to production and exportation, and that our Government should indicate their determination to take steps, either by means of a countervailing duty or by prohibition, to put a stop to them. Sir Nevile Lubbock made a most convincing speech, and was so well backed up, not only by Sir Thomas Sutherland and by the President, Lord Avebury, but also by many distinguished Colonial delegates, that the resolution was carried by a large majority.

This was exactly what the Government wanted. Immediate steps were taken to call a fresh Conference, which eventually met in Brussels in the winter of 1901. This Conference was a big affair and the foreign delegates knew that the British Government-for the first timemeant business. It required a very large table to accommodate delegates representing Belgium, Austria, Hungary, Germany, France, Spain, Great Britain, Italy, Holland, Roumania and Sweden.

This Conference had to deal not only with those abuses which were rampant in 1898 but also with a new method of carrying out, on a still larger scale, the process of exterminating all unaided competitors. The manufacturers in Germany and Austria had taken a leaf out of the Russian book and developed a new way 
of fighting the French. The industry in each country formed what is called a "Cartel." They were so similar, and their results so identical that it will be sufficient to describe, very briefly, the German Cartel. The consumption duty, that is, the duty actually paid by the consumer, was $10 \mathrm{~s}$. per cwt. ; but the import duty, that is, the duty which anyone outside would have to pay in order to enter into the competition, was 20 s. per cwt.just double. The surtax on imports was, therefore, $10 \mathrm{~s}$. per cwt. and, within the limit of that large amount, the home producer could raise his price to the consumer without fear of outside competition. But to effect this it was necessary that the whole industry should combine. They did so, and bound themselves down under severe penalties to adhere to the arrangement. The refiners were to raise the price to the consumer and to pay the raw sugar producers a fixed share of the resulting profit. The practical outcome was that the raw sugar producer received 3s. $6 \mathrm{~d}$. per cwt. more than the outside value of his sugar, while the refiner enjoyed the balance of the profit-4s. 6d. per cwt. These were, indeed, glorious profits. The great glut of sugar was rapidly increased, but the profit in the home market was so large that they could afford to sell their surplus for what it would fetch and yet make an abnormal profit on their total out-turn. The value of sugar in the world's markets fell 3s. per cwt. below the cost of production, but the German producers were delighted, declaring that the right policy was to keep prices down so as to crush all outside competition. They very nearly succeeded. This was regarded with dismay not only by the ordinary unaided producer but also by the rest of the beetroot industry itself, which had long enjoyed and still retained the smaller benefits so generously bestowed upon them by their paternal Governments. 


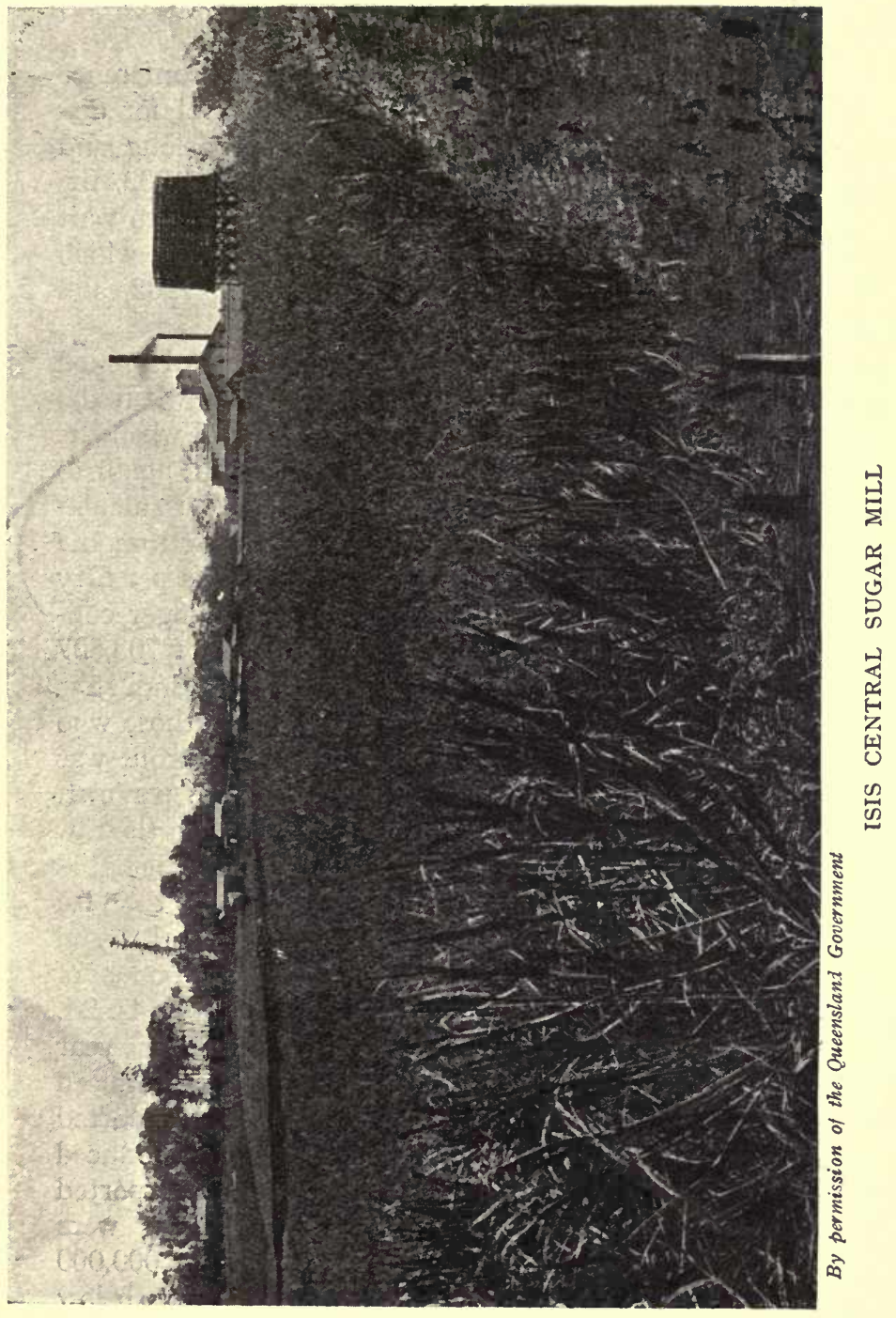


This was the state of tension in which the Conference met at Brussels, and this was the one subject for discussion-to abolish the Cartels. It was a long and tedious process, but by the end of February, 1902, the work was completed and all that remained was to wait anxiously for the ratification of the Convention which was provisionally signed on the 5th March, 1902, and came into force on the 1st September, 1903.

The usual margin between prices of raw and refined sugar in Germany was 3s. 6d. per cwt., but when the Cartel was in operation it rose to $10 \mathrm{~s}$. $6 \mathrm{~d}$., and when the Cartel was abolished by the Convention it fell again to the normal figure. On 15th January, 1902, a calculation of the profit arising from the Cartel, based on the prices of the day, gave the figure of 7.90 marks per fifty kilogrammes, that is, nearly $8 \mathrm{~s}$. per cwt. of sugar consumed. This, calculated on a consumption of 703,507 tons, showed a profit of $£ 5,558,495$ for the industry, with which they could make contributions to those who lost money on exports. The German Cartel profit was sufficient to furnish a bonus of about $5 \mathrm{~s}$. $5 \mathrm{~d}$. per cwt. on the refined exported, or $4 \mathrm{~s} .10 \mathrm{~d}$. per cwt. on the raw sugar exported. The Austrian Cartel profit, calculated in the same way, was found to amount to more than 9s. per cwt. of sugar consumed, showing an annual Cartel fund of $£ 2,957,868$, sufficient to furnish a bonus of 4s. 8 d. per cwt. on the refined sugar exported, or 4 s. 2 d. per cwt. on the raw sugar exported. In the year ending July 31st, 1902, Austria-Hungary produced $1,171,056$ tons, consumed 349,117 tons, and exported 739,186 tons. In the same year Germany produced 2,302,246 tons, consumed 743,520 tons, and exported $1,144,317$ tons. Together, these two countries were able to furnish the outside world with nearly 2,000,000 tons of sugar. They were selling it at $3 \mathrm{~s}$. per cwt. below 
the cost of production and hoped soon to become masters of the situation.

The Convention put a stop to the Cartels by fixing the surtax at a maximum of $2 \mathrm{~s}$. $6 \mathrm{~d}$. per cwt. This was more than enough to keep out competition, and the British delegates feared that a Cartel might be formed to exploit even this reduced surtax; but the situation was critical, and it was better to accept the compromise. Subsequent experience has shown that half that surtax suffices to keep out competition. The large surtaxes, therefore, can have had no other object than to enable producers to raise prices in the home market. This is why excessive surtaxes must always be regarded as a form of State aid calculated to stimulate production and exportation with the result of disturbing the natural course of the world's industry and trade. There is nothing to prevent the same system being applied to iron, steel, cotton or woollen goods or any other article of commerce.

The details of the Convention were summarized by the writer in the Economic Journal (Journal of the Royal Economic Society) for March, 1904, from which he makes the following brief extracts.

The first Article of the Convention declares that the contracting parties undertake to suppress direct and indirect bounties on the production or exportation of sugar, and proceeds to define, as follows, some instances of the way in which such advantages may result from State legislation.

(a) Direct bounties granted to export.

(b) Direct bounties granted to production.

(c) Total or partial exemption from taxation granted for a part of the manufactured product.

(d) Advantages derived from excess of yield. 
(e) Advantages derived from the exaggeration of the drawback.

(f) Advantages derived from any surtax in excess of the rate fixed by Article III.

Definition $(f)$, inserted at the instance of the British delegates, was absolutely essential in order to meet the case of the Cartel bounties. They proposed to define Cartel bounties as "advantages derived from any surtax," but in view of the critical state of the negotiations accepted the limitation. The first Article is, therefore, so far inconsistent that, though it declares the abolition of all bounties, it permits any Cartel bounty which may be obtained from the reduced surtax fixed by Article III. The figure of this surtax was, of course, a great bone of contention, but was finally fixed at six francs per 100 kilogrammes, that is, 2 s. $6 \mathrm{~d}$. per cwt.

The direct bounties in Germany, France, Austria and Holland came under definitions $(a)$ and $(b)$. The bounties defined under $(c),(d)$ and $(e)$ belong to one family and are practically interdependent. Levying the duty on an estimated yield is probably followed by the obtaining of a yield in excess of the estimate, and consequently by " a total or partial exemption from taxation for a part of the manufactured product." But this would not necessarily create a bounty unless the full amount of duty were returned in drawback on export. In that case the manufacturer can obtain the full duty from the home consumer; but if it were not so the exemption from taxation would merely operate as a reduction of duty to the consumer. Where the full drawback is returned on export, though the full duty has not been paid by the manufacturer, the drawback becomes practically an exaggerated one and the bounty 
is really the result of a combination of the cases defined in $(c),(d)$ and $(e)$.

The second Article abolishes such bounties as are here defined by prescribing excise supervision of factories and refineries, so that no duty shall be charged on the estimated yield, and therefore no drawback paid on exported sugar. The sugar will be manufactured and refined "in bond," that is, without having paid any duty; drawbacks will thus be abolished, and the sugar for home consumption will pay the duty when delivered for that destination.

The third Article fixes the maximum surtax at six francs per 100 kilogrammes.

The fourth Article is the penal clause, the object of which is to give the contracting States security that they shall not in future have to compete with bounty-fed sugar. It declares that a duty not less than the amount of the bounty shall be imposed in the markets of the contracting States on sugar from all countries that grant bounties. In the case of bounties arising from a surtax higher than that fixed by Article III, the countervailing duty shall be calculated by deducting from the surtax the figure so fixed and taking half the difference as representing the bounty.

These then are the salient points of the Convention: the decision to abolish all bounties; the establishing of manufacturing and refining "in bond"; the limitation of the surtax; and the security to the contracting Powers that bounty-fed sugar will no longer be tolerated in their respective territories.

There is one minor point in the Convention which calls for a word of comment. The fourth Article lays down the rules for countervailing a bounty by means of an equivalent duty, but it adds as an alternative that the high contracting parties reserve to themselves the power 10-(1463) 
to prohibit the importation of bounty-fed sugar. This appears to have arisen from some curious superstition on the part of the British Government that a duty might be regarded as contrary to the principles of free trade, but that prohibition could not fall under that stigma.

If this was the idea it shows a curious want of grasp of the subject. A bounty destroys free trade in the country which receives the bounty-fed commodity, because the producer of that commodity is at once placed in a position of favour as compared with his competitors who receive no bounty. The foreign producer is practically protected by his bounty in British markets if his sugar is allowed to be imported in open competition with sugar which receives no bounty. The effect is exactly as if the bounty-fed sugar were admitted free and the other, receiving no bounty, were struck with a duty. To eliminate this inequality is the sole object of the countervailing duty. It is, in fact, a duty on bounties, not on sugar. It accepts the bounty for the benefit of the whole nation of taxpayers by putting it into the Treasury, and leaves the sugar to compete with all other sugar on equal terms. Therefore, under a system of countervailing duties we do not lose the benefit of the bounty, we do no injustice to the bountyfed producer, and we save the consumer from the danger to his interests arising from the effect of bounties in discouraging and eventually destroying his natural sources of supply. None of these arguments can be used in favour of prohibition.

The Convention expired in 1908 and had to be renewed. The British Government, generally so simple-minded and easily over-reached, did a crafty thing. Five years previously they had yielded to the reasonable demand of the foreign governments who, for thirty years, had 
persistently urged that they could not be bound by treaty to abolish their bounties until Great Britain undertook that they should no longer have to compete on British markets with bounty-fed sugar. Having at last secured the abolition of the bounties, the British Government, at the earliest opportunity, turned round and declared that they were about to readmit bounty-fed sugar to their markets. The foreign governments were in a position of great difficulty. They had no desire to revert to the ruinous system of former days and they had to give in.

Russian sugar, with its bounty, was to come in without let or hindrance. There was a great flourish of trumpets. The system of restricted "importation" was to be abolished. This was really all moonshine. The world produced 14,000,000 tons of sugar, and we consumed one million and a half. There are at least $12,000,000$ tons (the rest goes to the United States) from which we were free to make our selection. There was, therefore, no restriction. Russia, it appears, after sending her usual exports to Finland and Persia, had an average surplus of about 40,000 tons, some of which might come here. What is this drop in the ocean of 14,000,000 tons? As it happens, Russia had then no surplus. So much for restriction of imports.

There were loud cries, when the Convention was coming into force in 1903, that the price of sugar would be raised enormously. Great political economists, with a turn for mathematics, sat down and calculated the exact figure. Our consumption, they said, was 1,600,000 tons, and the bounties were $\AA^{5}$ per ton. Multiply the consumption by five and you get $£ 8,000,000$. Behold the loss to the British consumer! They were not aware that price is governed by supply and demand and by nothing else. But, nevertheless, the figure was 
freely quoted even by statesmen of the highest rank, and was eagerly swallowed as an indisputable fact. They must have been quite surprised to find that supply and demand went on governing market prices just the same as usual, and, as there happened to be too much sugar, prices went down instead of up. Then a most fortunate accident happened for the alarmists. The European beetroot crop of 1904-5 suffered from a severe drought and produced 1,200,000 tons less sugar than the estimate. Prices naturally rose and the alarmists cried, "We told you so." The rise which took place was, in fact, a clear proof of the danger to consumers in having to depend on one crop, confined to a small portion of Europe, for their supply of sugar. And this dependence on one crop was the direct effect of the bounties. So it was the bounties that were really the cause of the scarcity and the high prices. Europe, of course, sowed a large acreage in 1905, on the strength of the good prices, and had a fine season and a bumper crop. In August, 1905, we were back again at the old price, a price even below the cost of production. ${ }^{1}$ The beetroot sugar industry still keeps up its production, and even continues to increase, but not to such an abnormal extent as during the bounty period. The industry has been firmly established and will continue to flourish, but it can no longer sell for export below cost price. Cane sugar now has a fair chance. The figures in Appendix III show that cane sugar is now forging ahead, and it will continue to do so, keeping pace with the constant increase in the world's consumption. The new fair fight between beet and cane will be an interesting study for many years.

1 See Appendix XV. 


\section{CHAPTER XII}

\section{THE SUGAR MARKET}

THERE are other sugars than the products of the cane and the beetroot, and they must not be forgotten. The most important is what is called, in the market, "Palmyra Jaggery," from India, of which at one time this country used to import appreciable quantities. Its production appears to be a considerable industry in India. The juice is tapped at the top of the tall palm-tree and caught in earthen pots suspended from a grooved stick which directs the flow of juice into its receptacle. ${ }^{1}$ The pots are collected each day and the juice boiled down to the crystallizing point.

Another tree that produces sugar is the sugar maple in America. Here the juice is really tapped from the stem and boiled down into sugar. The quantity annually consumed in America is about 11,000 tons. The people who live in the country of production tell us it is so nice that we shall never get a chance of tasting it

Coming now to the subject of the sugar market, there are still a select few who can recollect what the sugar market in Mincing Lane was before the advent of beetroot sugar, that is, in the early sixties. The West India merchants and their brokers, together with merchants and brokers who dealt in sugar from other quarters of the world, were the sellers. The buyers were the refiners and the wholesale grocers or dealers in raw

1 The tapping of the juice is often incorrectly described; there is no incision in the bark. The long flower is tied up and a piece cut off at the top. The pot is tied on and juice flows into it from the wound. It is cut again when the juice ceases to flow, and so on from day to day. 
grocery sugars. But these wholesale grocers had also another market to attend, and a very important onethe refined market. All the refined sugar consumed in the country practically came from British refiners, so that, in the case of London, a buyer from every wholesale grocer or dealer had to make a tour of the East End early every morning to call on some twenty refiners and buy their goods. In Mincing Lane work began at 9 a.m., public sales to value; then a visit to every private saleroom where West Indian sugar was on show; then the public sales at 1 o'clock, which often lasted for an hour or more; so that the industrious buyer often did not get his work done till 3 p.m.

The Mincing Lane sugar market of to-day ${ }^{1}$ is a very different thing. The public sales are a mere nothing, West India brokers have nearly disappeared, the advent of the merchant at noon is a thing of the past, and you can buy a thousand tons of sugar in five minutes. This transformation is all the result of the beetroot sugar industry. Beetroot came into Mincing Lane at first in pill boxes, carried furtively by the seller in his waistcoat pocket and shown in a deprecating way as being a very impertinent intrusion. Only one or two refiners would try the experiment, but they did not regret it. In Greenock one wide-awake sugar refiner informed his broker that he did not want to buy hundreds of tons, he wanted to buy thousands. Here was a grand opportunity for some intelligent and enterprising foreigner to develop a new business. He came exactly at the right moment, and at the end of his career he was one of the greatest sugar-brokers of the world. $\mathrm{He}$ not only supplied the refiners with their raw material but, eventually, had every kind of foreign refined ready for the wholesale grocer. One of the oldest established

1 Before the war. 


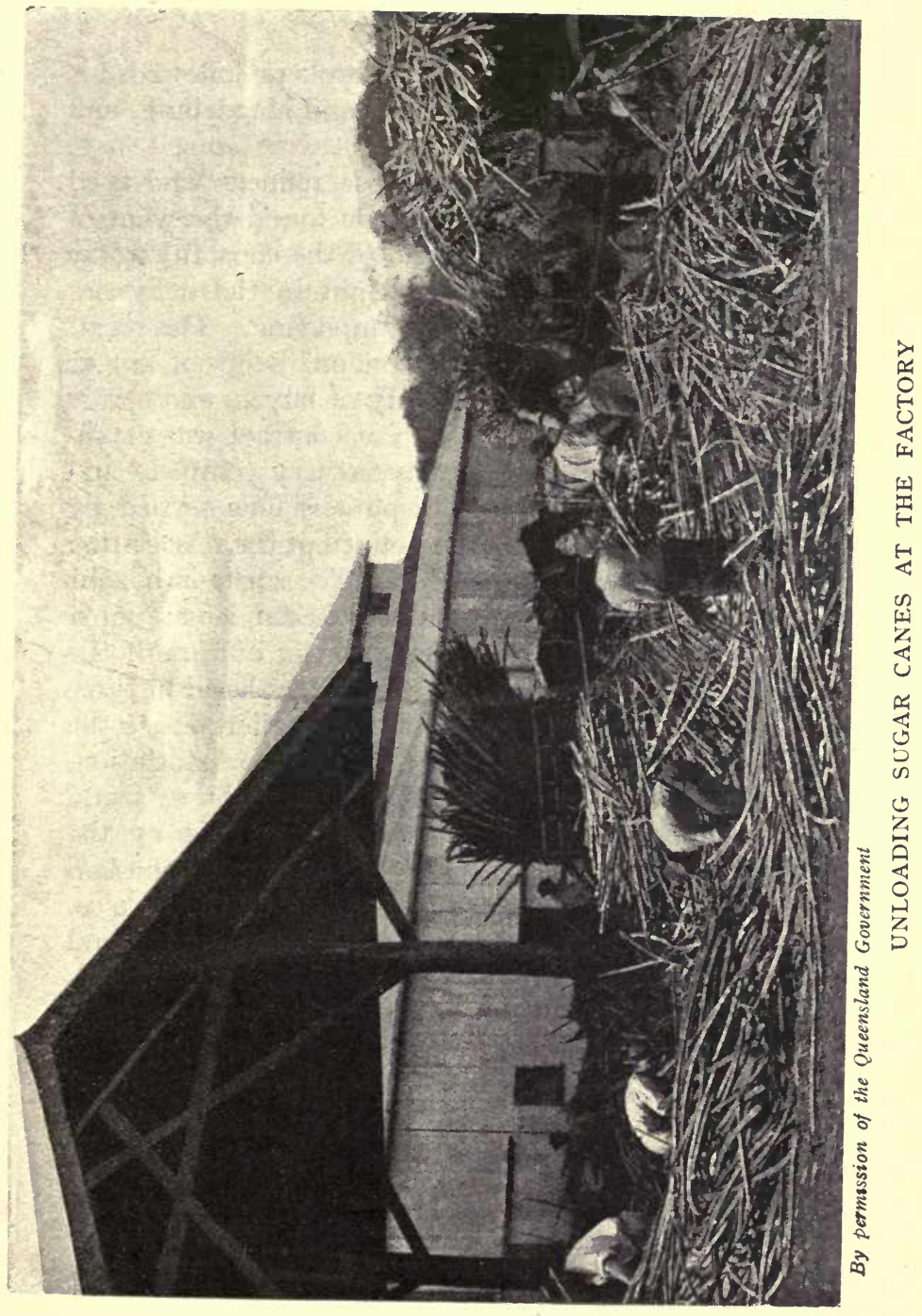


houses among the English sugar-brokers followed his example, opened branches in Paris and Magdeburg, and ran a very good race with him.

Then came a great help. Those refiners who used beetroot sugar on a large scale soon found the want of some organization for getting rid of the constant worry of complaints of quality and weight in the deliveries of the beetroot sugar they were importing. The result was the foundation of the London Beetroot Sugar Association. This organized body of buyers and sellers has worked admirably. A form of contract was established which became, eventually, a very complete and effectual document. Every dispute is now settled by arbitration, carried out by the Council of the Association in a simple but efficient manner. The sugar is bought and sold on the basis of analysis. Samples are most carefully taken under the supervision of officers of the Association. A portion of the sample is placed in three sealed bottles, of which one goes to the seller, one to the buyer, and the third to the laboratory of the Association. If there is a serious discrepancy between buyer's and seller's analysis the third sample is analysed by the chemist of the Association, and the average of the two nearest analyses is taken as the basis of the invoice. Here is at once a system which makes the buying and selling of sugar mere child's play. The large brokers with their branches abroad can let you have any quantity of sugar you desire.

The British sugar refiners now supply about 700,000 tons to our consumers, and at one time made it nearly all from raw beetroot sugar. That indicates the quantity of that commodity which we annually imported. But the foreign refiner now supplies our consumers with about 900,000 tons $^{1}$ of refined beetroot sugar every

1 This, of course, is a description of the normal state of things immediately before war upset everything. 
year, so that here we have $1,600,000$ tons accounted for without any of the old trouble of valuing and attending public sales, or visiting countless private show-rooms, at the expense of many hours of valuable time. There only remains to be dealt with in the old-fashioned way about 100,000 tons of grocery or miscellaneous cane sugar, including, of course, our fine colonial produce, such as the splendid yellow crystallized sugars from Demerara and the West India Islands. This is the change that has come over the Mincing Lane sugar market since 1860 .

But the change has not created a wilderness, as might be supposed. On the contrary, the members of the sugar market are there in swarms. This is the speculative market, a new invention not so very long ago, but now, in the eyes of the members, a very old affair. There is a "Call" in the morning, another in the afternoon, where prices fluctuate, not by $6 \mathrm{~d}$. per cwt. as in the old days of real buying of solid sugar, but by farthings or halfpennies. When the market is really active there may even be a violent rise of a penny. All this may seem very childish but it has its practical side. A big bonâ fide sugar-broker sells a thousand tons of solid sugar to a refiner, and he can at once cover his sale in the market by buying a thousand tons of imaginary sugar for delivery at once or at some future time. He is perfectly safe, thanks to the strict organization, and if he elects to take delivery he will get the sugar. He can thus hedge both his purchases and his sales, and without such a facility it would be impossible with safety to carry on the large operations necessary for the supply of sugar in these days. ${ }^{1}$

There was some pleasure and satisfaction in the old days in exercising the knowledge that comes from

1 This has disappeared in war time. 
practical experience and selecting with care and skill the best article at the lowest possible price. That part of expert knowledge in the sugar industry has gone.

The beetroot industry is beginning to get anxious as to its future prospects. Professor Dr. E. O. von Lippmann, at the head of the German industry both as expert and leader, a few years ago expressed his alarm with no uncertain sound. He points to the rapid recovery of cane sugar since the Brussels Convention, to its monster factories, to its large yields of sugar to the acre, and, worst of all, to its low cost of production. He speaks of the cost of production in Cuba as being down to 8s. per cwt. free on board. He has even heard of lower figures, down to $6 \mathrm{~s}$. $6 \mathrm{~d}$. per cwt., and of a factory which produces 78,000 tons of sugar a year. He quotes the figures from 1904 to 1909 , showing that cane sugar has increased from 48 per cent. to 54 per cent. of the world's production. ${ }^{1}$ Going further back he shows that in 1899 cane sugar produced only 31 per cent. We know that in those days even Java, with all its natural advantages, great skill and knowledge, declared that it could not stand against such artificial competition as then prevailed. He went on to remind his audience how he had urged, at that time, that the low prices were, from their point of view, in conformity with the interests of the European industry. But now, he continues, better prices contain a danger, because they are calculated to provoke a new and notable extension of the cultivation of the sugar cane. He also laments that German raw sugar has deteriorated in quality and that German refined sugar has lost its reputation. They must organize, he says, and if the industry will not take the necessary measures it is not for want of warning.

$1 \mathrm{He}$ probably made the same mistake as that which is pointed out in Appendix III. 
This is in a very minor key. In the days when beetroot was master he had urged that low prices must be maintained in order to crush competition. That he very nearly succeeded we all know, and the fact was admitted even by such a powerful authority as The Times. In the Financial Supplement to The Times of December 17th, 1909, there was a leading article on "The Rise in Sugar," in which the writer, after some interesting comments on the position, continued as follows-

"But what must strike the observing man who inquires into the facts of the situation is the probability that but for the Brussels Convention the rise in sugar in this country, instead of being 2s., might have been 20s. per cwt. For if the Convention had not put an end to the bounty system on the Continent the cane sugar industry by this time would have been practically dead, and we should have been entirely dependent on the supplies of the Continental beet growers. And it is the comparative failure of the beet harvest this year that is the real and only cause of the rise in sugar. .. . To all intents and purposes, then, we should be faced with a shortage of about half-amillion tons in the European needs for sugar were it not for the most welcome increase in the production of cane sugar, and that increase could not and would not have occurred under the bounty system."

The authors of the Brussels Convention were pleased to receive this unexpected and most weighty testimonial. For thirty years they were branded as economic infidels and heretics, but it appeared, on this very high authority, that their political economy was sound, that they have done a good deed and saved a valuable industry from 
destruction. A good deal of injury might have been avoided-injury to consumer as well as producer-if their advice had been listened to at the outset of the disease.

As a last word, we ask again, which is to win the race between cane and beet? Or are they to run a dead heat and divide the stakes? At one time the beetroot industry, as we have seen, was rather sad, while cane sugar was very cheerful and "going strong." Those connected with the latter declare that their adversary will never hurt them now, and can only live with the help of a surtax. This, at present, is not borne out by the facts; the beetroot industry shows no signs of reducing its production. But it is quite prepared to face the fact that, all artificial stimulus having been withdrawn, it will not continue to make its accustomed giant strides. M. François Sachs, the eminent Belgian expert and statistician, said, with regard to the rapid increase in the world's consumption, and therefore production :- " It is true that Europe, and certainly Belgium, will take but a feeble part in this increase in the production of the future."

Let us end with the hearty wish that both industries may flourish, each in its own sphere ; after their splendid efforts they both deserve it. 
(From Appendix to First Edition.)

APPENDIX I

Ten Remarkable Years of Progress

Ten Years of Sugar Production in Germany

\begin{tabular}{l|c|c|c|c|c|c}
\hline \multicolumn{1}{c|}{ Year } & Acres & Roots. Tons & $\begin{array}{c}\text { Roots } \\
\text { peracre } \\
\text { Tons. }\end{array}$ & Sugar. Tons & $\begin{array}{c}\text { Sugar } \\
\text { per 100 } \\
\text { of Root }\end{array}$ & $\begin{array}{c}\text { Sugar } \\
\text { per acre } \\
\text { Tons }\end{array}$ \\
$1899-00$ & $1,070,355$ & $12,466,000$ & $11 \cdot 64$ & $1,791,250$ & $14 \cdot 37$ & $1 \cdot 67$ \\
$1900-1$ & $1,119,015$ & $13,252,000$ & $11 \cdot 84$ & $1,974,800$ & $14 \cdot 90$ & $1 \cdot 76$ \\
$1901-2$ & $1,196,872$ & $16,000,000$ & $13 \cdot 38$ & $2,293,300$ & $14 \cdot 33$ & $1 \cdot 92$ \\
$1902-3$ & $1,069,110$ & $11,256,000$ & $10 \cdot 54$ & $1,750,600$ & $15 \cdot 53$ & $1 \cdot 63$ \\
$1903-4$ & $1,042,192$ & $12,706,000$ & $12 \cdot 16$ & $1,929,410$ & $15 \cdot 22$ & $1 \cdot 85$ \\
$1904-5$ & $1,037,005$ & $10,071,000$ & $9 \cdot 70$ & $1,605,400$ & $15 \cdot 94$ & $1 \cdot 54$ \\
$1905-6$ & $1,179,355$ & $15,727,000$ & $13 \cdot 34$ & $2,394,400$ & $15 \cdot 23$ & $2 \cdot 03$ \\
$1906-7$ & $1,110,457$ & $14,187,000$ & $12 \cdot 80$ & $2,242,100$ & $15 \cdot 80$ & $2 \cdot 02$ \\
$1907-8$ & $1,121,232$ & $13,483,000$ & $12 \cdot 02$ & $2,136,000$ & $15 \cdot 99$ & $1 \cdot 90$ \\
$1908-9$ & $1,087,215$ & $11,799,000$ & $10 \cdot 84$ & $2,080,000$ & $17 \cdot 63$ & $1 \cdot 91$ \\
Average & & & $11 \cdot 87$ & & $15 \cdot 49$ & $1 \cdot 83$ \\
\hline
\end{tabular}

Average of Ten Years, 1899-1908

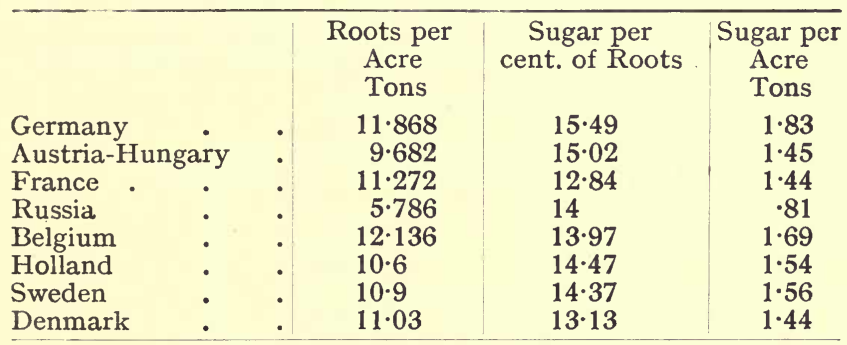

\section{APPENDIX II}

Home Consumption, 1909

Foreign Refined Sugar

British Refined Sugar

Manufactured (in Bond) in the United Kingdom Raw Cane Sugar
Tons

924,521

599,793

113,582

$1,637,896$ Tons. 
Home Consumption, 1909-contd.

Less Exports of British Refined . • • 32,256

Total consumption of Sugar $\quad$. $\quad$. $1,605,640$

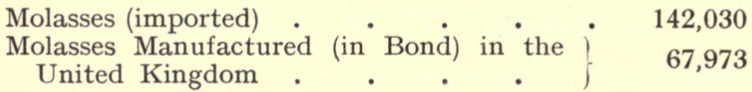

Total consumption of Molasses . . . 210,003 Tons,

\section{APPENDIX III}

Results of a German Sugar Factory, SEASON 1908-9

This is given not as i idicating the average results of beet sugar production, but as a remarkable instance of success in a good season.

Roots, 24,600 kilos. per hectare, equal to about 10 tons to the acre, against $10 \frac{1}{2}$ tons the year before.

Roots worked, 135,959 tons; average polarization, 17·10. Price of roots, 21s. per ton.

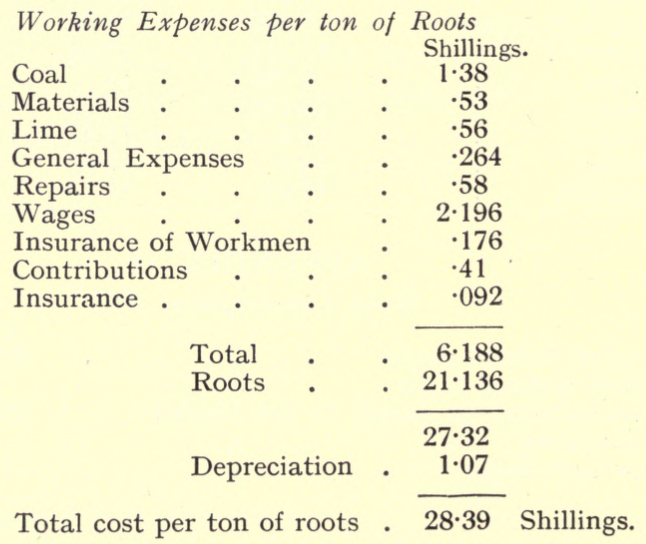


Six tons of roots produced one ton of sugar. The cost per ton of roots being 28.39 shillings, the cost per ton of sugar is 170.34 shillings, or $£ 810$ s., or $8 \mathrm{~s}$. $6 \mathrm{~d}$. per cwt.

\section{Sugar Produced}

$$
\begin{aligned}
& \text { First products (average analysis, 90.25). } \quad \begin{array}{c}
\text { Tons } \\
20,818
\end{array} \\
& \text { Second products (average analysis, 81.52) . 1,805 }
\end{aligned}
$$

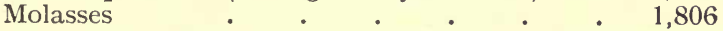

Yield per cent. of Roots

First products . . . 15.31

Second products $\quad . \quad 1.33$

Total . . 16.64 per cent.

Molasses . . . 1.33 ,, ,

Average Prices

First products, 10 s. per cwt., basis 88 , f.o.b.

\begin{tabular}{|c|c|c|c|c|c|}
\hline Receipts for & sugar & & 0 & & \\
\hline Expenses & . & & 8 & 6 & \\
\hline Profit & • & & 2 & U & \\
\hline
\end{tabular}
Second products, 8 s. 6 d. per cwt., basis 75 , f.o.b.

Profits, $£ 45,076$, equal to 29 per cent. on capital.

Dividend of 22 per cent. paid, after payments to reserves and bonuses.

Of the rest, $£ 8,669$ was paid to the growers on account of the good year and the short weight but good quality of the roots.

Dried pulp, 2,603 tons, consumed 1,482 tons of coal, and fetched $f 8,335$ net, after deducting expenses of drying.

Other factories paid 30 to 35 per cent. dividend. The high yield of 16 to 17 per cent. of sugar from the roots made the season a very profitable one to the factories. 


\title{
APPENDIX TO FOURTH EDITION
}

\author{
I.-Sugar Crops of the World \\ (Willett \& Gray, New York, October, 1917)
}

TONS OF 2,240 LB.

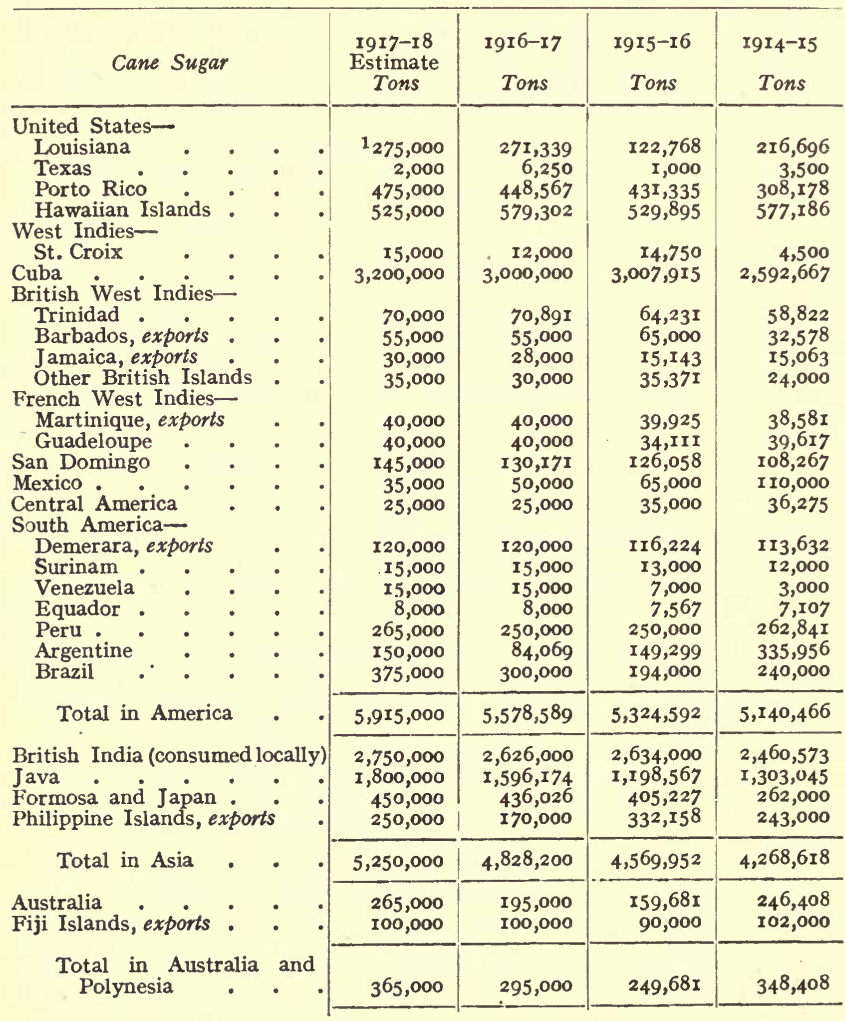

1 Estimate reduced to 225,000 tons. 


\begin{tabular}{|c|c|c|c|c|}
\hline Cane Sugar. & $\begin{array}{l}\text { I917-18 } \\
\text { Estinate } \\
\text { Tons }\end{array}$ & $\begin{array}{l}\text { 1916-7 } \\
\text { To }: s\end{array}$ & $\begin{array}{l}\text { 1915-1 } 6 \\
\text { Tons }\end{array}$ & $\begin{array}{l}\text { I9r } 4^{-15} \\
\text { Tons }\end{array}$ \\
\hline $\begin{array}{l}\text { Egypt (consumed locally) } \\
\text { Mauritius exports } \\
\text { Réunion, } \\
\text { Natal } \\
\text { Mozambique }\end{array}$ & $\begin{array}{r}100,000 \\
224,000 \\
45,000 \\
115,000 \\
50,000\end{array}$ & $\begin{array}{r}\text { 101, } 832 \\
209,169 \\
45,000 \\
\text { I } 14,504 \\
55,000\end{array}$ & $\begin{array}{r}98,964 \\
215,528 \\
45,000 \\
115,481 \\
50,000\end{array}$ & $\begin{array}{r}75,738 \\
277,164 \\
39,267 \\
91,619 \\
40,000\end{array}$ \\
\hline Total in Africa. . . & 534,000 & 525,505 & 524,973 & 523,788 \\
\hline Europe-Spain (cane) & 6,000 & 6,000 & 6,359 & 7,376 \\
\hline Total Cane Sugar Crops & $12,070,000$ & II 233,294 & 10,675,557 & 10,288,656 \\
\hline \multicolumn{5}{|l|}{ Beetroot Sugar } \\
\hline $\begin{array}{l}\text { Europe-Beet Sugar Crops } \\
\text { United States-Beet Sugar Crop } \\
\text { Canada-Beet Sugar Crop }\end{array}$ & $\begin{array}{r}3,849,000 \\
875,000 \\
12,500\end{array}$ & $\begin{array}{r}4,555,407 \\
734,577 \\
12,500\end{array}$ & $\begin{array}{r}5,077,760 \\
779,756 \\
17,641\end{array}$ & $\begin{array}{r}7,583,215 \\
646,257 \\
13,979\end{array}$ \\
\hline Total Beet Sugar Crops & $4,736,500$ & $5,302,484$ & $5,875,157$ & $8,243,45 I$ \\
\hline Grand Total-Cane and Beet & $16,806,500$ & $16,535,778$ & $16,550,714$ & $18,532,107$ \\
\hline $\begin{array}{l}\text { Estimated increase in } 1917-18 \\
\text { in the world's production }\end{array}$ & 270,722 & & & \\
\hline
\end{tabular}

\section{II.-Crops of Beetroot Sugar on the Continent of EUROPE}

(From Licht's " Monthly Circular.")

\begin{tabular}{|c|c|c|c|c|c|c|}
\hline & $\begin{array}{c}\text { I9I6-I7 } \\
\text { WAR } \\
W \text { E } G . \\
\text { Tons }\end{array}$ & $\begin{array}{l}\text { I9 }{ }_{3-14} \\
\text { Tons }\end{array}$ & $\begin{array}{l}\text { I9I2-I3 } \\
\text { Tons }\end{array}$ & $\begin{array}{l}\text { I } 91 \mathrm{I}-\mathrm{I} 2 \\
\text { Tons }\end{array}$ & $\begin{array}{l}\text { I9ro-I I } \\
\text { Tons }\end{array}$ & $\begin{array}{l}\text { I909-10 } \\
\text { Tons }\end{array}$ \\
\hline $\begin{array}{l}\text { Germany } \\
\text { Austria } \\
\text { France } \\
\text { Russia } \\
\text { Belgium } \\
\text { Holland } \\
\text { Others }\end{array}$ & $\begin{array}{r}\mathrm{I}, 350,000 \\
900,000 \\
181,385 \\
\mathrm{I}, 158,920 \\
133,210 \\
260,000 \\
571,892\end{array}$ & $\begin{array}{r}2,738,000 \\
1,710,000 \\
800,000 \\
1,750,000 \\
230,000 \\
230,000 \\
796,700\end{array}$ & $\begin{array}{r}2,732,189 \\
\mathbf{I}, 919,853 \\
978,838 \\
1,383,754 \\
300,253 \\
316,933 \\
709,243\end{array}$ & $\begin{array}{r}1,505,479 \\
1,154,606 \\
516,618 \\
2,058,635 \\
246,220 \\
267,607 \\
530,000\end{array}$ & $\begin{array}{r}2,606,122 \\
1,538,034 \\
724,897 \\
2,140,000 \\
284,714 \\
221,359 \\
590,000\end{array}$ & $\begin{array}{r}2,033,834 \\
1,256,751 \\
806,405 \\
1,126,853 \\
249,612 \\
198,456 \\
465,000\end{array}$ \\
\hline & $A, 555,407$ & $8,254,700$ & $8,34 I, 063$ & $6,279,165$ & $8, \mathrm{I} 05, \mathrm{I} 26$ & $6, \mathbf{I} 36,9$ I I \\
\hline
\end{tabular}




\section{III.-Progress in Cane and Beet Production since} 1903, the date of the Convention

\section{(Journal des Fabricants de Sucre, 10 October, 1917.)}

Beet

\begin{tabular}{|c|c|c|c|c|}
\hline Year & Cane & Europe & $\begin{array}{l}\text { United } \\
\text { States } \\
\text { and } \\
\text { Canada }\end{array}$ & $\begin{array}{c}\text { Total } \\
\text { World's } \\
\text { Production }\end{array}$ \\
\hline $\begin{array}{lll}1903-4 . & . & . \\
1904-5 . & \cdot & \text {. } \\
1905-6 . & . & 1 \\
1906-7 . & . & . \\
1907-8 . & . & . \\
1908-9 . & . & . \\
1909-10 . & . & . \\
1910-11 . & . & . \\
1911-12 . & . & . \\
1912-13 . & . & . \\
1913-14 . & . & .\end{array}$ & $\begin{array}{c}\text { TONS } \\
4,234,000 \\
4,594,000 \\
6,731,000 \\
7,329,000 \\
6,922,000 \\
7,633,000 \\
8,327,000 \\
8,390,000 \\
9,067,000 \\
9,232,000 \\
9,821,000\end{array}$ & $\begin{array}{c}\text { TONS } \\
5,881,000 \\
4,708,000 \\
6,932,000 \\
6,710,000 \\
6,562,000 \\
6,543,000 \\
6,137,000 \\
8,095,000 \\
6,279,000 \\
8,341,000 \\
8,179,000\end{array}$ & $\begin{array}{c}\text { TONS } \\
208,000 \\
209,000 \\
283,000 \\
433,000 \\
440,000 \\
384,000 \\
450,000 \\
455,000 \\
541,000 \\
635,000 \\
667,000\end{array}$ & $\begin{array}{c}\text { TONS } \\
10,323,000 \\
9,511,000 \\
13,946,000 \\
14,472,000 \\
13,924,000 \\
14,560,000 \\
14,914,000 \\
16,940,000 \\
15,887,000 \\
18,208,000 \\
18,667,000\end{array}$ \\
\hline $\begin{array}{l}\text { THE WAR } \\
1914-15 . \\
1915-16 . \\
1916-17 .\end{array}$ & $\begin{array}{l}10,288,000 \\
10,667,000 \\
11,169,000\end{array}$ & $\begin{array}{l}7,583,000 \\
5,077,000 \\
4,764,000\end{array}$ & $\begin{array}{l}660,000 \\
797,000 \\
747,000\end{array}$ & $\begin{array}{l}18,531,000 \\
16,541,000 \\
16,680,000\end{array}$ \\
\hline
\end{tabular}

1 The jump in the figure for cane sugar production, from $4,594,000$ tons in $1904-5$ to $6,731,000$ tons in $1905-6$, is misleading. It is caused by the sudden inclusion, by the statisticians, of a more or less imaginary figure as representing what was for the first time officially announced to be the estimate of the native production of sugar in British India. (See p. 89.) 
IV.-Progress of the European Beet Sugar PRODUCING Countries during the period of the Convention, 1903-14 (Journal des Fabricants de Sucre.)

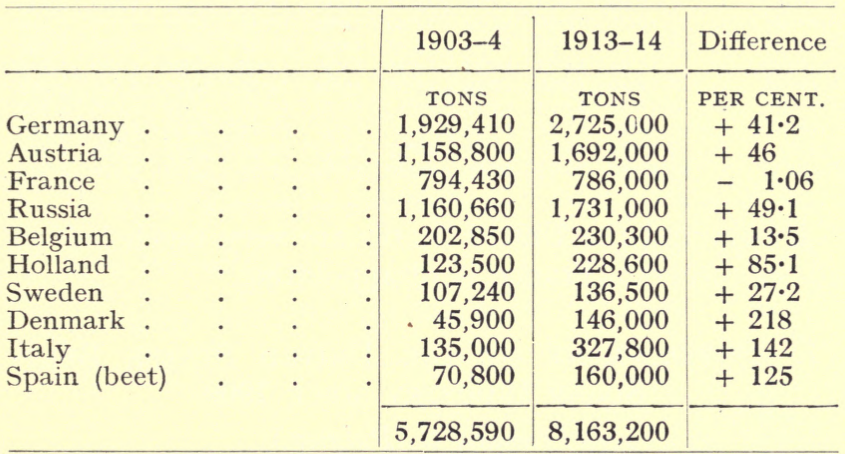

The progress of Germany, Austria, Belgium, Holland, and Sweden is a natural increase to keep pace with increased consumption. The increase in Russia is artificial, because there is still a bounty. Italy and Spain have protected markets and no surplus. The rapid growth of the Danish and Dutch industries is very creditable. There are several reasons for the stationary condition of France, of which high cost of production is one. 


\section{V.-Yield of Sugar from the Beetroot. Europe and the United States}

(Truman G. Palmer, Washington, U.S.A.)

\begin{tabular}{|c|c|c|c|c|c|c|c|c|c|c|}
\hline & \multicolumn{3}{|c|}{$\begin{array}{l}\text { Roots per Acre } \\
\text { Short Tons } \\
2,000 \mathrm{ll} \text { s. }\end{array}$} & \multicolumn{3}{|c|}{$\begin{array}{l}\text { Raw Sugar } \\
\text { Extraction, } \\
\text { per roo of Roots }\end{array}$} & \multicolumn{3}{|c|}{$\begin{array}{l}\text { Sugar per Acre } \\
\text { pounds }\end{array}$} \\
\hline & & I908-9 & $1910-1$ & $1913-4$ & $1908-9$ & 1910-1 & $19 \times 3-4$ & $1908-9$ & 1910-1 & I913-4 \\
\hline \multicolumn{2}{|c|}{ United States } & $9 \cdot 36$ & $10 \cdot 17$ & $9 \cdot 76$ & I3.86 & $14.0 \mathrm{r}$ & 14.40 & 2,594 & 2,848 & 2,810 \\
\hline Germany & - & $12 \cdot 08$ & 14.70 & $14 \cdot 17$ & $17 \cdot 61$ & 16.44 & $16 \cdot 08$ & 4,253 & 4,835 & 4,559 \\
\hline Russia & . & 6.99 & 8.74 & $7 \cdot 60$ & I $5 \cdot 21$ & $16 \cdot 12$ & $14^{\cdot 09}$ & 2,127 & 2,819 & 2,143 \\
\hline Austria & . & 10.71 & $12 \cdot 36$ & II.50 & $17 * 44$ & 14.85 & $15 \cdot 38$ & 3,737 & 3,672 & 3,500 \\
\hline France. & 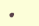 & $12 \cdot 36$ & 10.76 & 12.52 & 13.31 & $12 \cdot 90$ & $12 \cdot 87$ & 3,288 & 2,775 & 3,223 \\
\hline Belgium & . & 13.34 & $14 \cdot 53$ & $12 \cdot 33$ & I 4.96 & $14 \cdot 30$ & $15 \cdot 06$ & 3,990 & 4,156 & 3,716 \\
\hline Holland & - & $12 \cdot 46$ & $12 \cdot 96$ & II $\cdot 19$ & 15.87 & $15 \cdot 04$ & 14.77 & 3,954 & 3,898 & 3,306 \\
\hline Sweden & - & $12 \cdot 35$ & $14^{\circ} 03$ & 13.76 & 15.53 & 15.74 & 15.49 & 3,836 & $4,4 \mathrm{I} h$ & 4,262 \\
\hline Denmark & - & 12097 & 1531 & 13.93 & I5 & $14 \cdot 31$ & $15 \cdot 13$ & 3,893 & $4,38 \mathrm{I}$ & 4,216 \\
\hline Spain . & . & $15 \cdot 74$ & 10.82 & $10 \cdot 81$ & $12{ }^{\circ} 47$ & 1443 & 12.96 & 3,926 & 3,123 & 2,801 \\
\hline Italy . & - & $15 \cdot 14$ & $16 \cdot 63$ & $20 \cdot 89$ & $11 \cdot 70$ & II.94 & $11 \cdot 67$ & $3,54 \mathrm{I}$ & 3,972 & 4,874 \\
\hline
\end{tabular}

Russia and the United States are very much behind all the others. France is disappointing.

VI.-Development of the United States BeetSUGAR INDUSTRY SINCE 1900

(Truman G. Palmer.)

TONS OF 2,000 LB.

\begin{tabular}{|c|c|c|c|c|c|c|}
\hline Years & $\begin{array}{c}\text { Acres } \\
\text { harvested }\end{array}$ & $\begin{array}{l}\text { Raw } \\
\text { Sugar } \\
\text { Tons }\end{array}$ & $\begin{array}{c}\text { Roots } \\
\text { per Acre } \\
\text { Tons }\end{array}$ & $\begin{array}{c}\begin{array}{c}\text { Sugar } \\
\text { per Acre }\end{array} \\
\text { Pounds }\end{array}$ & $\begin{array}{c}\text { Sugar } \\
\text { Extrac- } \\
\text { tion } \\
\text { per 1oo } \\
\text { of Roots }\end{array}$ & $\begin{array}{c}\text { Tons of } \\
\text { of Sugar } \\
\text { per } \\
\text { Factory }\end{array}$ \\
\hline I900- I & 132,000 & 95,646 & $6 \cdot 15$ & $\mathrm{I}, 449$ & $11.78 \%$ & 2,813 \\
\hline $1901-2$ & 175,083 & 205, I II & 9.63 & 2,343 & I2. I7 & 5,697 \\
\hline $1902-3$ & 216,400 & 242,672 & $8 \cdot 76$ & 2,243 & 12.80 & 5,918 \\
\hline $1903-4$ & 242,576 & 267,337 & $8 \cdot 56$ & 2,204 & 12.87 & 5,455 \\
\hline $1904-5$ & 197,784 & 269,014 & 10.47 & 2,720 & I2.99 & 5,604 \\
\hline $1905-6$ & 307,364 & 347,690 & $8 \cdot 67$ & 2,262 & 13.04 & 6,686 \\
\hline $1906-7$ & 376,074 & 537,346 & II 26 & 2,857 & 12.68 & 8,529 \\
\hline $1907-8$ & 370,984 & 515,142 & I0.1 6 & 2,777 & $13 \cdot 67$ & 8,176 \\
\hline 1908- 9 & 364,913 & 473,204 & $9 \cdot 36$ & 2,594 & 13.86 & 7,632 \\
\hline rgo9-10 & 420,262 & 569,410 & $9 \cdot 7 x$ & 2,710 & I3.95 & 8,760 \\
\hline I9I0-II & 398,029 & 566,857 & $10 \cdot 17$ & 2,848 & $14^{\circ} \mathrm{OI}$ & 9,292 \\
\hline $1911-12$ & 473,877 & 666 ,III & 10.68 & $2,8 \mathrm{II}$ & 13.16 & 10,092 \\
\hline $\begin{array}{l}\text { I9I2-I3 } \\
\text { Estimate }\end{array}$ & 555,300 & 769,507 & $9.4 \mathrm{I}$ & 2,772 & 14.73 & $10,54 \mathrm{I}$ \\
\hline $1913-14$ & 580,006 & 814,890 & $9 \cdot 76$ & $2,8 \mathrm{ro}$ & 14.40 & $x I, 477$ \\
\hline
\end{tabular}


VII. - Quantity of Cane Sugar per Factory tuRned out in Cuba in the Year 1913-14

(Truman G. Palmer.)

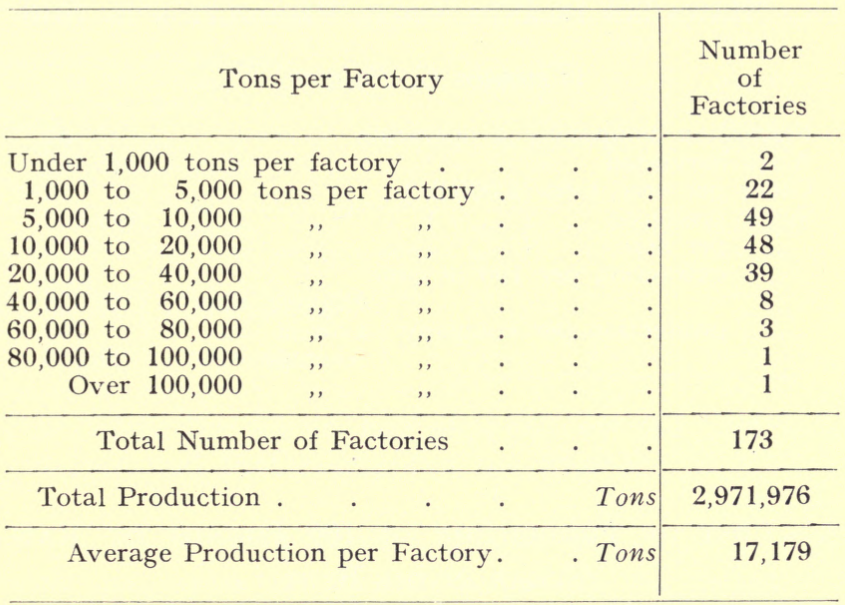

ViII.-Meltings of Sugar in Clyde Refineries

From William Connal \& Co.'s Monthly Circular, Glasgow, 31st December, 1917

\begin{tabular}{|c|c|c|c|c|c|c|c|c|c|}
\hline \multirow{2}{*}{\multicolumn{2}{|c|}{ Year }} & $\begin{array}{l}\text { West } \\
\text { India }\end{array}$ & $\underset{\text { Mauri- }}{\text { tius }}$ & Brazil & $\begin{array}{c}\text { Cuba } \\
\text { and } \\
\text { Porto } \\
\text { Rico }\end{array}$ & $\begin{array}{l}\text { Beet- } \\
\text { root }\end{array}$ & Java & $\begin{array}{l}\text { Other } \\
\text { Foreign }\end{array}$ & Total \\
\hline & & Tons & Tons & Tons & Tons & Tons & Tons & Tons & Tons \\
\hline I9I 3 & . & . 3,376 & $4 \mathrm{I} 5$ & - & 82,804 & 120,713 & 3,299 & 20,596 & 231,333 \\
\hline I9I 4 & . & . 5,570 & - & 890 & 64,283 & 68,945 & $25,84 \mathrm{I}$ & 35,092 & 200,621 \\
\hline I9I 5 & . & . - & $\mathrm{I} 8,59^{8}$ & 2,433 & 86,839 & - & 102,699 & 19,120 & 229,639 \\
\hline I9I 6 & . & . 4,800 & 9,460 & - & I 38,302 & - & 50,835 & $18, I_{15}$ & 221,512 \\
\hline 1917 & . & . 8,474 & - & 3,040 & I 57,238 & - & 60,979 & $7,454^{\circ}$ & 237,185 \\
\hline
\end{tabular}


IX.-Hawailan Islands Sugar Production in 1916

$$
\text { (Truman G. Palmer.) }
$$

Plantation companies in operation . . . 52

Acres harvested $\quad . \quad 5 \quad . \quad . \quad . \quad . \quad .115,489$

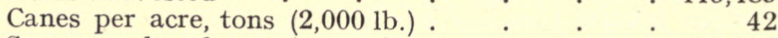

Sugar produced ,, ( , ) . . . . . . . 593,483

", per acre ,, ( ,, . . . . . . . 5.13

, extraction per 100 of cane . . . $\quad 12.2$

Highest, tons . 59,035

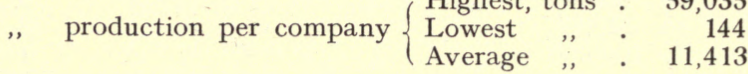

X.-Cost of Production of 100 Pounds of Raw Sugar In the BeEt

(Truman G. Palmer, Washington.)

DOLLARS PER IOO LB.

\begin{tabular}{|c|c|c|c|c|c|c|}
\hline Five-years' Average & $\begin{array}{l}\text { United } \\
\text { States }\end{array}$ & Germany & Russia & Austria & France & Holland \\
\hline I9o8-9 to $1912-13$ & $2 \cdot 30$ & $I \cdot 50$ & I.53 & $\mathbf{r} 49$ & $\mathbf{r} \cdot 78$ & I. 46 \\
\hline
\end{tabular}




\title{
XI.-Consumption of Sugar in the United States
}

\author{
(OFFICIAL)
}

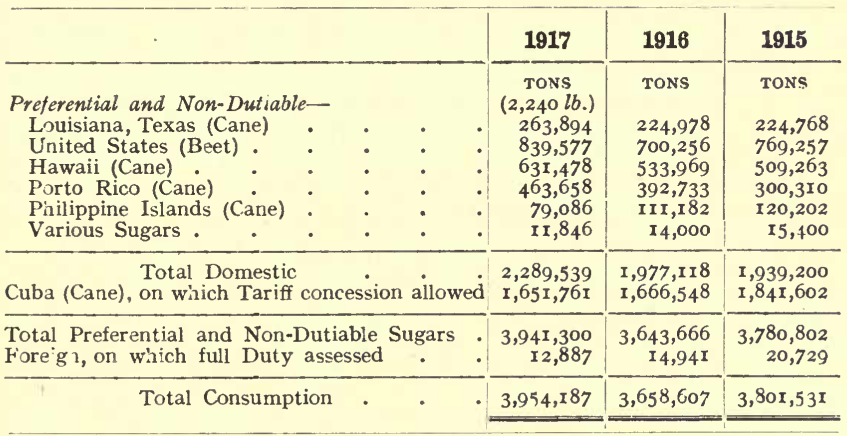

Practically the whole was supplied by the States, Territories, and Protectorates of the Republic.

\section{XII.-Our Home Consumption}

For the last complete year before the war, and the first complete year during the war.

Refined (Imported)

Refined (in Bond) in the United-Kingdom Raw .

\section{Total}

Less Exports of British Refined:

Total consumption of Sugar.

Molasses manufactured in U.K. .

Total consumption of Molasses.

\begin{tabular}{|c|c|}
\hline 1913 & 1915 \\
\hline $\begin{array}{l}\text { TONS } \\
899,327 \\
715,661 \\
116,942\end{array}$ & $\begin{array}{l}\text { TONS } \\
572,618 \\
784,316 \\
293,276\end{array}$ \\
\hline $\begin{array}{r}1,731,930 \\
23,271\end{array}$ & $\begin{array}{r}1,650,210 \\
4,972\end{array}$ \\
\hline $1,708,659$ & $1,645,238$ \\
\hline $\begin{array}{r}158,162 \\
85,584\end{array}$ & $\begin{array}{r}145,703 \\
70,125\end{array}$ \\
\hline 243,746 & 215,828 \\
\hline
\end{tabular}


XIII.-The Imports of Sugar into the United KINGDOM FOR THE LAST COMPLETE YEAR BEFORE THE WAR AND THE First COMPLETE YEAR DURING THE WAR-a very interesting comparison.

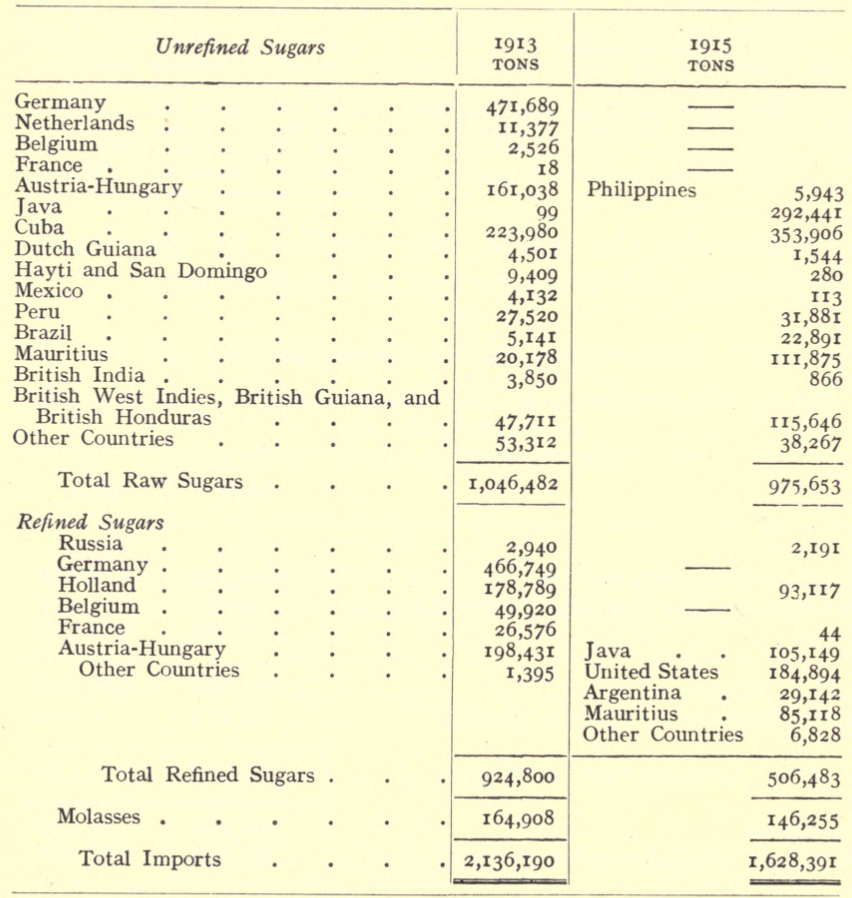


XIV.-European per capita Sugar Consumption (Willett \& Gray, New York.)

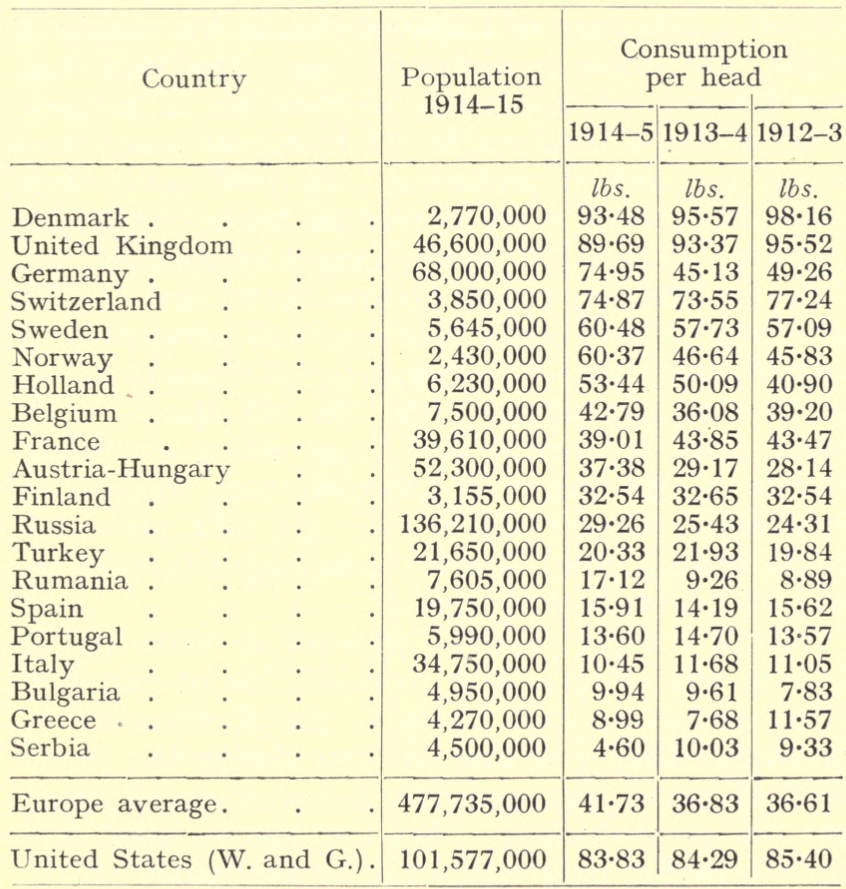


XV.-The Price of Sugar during the Convention PERIOD, 1903-1914

The average cost of production of European raw beetroot sugar, basis 88 per cent., f.o.b. Hamburg, is between 9s, and 10s. per cwt.

The price from September, 1903, to July, 1904, was below cost of production. A failure of the crop in 1904 caused a deficiency of $1,200,000$ tons in the supply of sugar, and prices consequently rose. The 1905 crop was a heavy one, and prices fell from 16s. in January, 1905, to 11s. in July and 8s. 9d. in August-once more below the cost of production. In 1906 prices were below 9s., and for many months far below cost of production. During 1907 prices ranged between 8s. and 10s. In 1908 they ranged between 9s. 6d. and 11s. 3d. The crop of 1909 was a poor one, and prices rose till August, 1910, when they began to fall down to 8s. 9d. in October, remaining below 10s. till March, 1911, when fears of another bad crop, which eventually showed a deficiency of $1,800,000$ tons, caused an inevitable and very serious rise. In 1912, prices fell to 9s. and in 1913 below 9s., and ranged between 9s. and $10 \mathrm{~s}$. until the war came.

This is a reply to those who try to make people believe, and to those who so readily do believe, that prices have been high owing to the abolition of the bounties. They can now see that during the period 1903-14 prices were generally below or round about the cost of production. They can also see that, consumers, having been compelled by the action of the bounties to be dependent on the bounty-fed area of Europe for their supplies, have to endure high prices whenever there is a deficient beetroot crop. The high prices are, therefore, caused by the bounties, not by their abolition. 


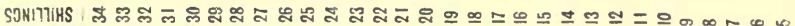

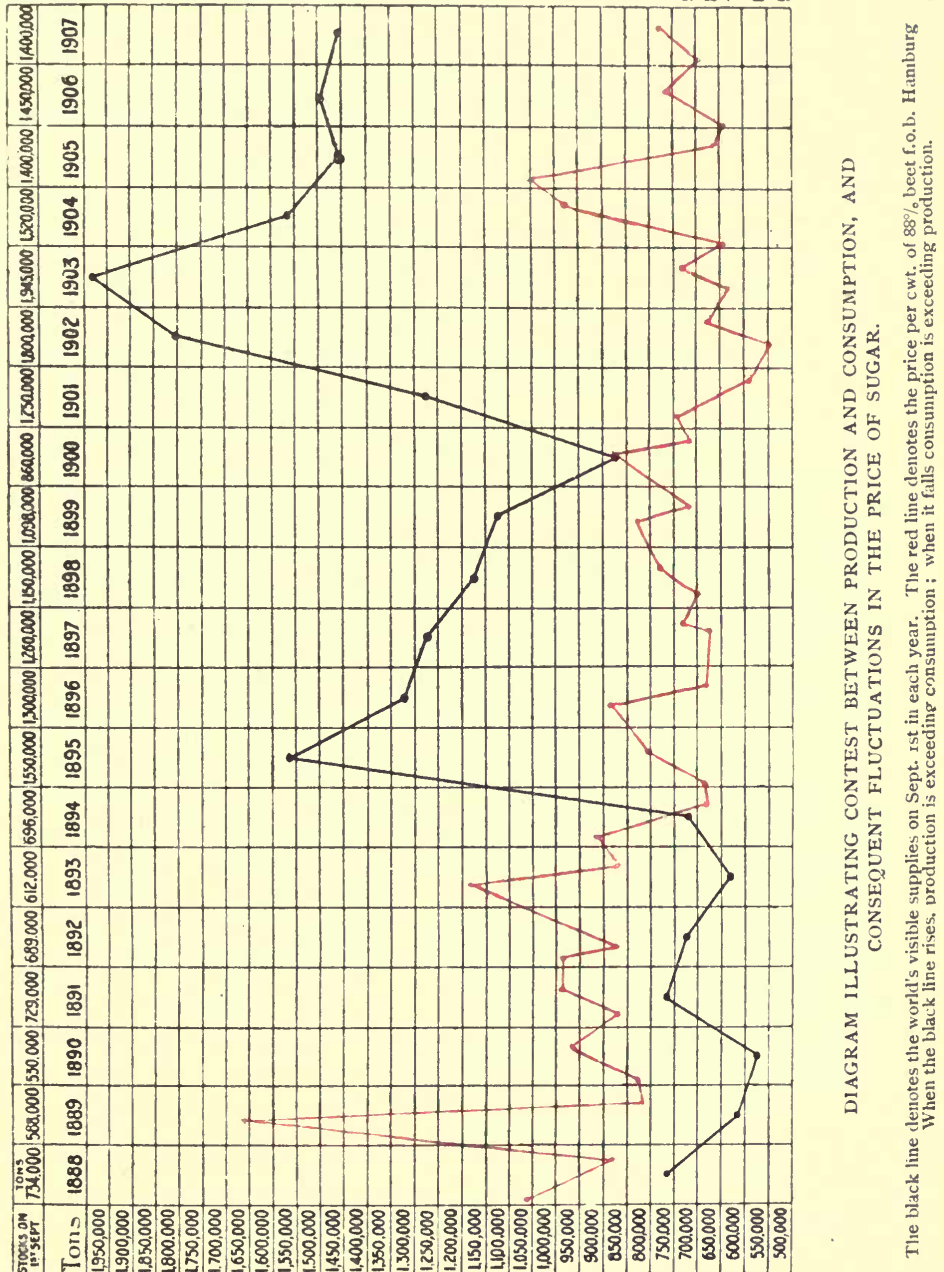

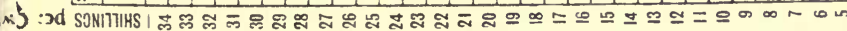




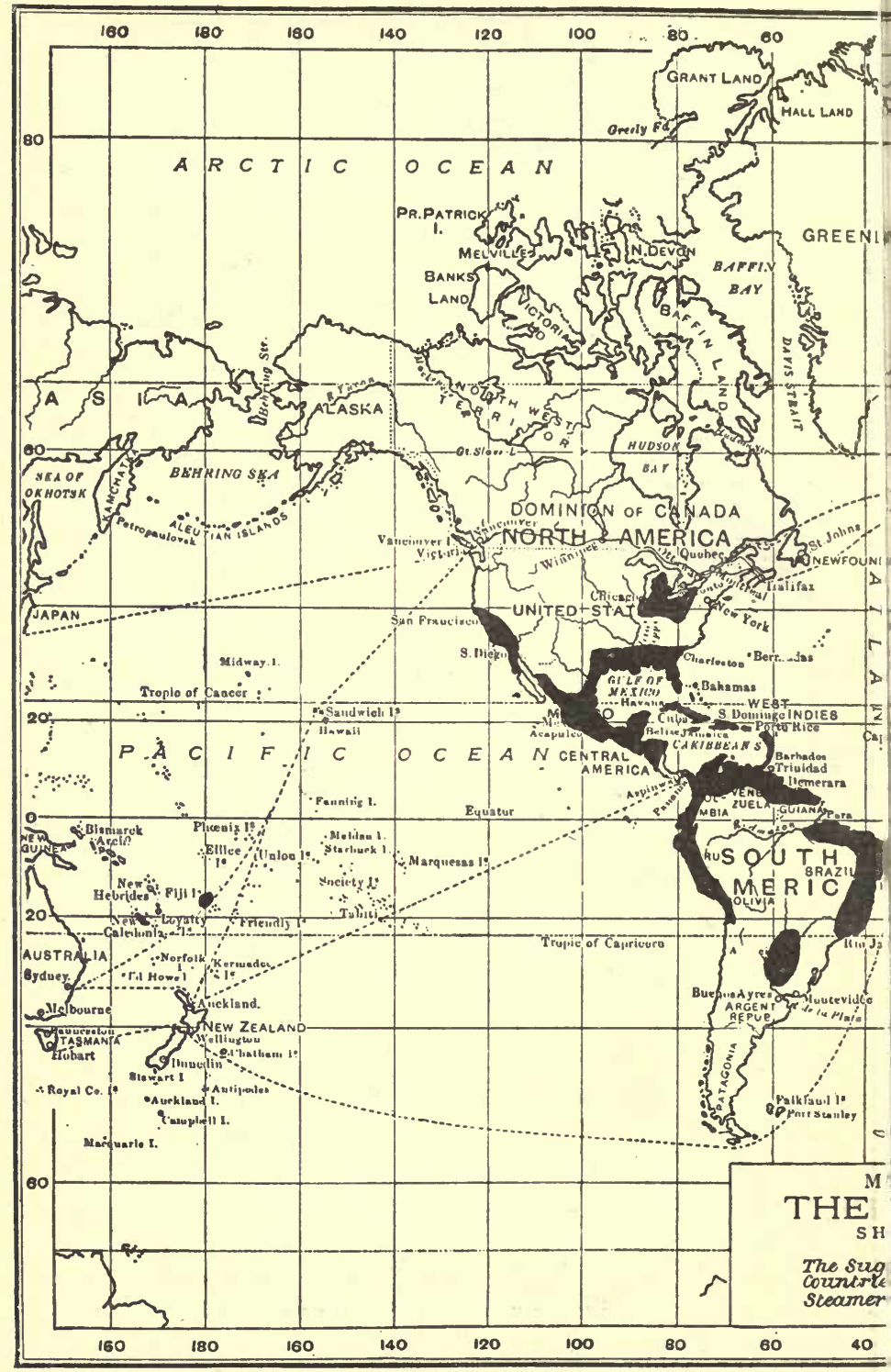





\section{INDEX}

American prices, 24

Refining Co., 118

Sugar, South, 24

Antiguan Sugar, 94

Archard, Francis Karl, 104

Argentine Sugar, 24, 98

Aspinall pan, The, 65

Australian Sugar, 25, 101

Avebury, Lord, 127

Barbados, 94

Beet, 17

\section{Analysis, 48}

Sowing of, 22 ; in Germany, 21, 24 ; Russia, 24 ; pits, 22 ; pulp, 47

Beet-sugar, discovery of, 104; history of industry in France and Germany, 104; in Austria, 109; in Russia, 110 ; Exports from Austria, France and Germany, 108 ; Cost of production in Germany and Russia, 110 ; European statistics, 112 ; in U.S.A., 115 ; fall of prices, 138 ; future of, 139

Berbice, 66

Boivin, 82

Bounties abolished, 131

Brazilian Sugar, 96

"Brewers' Sugar," 35

Bristol, 8

British Guiana Sugar, 25, 94
British Refining and Colonial Sugar Production, Select Committee on, 118 94 West Indian Sugar, 4,

Brown Sugar, 4 [127-9

Brussels Convention, The,

CANAdA, 115

Cane crops, dates of, 25 ; statistics of, 89

Cane-crushing, 26-37

"Carbo-hydrates," 35

Cartel, The German, 128 ; the Austrian, 130

Cartels abolished, 130

Centrifugal machine, The, 71

Chinese Sugar, 17

Clarification, 56-62

"Climax," 78

Colloids, 40

"Compensator," The, 32

Convention, The, 130-4, 143

"Copper Wall," The, 51

Congress of the Chamber of Commerce of the Empire, The, 127

Crushed Sugar :-White, 4 ; yellow, 4

"Crystallization in Motion,"

Crystalloids, 40

Crystals, White, 72

Cuban Sugar, 17, 24, 25, 69, 92,98

Cube Sugar, 86

Demerara Sugar, 48, 54, 69, 75 
Dextrose, 34

Diffusion Process, The, 39$47 ; 49$

Dominion Sugar Company, 116

Dubrunfaut, 77

Duncan, Mr. James, 10, 82

Egyptian Sugar, 25

Elsdorf, 88

Export Figures, 125

FIJI, 25

"First Products," 72, 75

Formosan Sugar, 14, 17, 25

Fructose, 78

Fryer, Alfred, 64; his Concretor, 64

Geerligs, Dr. Prinsen, 36, 75, 99

Glasgow refineries, 6

Glucose, 36, 76, 78

Golden Syrup. See Syrup

Granulated Crystals, 72

Greenock, 6; Sugar Exchange, The, 138

Green Syrup. See Syrup

"Gur," 50

Haiti Sugar, 94

Havana ", 4

Hawaian ", 91, 98

Horsin-Déon, 48

Hughes, 78

IMPORTATION Figures, 2

Indian Sugar, 25, 98, 137

Jamaica Sugar, 4, 48, 75, 94 Japan, 18

Java Sugar, 20, 25, 48, $61,69,72,91,94,98,142$ Jelinek, 58

LANGEN, Eugen, 62, 88

Levulose, 34
Lippmann, Prof., Dr.E.O., 142

Liverpool, 8

Loiseau, 59, 82

London Beetroot Sugar Association, The, 140

Louisiana Sugar, 17, 25, 90, 98, 109

Lubbock, Sir Nevile, 127

Maple Sugar, 137

Margraaf, 104

Mauritius Sugar, 4, 25, 101-3

Megass, 27-30 ; 47

Mexican Sugar, 25, 96

Minchin, Mr. 46

Mincing Lane Sugar Market, 137-40; how changed since 1860,141

"Molascuit," 78

Molasses, 47, 48, 75, 77, 78

"Molassine Meal," 78

Muscovado Sugar, 4, 20, 54

New South Wales, 101

“PAlmyra Jaggery," 137

Périer, 58

Peruvian Sugar, 69, 96

Philippines ", The, 17, 25, 100

Plant-cane crop, The, 18

Polariscope, The, 31

Porto Rican Sugar, 17, 91

Possoz, 58

QueEnsland Sugar, 101

Ratoon Crops, The, 20

Réunion, 95

Refineries:-East End, 4 ; at Greenock, 6 ; Leith, 6 See also Sugar Refining

"Reducing Sugars," 34, 35 Rillieux the Inventor, 67 Robert, Julius, 39

Rum, 75 
SACHS, M. François, 144

S. Domingo Sugar, 69, 95

S. Lucia Sugar, 94

Sandwich Islands Sugar, 17, 21, 92

Seedling Canes, 21

"Sereh" disease, The, 99

Spanish Sugar, 99

Steffen, the Inventor, 47

Sucrose, 35, 36, 77, 78

Sugar:-Consumption of, 3 ; Crystallizable, $\quad 31-4$; Houses, 3 ; " invert," 34 , $37,48,86$; percentages, cane and beet, 76 ; Uncrystallizable, 31,34

cane:-Analysed, 36 ; crops, 24 ; fibres, flower, growth, juice, leaves, 16 ; planted, 14 ; ripening, 16 - Duties, International Conference on, 117; in Brussels, 120, 142 ; Paris, 120 ; London, 120 Factories, control of, 78
Sugar, Refining, 3; in Bristol, 8,12 ; Lancs, 12 ; Liverpool, 7 ; London, 10 ; Manchester, 9; Scotland, $6,7,12$; Chapter on, 80-88 Surtax, Limitation of, 128 Sutherland, Sir Thomas, 127 Syrup, 76

_ Golden, 8, 35, 86 Green, 87

TAte, Sir Henry, 10, 82

Texas, 24

Treacle, 4

Trinidad, 66, 93, 98

Triple-effet, The, 67-9

Vacuum Pan, The, 51, 66, 70

WEST Indian Sugar, 3, 20, 25 , 51,69

West Indies, French, 95

Wetzel Pan, The, 65

Wiley, Dr., 115

“Yellow Crystals," 55

THE END

Printed by Sir Isaac Pitman \& Sons, Ltd., Bath, England.

$\mathrm{T}$-( $\left.\mathrm{I}_{4} 63\right)$ 





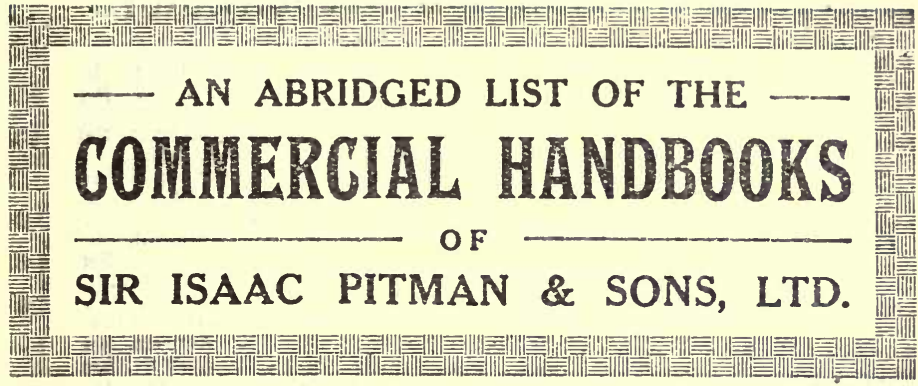

LONDON : 1 AMEN CORNER, E.C.4

BATE : Phonetic Institute. NEW YORK: 2 West 45 th St. IIEHBOURNE: The Rialto, Collins St.

The Prices contained in this Catalogue $::$ apply only to the British Isles :: TERMS-

Cash MUST be sent with the order, AND MUST INCLUDE AN APPROXIMATE AMOUNT FOR THE POSTAGE. When a remittance is in excess of the sum required, the surplus will be returned. Sums under $6 \mathrm{~d}$. can be sent in stamps. For sums of $6 \mathrm{~d}$. and upwards Postal Orders or Money Orders are preferred to stainps, and should be crossed and made payable to Sir IsaAc Pitman \& Sons, LtD.

Rernitances from abroad should be by means of Intcrnational Money Orders in Foreign Courities, and by British Postal Orders within the British Overseas Dominions. Colonial Postal Orders are not negotiable in England. Foreign stamps CANNOT BE ACCEPTED.

\section{ARITHMETIC}

FIRST STEPS IN COMMERCIAL ARITHMLTIC. BY ARTHUR E. Williams, M.A., B.Sc. In crown $8 v 0$, limp cloth, $80 \mathrm{pp}$. . . . . . . THE ELEMENTS OF COMMERCLAL ARITHMETIC. BY "THOMAS BROWN. In crown $8 \mathrm{vo}$, cloth, $140 \mathrm{pp}$. . . . . . . . . Net BUSINESS ARITHMETIC. Part I. In crown $8 \dot{v}^{\circ}$, cloth, i2o pp. 1 i . Answers

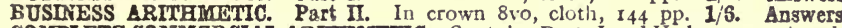
COMPLETE COMHERCIAL ARITHMETIC. Contains Parts I and II above mentioned. In crown 8vo, cloth, $264 \mathrm{pp}$. $.0 .62 / 6$. Answers SMAILER COMURRCIAL ARITHMETIC. By C. W. CRook, B.A., B.Sc. In crown 8yo, cloth $1 / 3$ net. Answers Net FIRST STEPS IN WORESHOP ARTTHMETIC. By H. P. GREEN. In crown 8vo. limp cloth, about $80 \mathrm{pp}$. . . . . . . . Net COMPLETE MERCANTIL ARITHMETIC. 'With Elementary Mensuration. By H. P. GreEN, F.C.Sp.T. In crown 8vo, cloth gilt, with Key, 646 pp. . Net Complete book without Key, 600 pp., $4 /-$ net. Key separately, $1 /-$ net. Also in three parts. Part I, 300 pp., 2/6 net. Part II, 208 pp., $1 / 6$ net. Part III, 100 pp. 1/- net.

COUNTING HOUSE MATHEMATICS. BY H. W. YORRITT and W. NiCKLIN, A.S.A.A. In crown 8vo, cloth, $120 \mathrm{pp}$. Net

ARITHMONTIC AND BOOK-KEEPING. By THOS. BROWN, F.S.S., and VinCENT E. Collinge, A.C.I.S. In two parts. Part I, I 24 pp. Part 2, II5 pp. Each in crown 8vo, cloth . . . . . Net

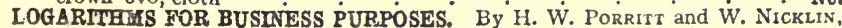
A.S.A.A. In crown 8vo, limp cloth RAPID METHODS IN ARITHMETIC. By JoHN JoHnston. Revised and Edited by G. K. BuckNall, A.C.I.S. (Hons.). New and En!arged Edition. In foolscap $8 \mathrm{vo}$, cloth, $96 \mathrm{po}$. . . . . Net EXERCISES IN RAPD VIETHODS IN ARITHMETIC. By JOHN JOHNSTON. In crown 8vo, cloth . . . . . . . Net METHOD IN ARITRMETIC. A guide to the teachins of Arithmetic. By G. R. F'URDIE, B.A. In crown $8 \mathrm{vo}$, cloth, $87 \mathrm{pp.}$. . . Not 


\section{BO0K=KEEPING AND ACCOUNTANCY}

FIRST STEPS IN BOOK-KEEPING. By W. A. HATCHARD, A.C.P., F.B.T. In crown1 8vo, limp cloth, $80 \mathrm{pp}$. . . . . . . . . Net

PRIMER OF BOOK-KEEPING. Thoroughly prepares the student for the study of more elaborate treatises. In crown 8vo, cloth, I44 pp. . 1/3. Answers, Net

EASY EXERCISES FOR PRIMER OF BOOK-KGIGPMG. In crown $8 \mathrm{vo}, 4^{8} \mathrm{pp}$.
BOOK-KEEPING FOR BEGINNERS. A first course in the art of up-to-date Bookkeeping. With Answers to the Exercises. By W. E. Hooper, A.C.I.S In

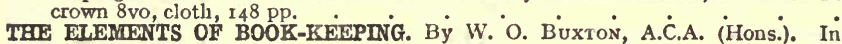
crown 8vo, cl oth, 157 po. . . . . . . . . Net

BOOK-KEEPING $\triangle N D$ COMMERCIAL PRACTICE. By H. H. SMITH, F.C.T., F.Inc.S.T. In crown $8 \mathrm{vo}$, cloth, $152 \mathrm{pp}$.

BOOK-KEEPING SIMPLIFIED. Thoroughly revised edition. By W. O. Buxton, A.C.A. (Hons.). In crown 8vo, cloth, 304 pp. . $2 / 6$. Answers, Net

ADVANCED BOOK-KEEPING. In crown 8vo, cloth, 187 pp. 2/6. Answers, Net

BIGHER BOOK-KKEPING AND ACCOUNTS. By H. W. PORRITT and W. NICKLIN, A.S.A.A. In crown $8 \mathrm{vo}$, cloth, 304 pp., with many up-to-date forms and facsimile documents

FULL COURSE IN BOOK-KंEEPING. By H. W. PorRirt and W. NickLIN, A.S.A.A. This volume consists of the popular text-book Higher Book-keeping and Accounts, to which has been prefixed a section on elementary Book-keeping. In crown 8vo, cloth gilt, $540 \mathrm{pp}$. . . . . . . . . Net

COMPLETE BOOK-KEEPING. A thoroughly comprehensive text-book, dealing with all departments of the subject. In crown 8vo, cloth, 424 pp. 3/6 net. Answers, Net

ADVANCED ACCOUNTS. A Practical Manual for the Advanced Student and Teacher. Edited by Roger N. CARTER, M.Com., F.C.A. In demy $8 \mathrm{vo}$, cloth gilt, $988 \mathrm{pp}$., with many forms and facsimile documents . . . . Net

DICTIONARY OF BOOK-KEEPING. A Practical Guide and Book of Reference for Teachers, Students and Practitioners. By R. J. Porters. In demy 8 vo, cloth gilt, with facsimiles, 780 pp. . . . . . Net

BOOK-KENPING FOR RETAILERS. By H. W. PिoriT and W. NickLiN, A.S.A.A. In crown $8 \mathrm{vo}$, cloth, $124 \mathrm{pp}$.

ADDITIONAL EXERCISES IN BCOK-KEEPING, NOS. I 'd II. New Editions. In crown $8 \mathrm{vo}, 56 \mathrm{pp}$. BOOK-KKEEPING TEST CARDS. Elem. and Inter. Per $\mathrm{s} i$. Net BUSINESS BOOK-KEEPING TRSNSACTIONS. No. I, 1/- net; No. II, $2 /$ - net.

EXAMINATION NOTES ON BOOK-KEEPIYG AND ACCOUNTANCY. BY J. BLAKE HARROLD, A.C.I.S., F.C.R.A. Cloth, $6 \frac{1}{2}$ in. by $3 \frac{1}{2}$ in., 56 pp. . . Net HOW TO POST THE LEDGER (BOOK-KEEPING DIAGRAMS). By J AMES MCKEE. In crown 8vo, $35 \mathrm{pp}$. . . . . . . . . . Net

HOTEL BOOK-KEEPING. With illustrative forms and exercices. In crown $8 \mathrm{vo}$,

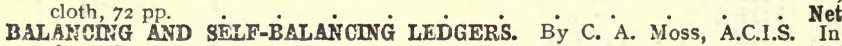
demy 8 vo, $24 \mathrm{pp}$.

BDOK-KMEPING AND ACCOUNTANCY PROBLEMS. By G. johnson, F.C.I.S. In crowil 8vo, cloth gilt, II2 pp. . . . . . Net

HOW TO TEACF BCOK-KEEPING. By H. W. PORRITT and W. NirkLiN, A.S.A.A. In crown 8vo, cloth, $180 \mathrm{pp}$.

COMBINED MANUSCRIPT BOOK FOR BOOK-KEEPING. In crown 4 to, stiff paper wrapper, $96 \mathrm{pp}$.

IDEAL ITANUSCRIPT BOOKS FOR BCOKK-KEEPING. Specially ruled and adapted for working the exercises contained in the Primer of Book-keeping. The sets consist of : Cash Book; Purchase Book; Sales Book and Journal; Ledger. Each

AVON EXFRCISE BOOKS FOR BOOK-KEUPING. Specially adapted for the exercises in Book-keeping Simplified or Advanced Book-keeping. Foolscap folio. Journal, 5d.; Cash Book, 5d.; Ledger

DOUBLE FNTRY IN ONE LESSON. BY R. FLEMING, A.C.I.S.

EXAMTIETION NOTES ON MUNICIPAL ACCOUNTANCY. By W. G. DAVIS, A.S.A.A. Size $6 \frac{1}{2}$ in. by $3 \frac{1}{2}$ in., cloth, 56 pp. . . . Net

BALANCE SHEETS : HOW TO READ AND UNDERSTAND THEM. By PHILIP TovEY, F.C.I.S. In foolscap $8 \mathrm{vo}$, cloth, 85 pp., with 26 inset Balance Sheets Net

HOW TO BECCME A QUALIFIED ACCOUNTANT. By R. A. WITTY, A.S.A.A. Second Edition. In crowli $8 \mathrm{vo}$, cloth, $120 \mathrm{pp}$. . . . . . Net

ACCOUNTANCY. By F. W. Pixley, F.C.A., Barrister-at-Law. In demy $8 \mathrm{vo}$, cloth, $318 \mathrm{pp}$. • • • • • • • • Net

AUDITING, ACCOUN'TNG AND BANKING. By FraNk Dó vLer, A.C.A., and $E$. Mardinor Harris, A.I.B. In demy $8 \mathrm{vo}$, cloth gilt, $328 \mathrm{pp}$. . . Not

8d.

$1 / 3$

bil.

$1 / 3$

1/3

1/8

1/-

1/-

$2 / 6$

3/6

$2 / 6$

6/-

6/-

$1 / 3$

$6 d$.

$1 / 6$

1/-

6 .

2/6

$6 d$.

2/-

$2 / 8$

1-

$4 d$.

$7 d$.

6d.

1/-

$1 / 6$

2/-

5!- 
MANUFACTURING BOOK-KCOEPING AND COSTS. By G. JoHNSON, F.C.I.S. In demy 8 vo, cloth gilt, I $20 \mathrm{pp}$. DEPRECIATION AND WASTING ASSETS, and their Treatment in Computing Annnal Profit and Loss. By P. D. LeAKE, F.C.A. In demy 8vo, cloth gilt, $257 \mathrm{pp}$. Net PRACTICAL BOOK-KAFEPING. By the same Author. In demy $8 \mathrm{vo}$, cloth, $420 \mathrm{pp}$.

IHE PRINCIPLES OF AUDITING. By F. R. M. DE PAula, F.C.A. In demy Nev, cloth gilt, $224 \mathrm{pp}$. COST ACCOUNTS IN PRINCIPLE AND PRACTICE. By A. Clifford RIDGWay, A.C.A. In demy $8 \mathrm{vo}$, cloth gilt, I20 pp. . Net

GOLD MINE ACCOUNTS AND COSTING. A Practical Hanual for Oficials, Accountants, Book-keepers, Etc. By G. W. TAIT. In demy 8vo, cloth gilt, $93 \mathrm{pp} . \quad \cdot \quad \cdot 0^{\circ} \cdot \cdot^{\circ} \cdot$ Net INCOME TAZ ACCOUNTS AND HOW TO PREPARE THEM. (See p. 8.)

COMPANY ACCOUNTS. A complete, practical Manual for the use of officials in Limited Companies and advanced students. By ArTHur Coles, F.C.I.S. In demy 8vo, cloth gilt, $320 \mathrm{pp}$.

THE ACCOUNTS OF EXECUTORS, ADMONISTRATORS AND TRUSTEES. BY William B. Phillips, A.C.A. (Hons. Inter. and Final), A.C.I.S. In deriy $8 \mathrm{vo}$, cloth gilt, $152 \mathrm{pp}$. Net

RAILWAY ACCOUNTS AND FINANCE. The Railway Companies (Accounts and Returns) Act, rgri. By AlLEN E. Newhook, A.K.C. In demy 8vo, cloth gilt,

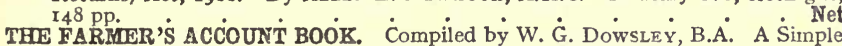
and concise System of Account Keeping specially adapted to the requirements of Farmers. Size, $15 \frac{1}{2}$ in. by $9 \frac{1}{2}$ in., half leather, I06 pp., with interleaved blotting paper . . . . . . Net

THE PERSONAL ACCOUNT BOOK. By the same Author." Size, $15 \frac{1}{2}$ in. by $9 \frac{1}{2}$ in., half leather, ro6 pp., with interleaved blotting paper . . . Net

\section{BUSINESS TRAINING, COPY BOOKS, ETC.}

COMMERCLAL READER (Junior Book). Our Food Supplies. By F. W. Chambers.

With over 70 illustrations, $240 \mathrm{pp}$.
COMMERCIAL READER (Intermediate Book). Our Manufacturing Industries. In crown $8 \mathrm{vo}$, cloth, $240 \mathrm{pp}$. Over I 50 illustrations

COMMERCIAL READER (Senior Book). An introduction to Modern Commerce. Contains over 160 black and white illustrations. In crown $8 \mathrm{vo}$, cloth, $272 \mathrm{pp}$. .

OFFICE ROUTINE FOR BOYS AND GIRLS. In three stages. Each in crown 8vo, $64 \mathrm{pp}$.

FIRST STEPS IN BUSANESS TRAINING. ỉy V. E. Collinge, A.C.I.S. In crown $8 \mathrm{vo}$, limp cloth, $80 \mathrm{pp}$. Net

COUNTING-HOUSE ROUIINE. 1st Year's Courss. By Vincent E. Collinge, A.C.I.S. In crown $8 \mathrm{vo}$, cloth, with illustrations, maps, and facsimile commercial forms, I62 pp. • • . . . Net

COUNTING-HOUSE ROUTINE. 2nd Year's Course. By Vincent E. Colinge, A.C.I.S. In crown $8 \mathrm{vo}$, cloth, with illustrations, maps and facsinnile commercial forms, $188 \mathrm{pp}$. . . . . . . Net

THE PRINCLPLES OF́ BUSLNEŚS. By JAmes Śtephenson, M.A., M.Com., B.Sc. Part r. In crown 8vo, cloth, 217 pp. . . . . . . Net Part 2. In crown 8vo, cloth, $320 \mathrm{pp}$. $\quad . \quad+\quad \cdot \quad \cdot \quad \cdot \quad$ Net

MANUAL OF BUSINESS TRAINING. Contains 66 maps and facsimiles. Eighth Edition, thoroughly revised and considerably enlarged. In crown $8 \mathrm{vo}$, cloth,

TRE PRINCIPLES AND PRACTXCE OF COMMERCE. BY J AMES STEPHENSON, M.A., M.Com., B.Sc. In demy $8 \mathrm{vo}$, cloth gilt, $64^{3}$ pp., with many illustrations, diagrams, etc.

COMMERCIAL PRACTICE. By ALERED ScHofleld. In crown $\dot{8}$ vo, cloth, $296 \mathrm{pp}$. . . . . . . Net

THE THEORY AND PRACTICE OF COMMERCE. Being a Complete Guide to Methods and Machinery of Business. Edited by I. HEELIS, F.C.1.S., Assisted by Specialist Contributors. In demy $8 \mathrm{vo}$, cloth gilt, $620 \mathrm{pp}$., with many facsimile forms Also in 2 vols., each : Net

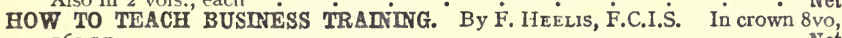
I $60 \mathrm{pp}$. Nat QUESTIONS IN BUSINESS TRAinnig. By $\dot{\mathrm{F}}$. HeElis, F.C.I.S. In crown 8 vo, cloth, I08 pp. . . . . . Pet

ANSWERS TO QUESTIONS IN BUSINESS TRAINInG. By the same Author. In crown 8 vo, cloth, about I6o pp. . . . . . . Net

A COURSE IN BUSINJSS TRALNING. ByंG. K. BúckNall, A.C.I.S. In crown 8vo, I92 pp. 
QUESTIONS AND ANSWERS IN BUSINESS TRAINIFG. By the same Author. In crown 8vo, cloth, $269 \mathrm{pp}$.

FACSIMUE COMMTERCLAL FORMS. New, Revised, and Enlarged Edition. Thirty* five separate forms in envelope . . . . . . . . Net Forms separately, per doz. - • . . Net

EXERCISE BOOK OF FACSIMUIE COMMRERCIAL FORMS. In large post 4 to, 32 pp.

FACSIMUE COMPANY FORMS. Thirty-four separate forms in envelope ? Net Forms separately, per doz.

COMMERCLA, COPY AND EXERCISE BOOKS. In foolscap folio, 32 pp. $\begin{array}{r}\text { Each } \\ \text { "NEW ERA " BUSINESS COPY BOOKS. By F. HEELIS, F.C.I.S. Civil Service }\end{array}$ Style. In three books, Junior, Intermediate, and Senior. Each in stout paper covers, large post 4 to, $32 \mathrm{pp}$.

BUSINESS TRADNING EXERCISE BOOK. Part 1 . By Jimes E. Sladen, M.A. (Oxon.), F.I.S.A. In large post 4 to, 64 pp. . . . Net

MANUSCRIPT LETTERS AND EXERCISES. In envelope. : : : : Net

OFFICE ROUTINE COPY BOOKS, Nos. 1, 2, ani 3. Each in large post 4 to, $24 \mathrm{pp}$.

COMMERCIAL HANDWRITING AND CORRESPONDENCE. In foolscap 4to,

BUSINESS HANDWRIIING. Seventh Edition, Revised. In crown $8 \mathrm{vo}$, cloth,

HOW TO WRITE $\triangle$ GOOD HAND. By B. T. B. Hollings. In crown 8 vo, oblong, 56 pp. F.C.1.S., etc. In crown $8 \mathrm{vo}$, cloth gilt, $200 \mathrm{pp}$. Net

THE BUSINESS GIRL'S HANDBOOK. BY C. CHISHOLM, M.A., and D. W. WALTON. Foreword by SARAH BERNHARDT. In crown 8vo, cloth, I76 pp.

THE BOY'S BOOK OF BUSINESS. By the same Authors. Foreword by Lieut.Gen. Sir R.S. S. BADEN-POWELL. In crown $8 \mathrm{vo}$, cloth, $176 \mathrm{pp}$. Net

BUSDNESS METHODS AND SECRETARIAL WORK FOR GIRLS AND WOMEN. By HELEN REYNARD, M.A., In crown 8 vo, cloth, 96 pp. . . Net

THE JUNIOR WOMAN SECRETARY. By ANNIn E. DAvis, F.Inc.S.T. In crown $8 \mathrm{vo}$, clnth, 100 pp., with illustrations

CLERKS: THEIR RIGETS AND OBLIGATIONS. By ĖWARD A. COPE. In foolscap $\delta$ vo, cloth, $160 \mathrm{pp}$. . Net

GUIDE TO BUSLESS CUSTOMS AND PRACTICE ON THE CONTLENT. BY EmiL Davies. In crown $8 \mathrm{vo}$, cloth, $154 \mathrm{pp}$. Net HOW TO GET $\triangle$ SITUATION ABROAD. By EMIL DAVIES. In crown 8vo, cloth, 70 pp.

HOW TO START IN IIFE. By A. Kingston. A Popular Guide to Commercial, Municipal, Civil Service, and Professional Employment. Deals with over to distinct kinds of Employment. Second Edition. In crown $8 \mathrm{vo}$, cloth, $128 \mathrm{pp}$. Net

GUIDE TO THE MERCANTHE BARINE. BY R. A. FLETCHER. A Guide to all who wish to join it. With illustrations. In crown $8 \mathrm{vo}$, cloth, $132 \mathrm{pp}$.

THE JUNIOR CORPORATION CLERK. BY J. B. CARRINGTON, F.S.A.A. In crown $8 \mathrm{vo}$, cloth gilt, with illustrations, $136 \mathrm{pp}$. . . Net

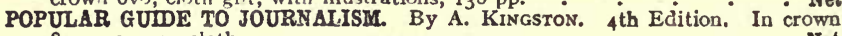

8V, I24 pD., cloth
PRACTICAI JOURNALISH AND NEWSPAPER LAW. By A. BAKER, M.J.I., and E. A. Cope. In crown 8 vo, cloth, 180 pp. . . . . . Net

\section{CIVIL SERVICE}

CIVII SERVICE GUIDE. By A. J. LAwFoRd JONES. In crown $8 \mathrm{vo}$, cloth, $29 \mathrm{pp}$. Net

DIGESTING RETURNS INTO SUMLIARIES. By A. J. LAWFORD JONES, of H.M. Civil Service. In crown 8vo, cloth, $84 \mathrm{pp}$. . . Net COPYING MANUSCRIPT, ORTHOGRAPHY, BANDWRITNG, etc. By the same Author. Actual Examination Papers only. In foolscap folio, $48 \mathrm{pp}$. . Net CIVI. SERVICE HANDWRITING GUIDE AND COPY BOOK. BY H. T. JESSOP, B.Sc. In crown $4^{\text {to },} 32 \mathrm{pp}$. CIVII SERVICE AND COMMERCIAT COPYNGG FORMS. In crowi $8 \mathrm{vo}, 40 \mathrm{pp}$. Net RULAD FORMS FOR USE WITH THE ABOVE. Books I and II. Each foolscap folio, $40 \mathrm{pp}$.

CIVII SERVICE AND' CONMERCIAL LONGं AND' CROSS TOTS. 'Two Series, each in crown $8 \mathrm{vo}, 4^{8} \mathrm{pp}$.

CIVI SERVICE ARITHMDITC TESTS. By P. J. VARLEY-TIPTON. In crown 8vo, cloth, $102 \mathrm{pp}$.

CIVIL SERVICE ESSAY RiRITING. By W. J. AdDis, M.A. In crown 8vo, limp cloth, ro8 pp. Net STUDIES IN ESSAY WRITING. By V.P. Pracock. In crown $8 v 0,64 \mathrm{pp}$. Paper Net 
CIVII SERVICE PRACIICE IN PRECIS WRITNG. Edited by ARTHUR REYNOLDS, M.A. (Oxon.). In crown 8vo, cloth, 240 pp. . . . . . . Net ELEMENTARY PRECIS WRITLG. BY WALTER SHAWCROSS, B.A. In crown 8vo, cloth, $80 \mathrm{pp}$. . . . . . . . . Net GUDE TO LNDEXING AND PRECIS WRITLA. By W. J. WLSTON, M.A., B.Sc. (Lond.), and E. BowkER. In crown Svo, cloth, rio pp. . . . Net

ITDEXTNG AND PRECIS WRITING. BY A. J. LAWFORD JONES. In crown 8vo, cloth, 144 pp. . . . . Net

EXERCISES AND ANSWERS IN INDEXUNG AND PRECIS WRITING. By W. J. Weston, M.A., B.Sc. (Lond.). In crown 8vo, cloth, $144 \mathrm{pp}$. . . Net

\section{ENGLISH AND COMMERCIAL CORRESPONDENCE}

FIRST STEPS IN COMOTERCIAL ENGLISH. By W. J. WeSTON, M.A., B.Sc. (Lond.). In crown 8vo, limp cloth, $80 \mathrm{pp}$. . . . . . Net

FIRST STEPS IN BUSDVESS LETIER WRITING. By FRED HALL, M.A., B.Com., F.C.I.S., etc. In crown $8 \mathrm{vo}$, limp cloth, $80 \mathrm{pp}$. . . . Net GUIDE TO COMMRRCIAL CORRESPONDENCE AND BUSINESS CONIPOSITION. By W. J. Weston, M.A., B.Sc. (Lond.). In crown 8vo, cloth, 146 pp., with many facsimile commercial documents.

MANUAL OF COMDERCLAL ENGLISH. By WALter Shawcross, B.A. Including Composition and Précis Writing. In crown 8vo, cloth gilt, $234 \mathrm{pp}$. . . Net

HOW TO TEACH COMMERCIAL ENGLISH. By WALIER SHAwCross, B.A. In crown 8vo, cloth gilt, 160 pp. . . . . . . Net COMMISRCIAL CORBESPONDENCE AND COMMERCLSL ENGLISE. In crown 8vo, cloth, 272 pp.

ENGLISH MERCANTILE CORRESPONDarice. in crown 8 vo, cloth gilt, 260 pp.

EIRST STEPS IN BUSINESS CONPOSITON. Edited by R. W. HollaNd, M.A., M.Sc., LL.D. In crown 8 vo, limp cloth, $80 \mathrm{pp}$. . . . Net ENGLISE COMPOSITION AND CORRESPONDENCE. By J. F. DAVIs, D.Lit., M.A., LL.B. (Lond.). In crown 8vo, cloth, ris pp. . . . . . . Net

A GUIDE TO ENGLISE COMPOSITION. By the Rev. J. H. BAcoN. II2 pp. Paper

ENGISH GRAMmAR New Edition, Revised and Enlarged by C D. PuNchoth 9d. 81. B.A. (Lond.). In crown 8vo, cloth, $\mathrm{r}_{4} 2 \mathrm{pp}$. Net

ENGLISE GRAMIAR AND COMPOSIIION. By W. J. 'WEsTon, M.A., B.Sc. (Lond.). In crown 8vo, cloth, $320 \mathrm{pp}$. . . . Net

SETF-HWIP EXERCISES IN ENGLISH (Reform Method). In crown 8vo, cloth, $80 \mathrm{pp}$. $\quad$ Net

NOTES OF LESSONS ON ENGLISR. 'In cromn $8 \mathrm{vo}$, cloth, $208 \mathrm{pp} . \quad$. $\quad$ - Not

PUNCTUATION CBART. Size $7 \frac{1}{2}$ in. by $9 t$ in., mounted on card eyeletted and

PUNCTUAMON AS A MEANS OF EXPRÉSSION. By A. E. Loveli, M. $\dot{A}$. In crown $8 \mathrm{vo}$, cloth, $80 \mathrm{pp}$.

$\left.\begin{array}{l}\text { PRECIS WRITING } \\ \text { ESSAY WRITING }\end{array}\right\}$ (See CIVIL SERVICE, page 4 and above.)

STUDIES IN FLOCUION. By E. M. CoRbould (Mrs. Mark Robinson). With over roo selections for Reciters and Readers. In crown 8 vo, cloth gilt, 270 pp Net POCKET DICTIONARY. Royal $32 \mathrm{mo}, 5$ in. by 3 in., cloth gilt, 362 pp. . . Net COMMIERCIAL DICTIONARY. In foolscap 8vo, paper boards, r92 pp. . - Net BCOK OF HOHONYMS. With copious Exercises on Homogeneous, and Homophonous Words and chapters on Compound Hyphenated Words, etc. By B. S. BARRETT. In crown 8 vo, cloth, 203 pp.

\section{COMMERCIAL GEOGRAPHY}

FIRST STEPS IN COMMERCIAL GEOGRAPHY. By James Stephenson, M.A., B.Com. There are 16 maps and diagrams included. In crown $8 \mathrm{vo}$, limp cloth, $80 \mathrm{pp}$.

THE WORLD AND TrS COMMERCE. In crown 8 vo, cloth, $128 \mathrm{pp}$. , with 34 maps.

THE BLEMENTS OF COMMERCIAL GEOGRAPHY. By C. H. GRANT, M.Sc., F.R.Met.Soc. In crown 8 vo, cloth, $140 \mathrm{pp}$. Net

COHMERCIAL GEOGRAPHY OF THE BRITISH ISLES. In crown $8 \mathrm{vo,} \mathrm{cloth,}$ r 50 pp., with 34 coloured maps and plates, three black and white maps, and

COMPIERCLAL GEOGRAPBY OF THE 'BRITISH ERPIRE ABROAD AND FOREIGN COUNTRIES. In crown 8 vo, cloth, 205 pp., with 35 coloured maps and plates, II black and white maps, and end-paper maps 
COMMERCHAL GEOGRAPEY OF THE WORID. In crown $8 \mathrm{vo}$, cloth, 350 pp., with about 90 maps and plates

EXAMTNATION NOTES ON COMMERCIAL GEOGRAPHY. By W. P. RUTTER, M.Com. Size $6 \frac{1}{2}$ in. by $3 \frac{1}{2}$ in., cloth, $120 \mathrm{pp}$. . . Net COMMERCIAL ATMAS. In crown 4 to, cloth, i 28 pp., $58^{\circ}$ maps and explanatory

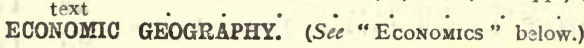

\section{COMMERCIAL HISTORY}

THE ELEMFNTS OF COMMERCIAI HISTORY. By FRED HALL, M.A., B.Com., F.C.I.S. In crown 8vo, cloth, I64 pp. . . . . . . . Net COMMERCLAL HISTORY. By J. R. V. MI gilt, $272 \mathrm{pp}$.

INDỨSTRIAT AND SOCIAL HISTORY். By Grorge Collar, B.A., B.Ś. (Ĺnd.). In crown $8 v^{\circ}$, cloth, with over roo illustrations, $284 \mathrm{pp} . .$. ... ECONOMIC HISTORY. (See "Economics" below.)

\section{ECONOMICS}

THE ELEMENTS OF POLITCAL ECONOMY. By H. HALl, B.A. In crown 8vo, GUDE TO POLITICAL ECONOMY். By F. $\dot{H}$. SPENCER, D.Sc., LL.B. In crown 8vo, cloth gilt, $232 \mathrm{pp}$. OUTLINES OF THE ECONOMIC HISTORY OF ENGLAND : A Study in Social
Development. By H. O. MEREDITH, M.A., M.Com. In demy $8 \mathrm{vo}$, cloth gilt, Development. By H. O. Meredith, M.A., M.Com. In demy 8vo, cloth gilt, ECONOMIC GEOGRAPHY. By J OHN MCFARLANE, M.A., $\dot{M}$. Com. In demy 8 vo, cloth gilt, 568 pp., I8 illustrations. Net THE HISTORY AND ECONOMICS OF TRANSPORT. By A. W. KIRKALDY, M.A., B.Litt. (Oxford), M.Com. (Birm.), and A. Dudley Evans. In demy 8vo,
cloth gilt, $350 \mathrm{pp}$.

LABOUR, FINANCE, AND TRE WAR. Being the Results of Inquiries arranged by the Section of Economic Science and Statistics of the British Association for the Advancement of Science, during the years 1915 and 1916. Edited and with a Preface by Adam W. Kirkaldy, M.A., B.Litt. (Oxford), M.Com. (Birm.). In demv 8va, 350 po. . . . . . . . Net

FNANCE AND INDUSTRY; War Expedients and Reconstruction. Edited by ADAM W. KIRKALDY, M.A., B.Litt. In demy 8vo Net

DIUTIONARY OF ECONORIC AND BANKING TERMS. By W. J. WESTON, M.A., B.Sc. (Lond.), and A. CREw, Barrister-at-Law. In crown 8vo, cloth gilt, $150 \mathrm{pp}$.

ECONOMICS FOR BUSTNESS MEN. By W. J. WESTON, M.A., B.Sc. (Lond.). In crown $8 \mathrm{vo}, \mathrm{r} 30 \mathrm{pp}$., cloth THE ECONOMUCS OF TELEGRAPHS AND TELFPHONES. BY JoHN LEE, M.A. In crown $8 \mathrm{vo}$, cloth gilt, $92 \mathrm{pp}$. . . . . . . . Net

\section{BANKING}

THE ELEMENTS OF BANKING. By J. P. GANDY. In crown 8vo, cloth, 140 pp. Net BANK ORGANISATION, HANAGEMENT, BND ACCOUNTS. BY J. F. DAVIS, M.A., D.Lit., LL.B. (Lond.) In demy $8 \mathrm{vo}$, cloth gilt, $\mathrm{r} 65 \mathrm{pp}$., with forms . Net

MONEY, EXCHANGE, AND BANKING. In their Practical, Theoretical, and Legal Aspects. By H. T. EAston, A.I.B. Second Edition, Revised. In demy 8vo, cloth, 3I2 pp. . . . Net

PRACTICAL BANKTNG. By J. F. G. BAgShaw. With Chapters on The Principles of Currency, by C. F. HANNAFORD, A.I.B., and Bank Book-keeping, by W. H. PEARD. In demv $8 \mathrm{vo}$, cloth gilt, about $400 \mathrm{pp}$. Net

BANKERS; SECURITIES AGAINST ADVANCES. By LAWRENCE A. FogG, Cert. A.I.B. In demy 8 vo, cloth gilt, I23 pp. . . . . . Net

DICTIONARY OF BANKING. A Complete Encyclopaedia of Banking Law and Practice. By IV. THomson, Bank Inspector. Recently Revised. In crown 4 to,

FOREIGN EXCHANGE AND FOREIGN BILLS IN THEORY END IN PRACTICE. By W. F. Spalning. Cert. A.I.B. In demv $8 \mathrm{vn}$, chith gilt. $207 \mathrm{np}$. * Net

EASTERN EXCHANGE. By W. F. SPALDING. In demy 8vo, cloth, 375 pp., illustrated cé SHEETS AND ĖOW TO PREPARE THEM. By J. F. G. BAGSH Net. 


\section{INSURANCE}

THE ElementS OF INSURANCE. By J. Alfred Iike. In crown 8 vo, cloth,

Insur pp. for the Student and the Business Matl. With sections on Wurkmen's Compensation Insurance, by W. R. STRoNG, F.I.A., and The National Insurance Scheme, by Vyvyan Mark, F.F.A., F.I.A. Third Edition. Revised and Enlarged. In demy $8 \mathrm{vo}$, cloth gilt, $440 \mathrm{pp}$. . . . . . . Net GUDE TO LIFE ASSURANCE. By S. G. LEIGH, F.I.A. In crown 8 vo, cloth gilt, $192 \mathrm{pp}$. . . . . . . . Net INSURANCE OFFICE ORGANISATION, MANAGENENT, AND ACCOUNTS. BY T. E. Young, B.A., F.R.A.S., and Richard MAsters, A.C.A. Second Edition, Revised. In demy $8 \mathrm{vo}$, cloth gilt, $\mathrm{I}_{4} 6 \mathrm{pp}$. . . . . Net GUDE TO MARINE INSURANCE. By HENRY KeATE. In crown 8vo, cloth gilt,

THE PRINCIPLES OF MARINE LAW. (Sé p. x.

\section{SHIPPING}

SHIPPING. By A. Hall and F. Heywood. In crown 8vo, cloth, $x_{3} 6 \mathrm{pp}$. Net

SHIPPING OFFICE ORGANISATION, MANAGERENT, AND ACCOUNTS. BY

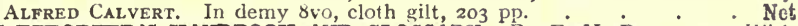
THE EXPORTER'S HANDBOOK AND GLOSSARY. By F. M. DUdENEY. W'ith Foreword by W. Eglington. In demy $8 \mathrm{vo}$, cloth gilt, $25+\mathrm{pp}$. . . Net

CONSULAR REQUIREMENTS FOR EXPORTERS AND SHIPPERS TO GLL PARTS OF TFIE WORLD. By J. S. NOWERY. In crown 8 vo, cloth, $82 \mathrm{pp.}$. Net

CASE AND FREIGHT COSTS. The principles of calculation relating to the cost of, and freight on, sea or commercial cases. By A. V. E. Crosfield. In crown 8 vo, cloth, $62 \mathrm{pp}$. . . . . . . . Net

HOW TO DO BUSINESS WITH RUSSIA. By C. E. W. PETERSSON and W. Barnes Steveni. In demy $8 \mathrm{vo}$, cloth, $200 \mathrm{pp} . \quad . \quad . \quad . \quad . \quad$. Net

\section{SECRETARIAL WORK}

COMPANY SECRETARIAL WORK. BY E. MARTIN, F.C.I.S. In crown 8vo,

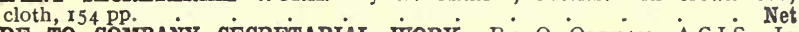
GUIDE TO CONPANY SECRETARIAL WORK. BY O. OLDHAM, A.C.I.S. In crown 8 vo, cloth gilt, $256 \mathrm{pp}$.

THE COMPANY SECRETARY'S VADE MECUM. Edited by PHIIP TOVEY, F.C.I.S. Second Edition, Enlarged and Revised. In foolscap 8vo, cloth, $247 \mathrm{pp}$. . Net

GUDE FOR THE COMPANY SECRETARY. By ARTHUR COLES, F.C.I.S. Illustrated with 75 facsimile forms. Second Edition, Revised and Enlarged. In demy 8vo, cloth gilt, $432 \mathrm{pp}$. . . . . . . . . Net

SECRETARY'S HANDBOOK. Edited by Herbert E. Blain. In demy 8vo, cloth gilt, $168 \mathrm{pp}$. . . . . . Net

THE CHAIRMAN'S MANUAC. By GúdDON PALIN, of Gray's Inn, Barrister-at-Law, and ERNEST MARTIN, F.C.I.S. In crown 8vo, cloth gilt, ro2 pp. . . Net

PROSPECTUSES: HOW TO READ AND UNDERSTAND THEM. By PHILP TOVEY, F.C.I.S. In demy $8 \mathrm{vo}$, cloth gilt, rog pp. Net

OUTLINES OF TRANSFER PROCEDURE IN CONNECTION WITH STOCKS, SHARES, AND DEBENTURES OF JOINT STOCK COMPANIES. BY F. D. HEAD, B.A. (OxOn), of Lincoln's Inn, Barrister-at-Law. In demy 8vo, cloth gilt, II2 pp. . . . . . Net

THE TRANSFER OF STOCKS, SHARES, AND OTHER MARKETABLi SECURITIES. A Manual of the Law and Practice. By F. D. HEAD,B.A. (Oxon). Second Edition, Revised and Enlarged. In demy 8vo, cloth gilt, 220 pp. . . Net

WHAT IS THE VALUE OF A SHARE? By D. W. Rossiter. In demy 8 vo, limp cloth, 20 pp. . . . . . . . Net

HOW TO TAKE MINUTES. Edited by E. MARTIN, F.C.I.S. Second Edition, Enlarged and Revised. In demy $8 \mathrm{vo}$, cloth, $126 \mathrm{pp}$. . . . . Net

DICTIONARY OF SECRETARIAL LAW AND PRACTICE. A comprehensive Encyclopaedia of information and direction on all matters connected with the work of a Company Secretary. Fully illustrated with the necessary forms and documents. With sections on special branches of Secretarial Work. Witlı contributions by nearly 40 eminent authorities. Edited by PhxLx TOveY, F.C.I.S. In one vol., half leather gilt, $940 \mathrm{pp}$. Second Edition, Revised and Enlarged . . Net 


\section{INCOME TAX}

PRACICAL INCOKE TAX. A Guide to the Preparation of Income Tax Returns. By W. E. SNELLING, of the Inland Revenue Department. In crown $8 \mathrm{vo}$, cloth, I $36 \mathrm{pp}$.

INCOME TAX ÁCCOUNTS AND FOW TO PREPARE THEM. In crown 8 vi, cloth, $136 \mathrm{pp}$.

LNCOME TAX AND SUPFR-TAX PRACTICE. Including a Dictionary of income Tax and specimen returns, showing the effect of recent enactments dowi to the Financ? Act, I9I7, and Decisions in the Courts. By W. E. SNELLiNG. In deny $8 \mathrm{vo}$, cloth gilt, $450 \mathrm{pp}$. . . . . . . . Net

DNCOME TAX TABLES, and Guide to the Deduction of Tax from Dividends, Interest, Ground Rents, ctc. Compiled by W. E. SNelling. In demy 8 vo, cloth gilt, $185 \mathrm{pp}$.

INCOME TAX AND SUPER-TAX LAW AND CASES. Including the Finance Act, 1917. With an Analysis of the Schedules, Guide to Income Tax Law, and Notes on Land Tax. By W. E. SNellivg. Third Edition, Revised. In demy 8vo, cloth gilt, $432 \mathrm{pp}$.

EXC aSS PROFInS (iacluding Excess Mineral Rights) DUTY, and Levies under the ifunilions ci War Acts. Incorporating the Provisions of the Income Tax Acts made applicable by Statute and by Regulation, also the Regulations of the Commissioners of Inland Revenue, and of the Minister of Munitions. By W. E. SNÉLliNG. Third Edition, Revised and Enlarged. In demy 8vo, cloth gilt, $262 \mathrm{pp}$.

\section{BUSINESS ORGANISATION AND MANAGEMENT}

IEE PSYCHOLOGY OF MANAGEMENT. The Function of the Mind in Determini:ig, Teacining, and Installing Methods of Least Waste. By L. M. GILBretr. In demy 8 vo, cloth gilt, $354 \mathrm{pp}$. . . . . Net

OFFICE ORGANISATION AND MANAGEMENT, INCLUDWG SECRETARIAL WORY. By Lawrence R. Dicksee, M.Com., F.C.A., and H. E. Blain. Fourtiı Edition, Revised. In demy 8vo, cloth gilt, 306 pp. . . . Net

MUNICIPAL OEFICE ORGANISATION AND MANAGEMENT. A comprehensive Manual of information and direction on matters connected with the work of Officials of Municipalities. Edited by W. BATESON, A.C.A., F.S.A.A. With contributions by eminent authorities on Municipal Work and Practice. In crown 4 to, half leather gilt, with 250 forms, diagrams, etc., $503 \mathrm{pp}$. . Net

COUNTRTG-HOUSE AND FACTORY ORGANISATION. BY J. GILMOUR WILLIAMSON. In demy $8 \mathrm{vo}$, cloth gilt, $182 \mathrm{pp}$. Net

SOLICITOR', OFFICE ORGANISATION, MANAGEMENT, AND ACCOUNTS. By E. A. Cope, and H. W. 1H. RoBINs. In demy 8vo, cloth gilt, 176 pp., with numcrous forms

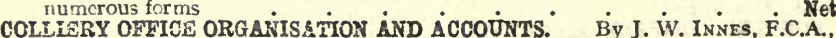
and T. COLIN CAMPBELl, F.C.I. In demy $8 \mathrm{vo}$, cloth gilt, $135 \mathrm{pp}$. Net

CLUBS AND THEIR MANAGEMENT. By FRANCIS W. PIXLEY, F.C.A. Of the Middle Temple, Barrister-at-Law. In demy $8 \mathrm{vo}$, cloth gilt, $240 \mathrm{pp}$. . Net

DRAPERY BUSINESS ORGANISATION, MANAGEMENT AND ACCOUNTS. BY J. ERNEST BAYLEY. In demy $8 \mathrm{vo}$, cloth gilt, $302 \mathrm{pp}$. Net

GROCERY BUSINESS ORGANISATION AND HANAGEMIENT. By C. L. T. BEEching. With Chapters on Buying a Business, Grocers' Office Work and Book-keening, and a Model Set of Grocer's Accounts. By J. Arthur Smart. In derry $8 \mathrm{vo}$, cloth gilt, $160 \mathrm{pp}$, with illustrations . . . . Net INDUSTRIAL TRAFIC HANAGEMENT. By GEO. B. LISSENDEN. With a Foreword by C. E. MU;GRAve. In demy 8vo, cloth gilt, $260 \mathrm{pp}$. . . Net SHIPPNG ORGANISATION, MANAGEMENT AND ACCOUNTS. (See p. 7.)

IN SURANCE OFFICE ORGANISATION, MANAGEMENT AND ACCOUNTS. (See p. 7.) BANE ORGANISATION AND MANAGEIEENT. (See p. 6.)

STOCKBROKTRS' OFFICE ORGANISATION, MANAGEMENT AND ACCOUNTS. (See p. 10.)

THE CARD INDEX SYSTaR. Its Principles, Uses, Operation, and Component Parts. In crown 8vo, cloth, roo pp. . Net

FIUING SYSTEMS. Their Principles and Their Application to Modern Office Requirements. By E. A. COPE. In crown $8 \mathrm{vo}$, cloth gilt, 200 pp., with illustrations . . . . . . . . Net a manual of dupiicating. 'By W. Désborougir. In demy $8 \mathrm{vo}$, cloth, $90 \mathrm{pp}$.

\section{ADVERTISING AND SALESMANSHIP}

ADVERTISING. By HowARD BRIDGEWATER. In crown $8 \mathrm{vo}$, cloth, $120 \mathrm{pp}$. . Net HANDBOOK OF ADVERTISING. By CHRISTOPHER JONES. In crown \&vo, cloth 


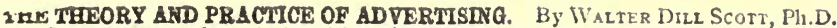
In large crown $8 \mathrm{vo}$, cloth, with $6 \mathrm{x}$ illustrations, $240 \mathrm{pp}$. . . . . Net

THE PSYCHOLOGY OF ADVRRTISING. By the same Author. In large crown Svo, cloth gilt, with 67 illustrations, $282 \mathrm{pp}$. . . . . . . . Net

ADVERTISING AS A BUSLNESS FORCE. 'By P. T. C̈IERINGToN, Ii demy 8vo, cloth gilt, $586 \mathrm{pp}$.

THE PRINCIPLES OF ADVERTISTIG ARRANGEMENT. By 'F. A. PARSONS. Size 7 in. by rof in., cloth, $128 \mathrm{pp}$., with many illustrations . . . Net

THE NEW BUSDESS. By HARRY TIPPER. In demy $8 \mathrm{vo}$, cloth gilt, $406 \mathrm{pp}$. Net

THE CRAFT OF SILENT SALESMAVSHIP. A Guide to Advertisement Construction. By C. MAXWell TREgurtha and J. W. Frings. Foreword by T. Swinborne SHELdRAKe. Size, $6 \frac{1}{2}$ in. by $9 \neq$ in., cloth, $98 \mathrm{pp}$., with illustrations . Net

SALESMANSHIP. By W. A. Corbion and G. E. Grimsdale. In crown 8vo, cloth, I86 pp. . . . . . . Net

PRACTCAL SAIESHANSHIP. By N. C. FowLER, assisted by 29 expert Salesmen, etc. In crown 8vo, cloth, $337 \mathrm{pp}$. . . . . . . Net

COMMERCIAL TRAVEIITG. BY ALBERT F. BuLl. In crown $8 \mathrm{vo}$, cloth gilt, I70 pp.

\section{BUSINESS HANDBOOKS AND WORKS OF REFERENCE}

COMMERCLAT ENCYCLOPAEDIA AND DICTIONARY OF BUSINESS. Edited by J. A. Slater, B.A., LL.B. (Lond.). Of the Middle Temple and North-Eastern Circuit, Barrister-at-Law. Assisted by upwards of 50 specialists as contributors. A reliable and comprehensive work of reference on all commercial subjects, specially designed and written for the busy merchant, the commercial student, and the modern man of affairs. With numerous maps, illustrations, facsimile business forms and legal documents, diagrams, etc. In 4 vols., large crown 4 to (each about $450 \mathrm{pp}$.), cloth gilt Half leather gilt designed for commercial students, clerks, and teachers. Edited by ROBERT W. HollaNd, M.A., M.Sc., LL.D. Assisted by upwards of 40 Specialists as contributors. With many maps, illustrations, documents, Diagrams, etc. Complete in 2 vols., crown 4 to - cloth gilt, about 900 pp., sprinkled edges . . . Net

BUSINESS MAN'S GUIDE. Edited by J. A. SLATER, B.A., LL.B. Seventh Edition, Revised. In crown 8 vo, cloth, $520 \mathrm{pp}$.

PUBLIC MAN'S GUIDE. Edited by J. A. Slater, B.A., Li.B. (Lond.). A Handbook for all who take an interest in questions of the day. In crown $8 \mathrm{vo}$, cloth

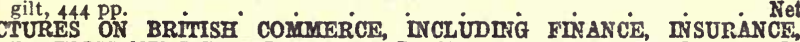
BUSINESS AND INDUSTRY. By the RT. HON. FREDERICK HUTH J ACKSON, G. ARMITAGE-SMITH, M.A., D.Litt., ROBERT BRUCE, C.B., etc. In demy 8 vo, cloth gilt, 295 pp. . . . Net

THE MONEY AND THE STOCK AND SHARE MARKETS. By EML DAVIES. In crown $8 \mathrm{vo}$, cloth, 124 pp. . . . . Net

TRE EVOLUTON OF TBR PIONEY MAREET (1385-1915). An Historlcal and Analytical Study of the Rise and Development of Finance as a Centralised, Coordlnated Force. By Ellis T. Powell, LL.B. (Lond.), D.Sc. (Econ., Lond.), Fellow of the Royal Historical Society, the Royal Economic Society, and the Institute of Journalists; of the Inner Temple; Barrister-at-Law. In demy $8 \mathrm{vo}$, cloth gilt, $748 \mathrm{pp}$. Net

THE HISTORY, LAW, AND PRACTICE OF THE STOCK EXCHANGE. BY A. P. POLEY, B.A., Barrister-at-Law, and F. H. CARRUTHers Gould, of the Stock Exchange. Second Edition, Revised. In demy $8 \mathrm{vo}$, cloth gilt, $348 \mathrm{pp}$. . Net

STOCKBROKKER' OFFICE ORGANISATION, MANAGEMENT AND ACCOUNTS. By J. E. DAY. In demy 8vo, cloth gilt, $242 \mathrm{pp}$. Net

DICTIONARY OF THE WORLD'S COMMERCIAI PRODUCTS. By J. A. SLATER, B.A., LL.B. (Lond.). Second Edition, Revised. In demy $8 \mathrm{vo}$, cloth, I6 3 pp. .

OFFICE DESK BOOK. Second, Revised and Cheaper Edition. In crown 8vo, cloth, 309 pp. . . . . . . . . . . . Net

TELEGRAPH CIPHERS. A condensed vocabulary of $101,000,000$ pronounceable artificial words, all of ten letters. By A. W. E. CrosFIELD. Size I2 in. by 12 in., cloth

MASTERS' NEW READY RECKONER. Pitman's Edition. 'Contains 63,000 calculations. In foolscap $8 \mathrm{vo}$, cloth, $358 \mathrm{pp}$. . . . . . Net

DISCOUNT, COMMISSION, AND BROKERAGE TABLES. By ERNEST HEAVINGHAM.

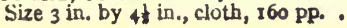


BỨSINESS TERMS, PHRASES AND ABBREVIATIONS. Fourth Edition, Revised and Enlarged. In crown $8 \mathrm{vo}$, cloth, $280 \mathrm{pp} . . . . .2 \mathrm{.}$. .

MERCANTILE TERMS AND ABBREVIATIONS. Containing over $i, 000$ terms and 500 abbreviations used in commerce, with definitions. Size 3 in. by 4 in., cloth, $126 \mathrm{pp}$.

TRAMWAY RATING VALUATIONS AND INCOME TAX ASSESSMENTS. By F. A. Mrtcheson. In demy 8vo, cloth gilt ... . . . . Net THE TRADER'S GUIDE TO COUNTY COURT PROCEDURE. In foolscap 8vo, cloth, II2 pp.

A COMPLETE GUIDE TO THE IMPROVEMENT OF THE MEMORY. By the late Rev. J. H. BAcon. In foolscap 8vo, cloth, iI 8 pp. . . Net HOW TO STUDY AND REMEMBER. BY B. J. DAVIES. Third Edition. In crown 8vo

THE NEW REGISTER-ACCOUNT BOOK. Compiled by H. R. STANILAND, P.C.T., A.C.T.S. Size 9 in. by $5 \frac{1}{2}$ in., 50 pp., specially ruled, qr. cloth. . Net

TRADER'S HANDBOOKS. In crown 8vo, cloth, $260 \mathrm{pp}$. . . . Each Net Drapery and Drapers' Accounts. By RichARD BEYNON.

Grocery and Grocers' Accounts. By W. F. Tupman.

Ironmongery and Ironmongers' Accounts. By S. W. Francis.

\section{COMMON COMMODITIES OF COMMERCE}

Each book in crown $8 \mathrm{vo}$, cloth, with many illustrations, about $130 \mathrm{pp}$. . Net TEA. From Grower to Consumer. By A. I BBETSON.

COFFEE. From Grower to Consumer. By B. B. Keable.

SUgar, Cane and Beet. By Geo. Martineau, C.B.

OILS. Animal, Vegetable, Essential, and Mineral. By C. Ainsworth Mitcherr, B.A., F.I.C.

WHEAT AND ITS PRODUCTS. BY ANDREW MILLAR.

RUBBER. Production and Utilisation of the Raw Product. By C. BeAdLe and H. P. Stevens, M.A., Ph.D., F.I.C.

IRON AND STEEL. Their Production and Manufacture. By C. Hood.

COPPER. From the Ore to the Metal. By H. K. PICARD, Assoc. Royal School of Mines, Mem. Inst. of Min. and Met.

COAL. Its Origin, Method of Working, and Preparation for the Market. By Francis H. WILSON, M.Inst.M.E.

TIMBEER. From the Forest to its Use in Commerce. By W. Bullock.

LEATMER. From the Raw Material to the Finished Product. By K. J. ADcock.

COTrON. From the Raw Material to the Finished Product. By R. J. PEAkE.

SILK. Its Production and Mannfacture. By LUTHER HOOPER.

WOOL. From the Raw Material to the Finished Product. By J. A. Hunter.

LINEN. From the Field to the Finished Product. By Alfred S. Moore.

TOBACCO. From Grower to Smoker. By A. E. TANNER.

CLAYS AND CLAY PRODUCTS. By Alfred B. SEARle.

PAPER. Its History, Sources, and Production. By H. A. MADdox, Silver Medallist, Paper-making, r9o9.

SOAP. Its Composition, Manufacture, and Properties. By William A. Simmons, - B.Sc. (Lond.), F.C.S.

Other volumes in preparation. 
WILLS, EXECUTORS, AND TRUSTEES. With a Chapter on Intestacy. By J. A. Slater, B.A., LL.B. (Lond.). In foolscap $8 \mathrm{vo}$, cloth, 122 pp. . Net

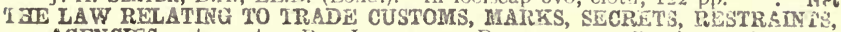
AGENCIES, etc., ete. By LAWRENCE DUCKWORTH, Barrister-at-Law. I.1 foolscap 8vo, cloth, II6 pp. . . . . J Jet

BIERCANTHE LEW. By J. A. Slater, B.A., Li..B. (i. md.). In demy 8vo, (cleth gilt, $464 \mathrm{pp}$. Third Edition, Revised . . . . Net

BIIS, ChEQUES, AND NOTES. By J. A. Slater, B.A., Ll.B. Second Edition, Revised. In demy $8 \mathrm{vo}$, cloth gilt, $2 \mathrm{I}_{4} \mathrm{pp}$. . . . . Net

PRINCIPLES OF MARINE LAW. By LAWRENCE Duckworth. Third Edition, Revised and Enlarged. In demy 8vo, cloth gi't, $400 \mathrm{pp}$. . Net

OUTLRNES OF COMPAiYY LAW. BY F. D. HEAD, B.A. (Oxon.). In demy 8vo,

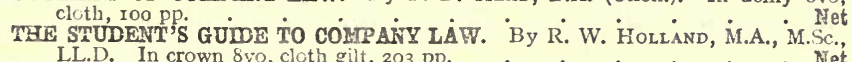

EXANDNATION NOTES CN COMPANY LAW. By R. W. Holland, il.A., M.Sc., LL.D. Cloth, $6 \frac{1}{2}$ in. by $3 \frac{1}{2}$ in., $56 \mathrm{pp}$. . . Net

COMPANISS AND COMPANY LAW. TOgether with the Companies (Consolidation) Act, 1908, and the Act of I9I3. By A. C. ConNell, LL.B. (Lond.). Second Edition, Revised. In demy 8 vo, cloth gilt, $34^{8} \mathrm{pp}$. Net

COMPANY CASEL LAW. A digest of leading decisions. By F.D. HEAD, B.A. (Oxon.). In demy $8 \mathrm{vo}$, cloth gilt, 314 pp. Net

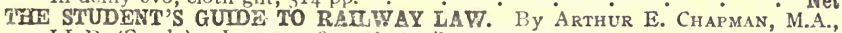
LL.i. (Camb.). In crown 8vo, cloth gilt, $200 \mathrm{pp}$. . . . . . Net

RAILWAY (REBATES) CASE LAW. BY GEO. B. LisSenden. In demy sio, cloth gilt, $450 \mathrm{pp}$. . Net

TIE LAW RELATNG TO SECRET COMMISSTONS AND BRIBES (CHRISTMAS BOXES, GRATUITIES, TLPS. etc.). The Prevention of Corruption Act, 1606. BY ALBERT CREW, of Gray's Im, and the South-Eastern Circuit, Barrister-at-Law. In demy $8 \mathrm{vo}$, cloth gilt, $198 \mathrm{pp}$. . . Net

HOUSEHOTD LAW. BY J. A. Slater, B.A., Li.B. (Lond.). In demy $8 v 0$, cloth gilt 3 I6 pp.

THE JAW OF CARRIAGE. By J. E. R. SंTEPHENS, B.A., of the Middie Temple, Barrister-at-Law. In demy $8 \mathrm{vo}$, cloti gilt, $310 \mathrm{pp}$. Net

THE LAW RELATIYG TO THE CARRIAGE BY LAND OF PASSENGERS, ANIMALS, AND GOODS. By S. W. CLARKE, of the Middle Temple, Barristerat-Law. In demy $8 \mathrm{vo}$, cloth gilt, $350 \mathrm{pp}$. Net

THE STUDENT'S GUDW TO BATKRUPTCY LAW AND WINDRT UP OF COMPANIES. By F. PORTER FAUSSET, B.A., LL.B., Barrister-at-Law. In crown $8 \mathrm{vo}$, cloth gilt, I96 pp. . . . . . . . Net

BANKRUPTCY, DEFDS OF ARRANGEMEENT AND BLIS OF SATE. By W. VAlentine Ball, M.A., and G. Mills, B.A., Barristers-at-Law. Third Edition, Revised and Enlarged. In demy 8vo, cloth gilt, $364 \mathrm{pp}$. . . . Net

FARM LAW. By M. G. Johnson. In demy 8 vo, cloth gilt, r6o pp. : : Net

GUDE TO THE LAW OF IICENSING. The Handbook for all Licence Holders. By J. Wells Thatcher. In demy $8 \mathrm{vo}$, cloth gilt, $196 \mathrm{pp}$. . . . Net

LAW OF REPAIRS AND DLLAPIDATIONS. A Handbook for Students and Practitioners. By T. CATO WORSFOLD, M.A., LL.D. In crown 8vo, cloth gilt,

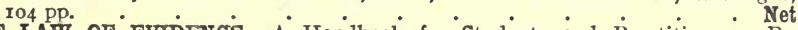

TEE LAW OF EVIDENCE. A Handbook for Students and Practitioners. By W. Nembiard HibeERT, LL.D. (Lond.), Barrister-at-Law of the Middle Temple. In crown 8vo, cloth gilt, I 44 pp. Second Edition, Revised . Net

THE LAW OF PROCEDURE. A Handbook for Students and Practitioners. By the same author. In demy $8 \mathrm{vo}$, cloth gilt, $122 \mathrm{pp}$. . Net

IFANDBOOK OF LOCAL GOVERNMENT LAW. BY' J. WELLS THATCHER. In large crown 8vo, cloth gilt, $250 \mathrm{pp}$. Net

THE IAW RELATTNG TO THE CIILD : ITS PROTECTION, EDUCATION, AND EMPLOYMINT. By R. W. Holland, M.A., M.Sc., LL.D. In demy 8vo, cloth gilt, I $66 \mathrm{pp}$.

INCOUE TAX AND SUPER-TAX IAW AND CASES. (See p. 8.)

\section{FOREIGN LANGUAGES}

\section{FRENCH}

6 CEILD'S FIRST STEPS IN FRENCH. By A. VIZETELLY. An elementary French reader with vocabulary. Illustrated. In crown 8vo, limp cloth, $64 \mathrm{pp}$.

FRENCG COURSE. Part I. In crown 8vo, 94 pp. Paper, 6d, net; cloth Net

KEY TO PITMAN'S FRENCH COURSE. Parts I azd If In crown 8vo, each Net 
PITHAN'S SHORTHAND PASMURS. In three buoks: Elementary, Intermediate, and Advanced . . . . . Each, 6d. Keys, each PJ TMAN'S SFORTHAND READING LESSONS. Nos. 1,2 and 3 . Each IK YS TO "PITINAN'S SHORTHAND READING LESSONS," NOS, I, 2, and 3 Each PEIMAN'S SHORTHAND COPY BOOKS. Nos. 1, 2, 3, and 4. An entirely new series covering the theory of the system. Foolscap 4 to ( $8 \frac{3}{3}$ in. by $6 \frac{1}{2}$ in.) . Each

FITHAN' 'S SHORTAAND DRILL EXERCISES. Oblong

CCMPENT OE PITMAN'S SHORTHAND.

PITMAN'S SHORTHAND LNS'IRUCTOR. Complete Instruction in the System. Cloth

THE CANTWWARY CHANGES TN PITMAN'S SHORTRAND Key, 1/-; cloth SUMMARIES FROM "PIMAN'S SHORTHAND INSTRUCTOR." Size, $2 \frac{7}{8}$ in. by 4 in.

PIIMAN'S SHORTHAND MANUAL. Contains instruction in the Intermediate Style, with roo Exercises

PITRAN'S SHORTHAND GRADUS. Writing Exercises in ordinary print for Manual

FIL LIAN'S SHORTHAND REPORTER. Containing instruction in the Advanced Style : with 52 Excrciscs

6.

2d.

REFORTITG EXERCISES. Exercises on all the rules and contracted words. In ordinary print, counted for dictation . . . . . . 6d.; Key PTXYAN'S SHORTHAND CATECHISM. In crown 8vo

FICHAN'S SHORTHAND WRITUG EXERCISES AND EXAMINATTON TESTS. In crown 8vo, paper boards

EXAKITATION NOTES ON PITMAN'S SHORTHAND. By H. W. B. WILSON. 8 in. by $3 \frac{8}{4}$ in., cloth

GRADED SHORTHAND READTNGS.

Hlementary, with Key. In crown 8vo, oblong

\section{Intcrmediate, with Key. In crown $8 \mathrm{vo}$, oblong}

Advanced, with Key. In crown $8 \mathrm{vo}$, oblong

GRADUATED TESTS IN PITMAN'S SHORTHAND. Illustrating all the rules in the Intermediate Style. In note-book form, post 8 vo $\left(6 \frac{1}{2}\right.$ in. by $4 \frac{1}{2}$ in.), with ruled paper

PROGRESSIVE 'STUDIES IN PITMAN'S SHORTHAND.

TAIKS WITH SHORTHAND STUDENTS. BY JAMES HYNES

CTATS ABOUT PITMAN'S SHORTHAND. BY GEORGE BLETCHER

PITIAN'S SHORTHAND RAPID COURSE. A Series of Twenty Simple Lessons covering the whole of the system and specially adapted for business purposes. In crown 8vo. . . . . . . . . . Cloth

PITMAN'S SHORTMAND RAPID COURSE, ADDITONAL EXERCISES ON

READING EXERCIS ES ON THE RAPID COURSE (In Shorthand), crowa 8vo, 62 pp.

PITMAN'S SHORTHAND COMMLRCIAL COURSE. Specially adapted for commercial students

$\mathbf{K e y , ~ 1 / 6}$; Additional Ex Cloth

PITMAN'S EXERCISES IN BUSLNESS SHORTHAND. By A. BENJAMIN, I.P.S. (Hons.), F.C.Sp.T.

\section{GRAMMALOGUES AND CONTRACTIONS}

GRAMMALOGUES AND CONTRACXIONS. For use in classes

VEST POCKET LIST OF GRAMMAZOGUES AND CONTRACIION'S OF PITMAN'S SHORTHAND. 2 s in. by $\mathrm{r} \frac{3}{4}$ in., limp cloth

EXERCISES ON THE GRAMRALOGUES AND CONTRACITONS OF PITMAN'S SHORTHAND. By J. F. C. GRow. In Shorthand, with Key. In crown 8vo,

IIOW TO PRACTISE AND MEINORISE THE GRAMMALOGUES OF PITMAN'S SHORTHAND. Compiled by D. J. GEORGE. Size 7 in in. by 5 in.

\section{SHORTHAND DICTIONARIES}

PTTWAN'S ENGLISH AND SHORTHAND DICTIONARY. In crowi $8 \mathrm{vo}$, cloth, $820 \mathrm{pp}$. PTKMAN'S SHORTH AND DICTIONARY. CrOWn $8 V^{\circ}$ ( 71 in. by 51 in.), $378 \mathrm{pp}$. Cloth

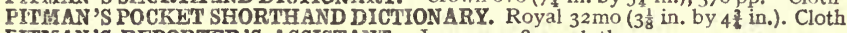
FITLEAN'S REPORTER'S $\triangle$ SSISTANT. In crown 8vo, cloth 


\section{SHORTHAND PHRASE BOOKS, ETC.}

PHONOGRAPHIC PHRASE BOOK. . . . . . . 1/-; Clith SHORTHAND WRIIERS' PHRASE BOOKS AND GUIDES. Each in foolscap 8vo, Cloth . . . . . . Not Electrical and Engineering, Shipping, Railway, Estate Agents, etc., Printing and Publishing, Insurance, Banking, Stockbroking and Financial, Commercial, Legal, Municipal, Iron and Steel Trades, Civil Engineering, Naval and Military. Others in preparation.

MEDICAL REPORTING IN PITMAN'S SHORTHAND. By H. DICKINSON. With an Introduction and Lists of Phraseograms, Outlines, and Abbreviations. In crown 8vo, cloth SHORTHAND CLERK'S GUIDE. BÿVINCENT E. CoLLINGE, A.C.I.S. In crown 8vo, cloth .

\section{DICTATION AND SPEED PRACTICE BOOKS}

SPECIALISED CORRESPONDENCE BOOKS. (1) The Chemical Trade. (2) The Paper Trade. (3) The Building Trade. In ordinary print . . Each GRADUATED DICTATION BOOKS. (1) Political Speeches. (2) Sermons. (3) Commercial. (4) Speeches (Commercial) and Addresses. Il ordinary print. In

GR ADUATED DICTATION BOOKS. (New Sries) I and II. $: \dot{*}^{\circ}$. Each

GRADUATED COMMERCIAL LETTERS FOR DICTATION. 81 in. by 6 in. .

REPORTING PRACTICE. In crown 8vo, cloth .

PROGRESSIVE DICTATOR. Third Edition. In crown 8vo, cloth .

SHORTHAND CANDIDATE'S DICTATION EXERCISES. In crown 8vo, cloth :

COMMERCIAL DICTATION AND TYPEWRIIING

SPEED TESTS AND GUDE TO RAPID WRITLNG IN SHORTHAND. In crown 8 vo, cloth

FIVE MUNUTE SPEED TESTS. With Introduction on Acquisition of Speed by P. P. JACKSON. In crown 8vo, cloth

CUMULATIVE SPAILER AND SHORTHAND VOCABULARY. By CHARLES E. SMITH. In crown 8vo, cloth

POCKET DICTATION BOOKS, Nंos. $1,2,3$, and 4 . $2 \frac{7}{9}$ in. by $3 \frac{3}{4}$ in. : Each SPEED TRAINING IN PITMAN'S SHORTHAND. By T. F. MARRINER . . ACQUISITION OF SPEED IN SHORTHAND. By E. A. COPE. In ordinary print.

BROWN'S SHORT-CUTS IN SHORTHAND. By Grorge BROWN, F.I.P.S. In crown $8 \mathrm{vo}$.

THE STENOGRAPHIC EXPERT. By W. B. BotTome and $\dot{W}$. F. Śmart. In demy $8 \mathrm{vo}$, cloth . . . . . . Net SHORTHAND COMMERCIAL LETTER-WRITER. Advanced Style : 1 -; Key OFFICE WORK IN SHORTHAND. Specimens of Legal and other Professional Work commonly dictated to Shorthand clerks, in the Advanced Style 1/-; Key COMMERCIAL CORRESPONDENCE IN SHORTHAND. In crown 8vo, cloth

BUSINESS CORRESPONDENCE IN SIIORTHAND. In the Advanced Style. 1/-; Key TRADE CORRESPONDENCE IN SEORTHAND. In the Advanced Stvle. 1/-; Key MISELLANEOUS CORRESPONDENCE IN PITMAN'S SHORTHAND. First, Second, and Third Series. Advanced Style, with Keys in ordinary print. Each in crown $8 \mathrm{vo}$, oblong. Limp cloth

\section{SHORTHAND READING BOOKS}

In the Elementary Style.

ARSOP'S FARLES

EASY READINGS. With Key

LEARNER'S SHORTHAND READER. Illustrated.

STIRRING TAKES

In the Intermediate Style.

PITMAN'S PHONOGRAPHIC READER, No. 1. With Key .

GULIVER'S VOYAGE TO LILIPUT. By Jonathan Swift. With Key. Cloth SUBMARINE XY AND OTHER STORIES. Illustrated

THE VICAR OF WAKEFIELD. By OLIVER Goldsmitr. Illustrated. $2 /-$; Cloth TALES AND SKETCHES. By WaShINGTON IRving. With Key. 1/-; Cloth TALES OF ADVENTURE. By various Authors

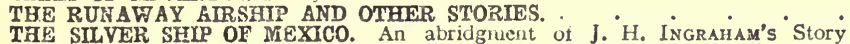

SFLFCT READTNGS, NOS, 1 and 2 Cloth THE BOOK OF PSALMS. Bible Authorised Version. 'Cloth gilt, red edges : Each

64.

6d.

6d.

$8 d$.

6d.

1/6

$1 /-$

2/6

1/6

1/-

1/-

$1 / 6$

6d.

$2 / 6$ 
COMGERCLAL READERS IN SHORTHAND. Commodities. (3) Leaders of Commerce. (4) Gatoways of British Commerce.

In the Advanced Stylo.

PBONOGRAPBIC READER II. With Key

A CHRISTMAS CAROL. BY CHARLES DICKENS.

TALES FROM DIOKENS

THE SIGN OF FOUR. By SIR A. CONAN DOYLE

A

SELF-CULTURE. BY J. S. BLACKIE. Eaci, cloth

.1/-; Cloth, 1/6; Key THE LEGEND OF SLEEPY HOLLOW. By WASIINGTON IRving. With Key : RIP VAN WINKLE. By WASHINGTON IRVING. With Key $\triangle$ COURSE IN BUSINESS TRAINIYG. By G. K. BuckNall, A.C.I.S. (Shorthand Edition), $288 \mathrm{pp}$.

\section{SHORTHAND TEACHERS' BOOKS}

PITMAN'S SHORTEAID TEACHER'S HBIDBOOK. In crown 8vo, cloth

NOTES OF LESSONS ON PITHAN'S SFORTHAND. Size 8 in. by 3 in., cloth PREPARATION FOR A SHORTHAND TEACHER'S EXAMTNATION. Size 8 in. by 3 ill., cloth

A COMMENTARY ON PITHAN'S sBORTHAND. By J. W. TAYLOR. "In foolscap $8 \mathrm{vo}$, cloth gilt, $44^{8} \mathrm{pp}$.

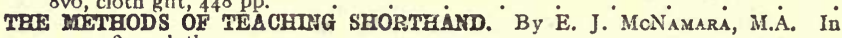
crown 8vo, cloth

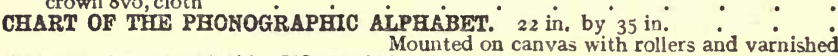
CRARTS ON PITMAN'S SHORTHAND. Twenty large Charts (22 in. by 35 in.)

\section{TYPEWRITING}

TBE JUNIOR TYPIST. By ANNIE E. DAvis. Demy 8vo, cloth

NEW COURSE IN TYPEWRITTHG. By Mrs. SMITH Clough. Large post 4 to

PITHAN'S TYPEWRITER MANUAT. Can be used with any machine. Sixth Edition. Large post 4 to, cloth

PITMAN'S TYPEWRITIYG EXAMPLES for any machine-

On cards, 48 examples, foolscap folio

In oblong note-book, for standing by the side of the machine .

In note-book form, in covers

PIIRAN'S EXTRCISES AND TESTS IN TYPEWRITWG. Foolscap folio. Quarter cloth. Third Edition, revised

HOW TO THACH TYPEWRITING. By Kate Pickard, B.i. (Lond.). Crowi 4to. cloth . . Net PRACTICAL COURSE IN TOUCH TYPEWRITING. 'By C. E. Smiti. English Edition, revised and enlarged. Size, $8 \frac{1}{2}$ in. by $\mathbf{I}$ in.

PRACTICAL TOUCH TYPEWRITING CAART. Size, 30 in. by $40 \mathrm{in}$. $^{\circ}$. Net

REMUNGTON TYPEWRITER MANUAL. FOR Nos. 5 and 7 , ro and II. With Exercises and Illustrations. Ninth Edition. Large post 4to. . .13; Cloth THE UNDERWOOD TYPEWRTTER MANUAL. BY A. J. SYLVESTER. 1, arge pust 4 to

BAR-LOCK TYPEWRITER NinANUAL (Group System of Touch Typewriting). By H. ETHERIDGE. Latge post $4^{\text {to }}$

INSTRUCTIONS ON THE REMIJGTON (Nos. $7, \dot{8}$, ro and ii), YosT (Ño. ro), and BARLOCK TYPEWRITERS. Each, demv 8vo

2:6

1.6

$2 /-$

2/-

6d.

KODERN-TYPEWRITRG AND MANUAL OF OFFICE FROCEUURE. By A. E. Morton. $6 \frac{1}{2}$ in. by $9 \frac{1}{2}$ in.. cloth

\section{PERIODICALS}

Complcte list post free on application.

PITMAN'S JOURNAL. Subsctiption, which may begin at any time, 10/10 ver dunuin, post free. (Estab. 1842$)_{2} 32 \mathrm{pp}$.

FITHAN'S SEORTHAND WEEKLY. (Estab. 1892.)

Werklv 2d. by post $22 \pi$.

Weekly $2 \mathrm{~d}$., by post $2 \frac{1}{2} \mathrm{~d}$.

Pitman's Complete Commercial and Shorthand Catalogues containing rull particulars of the books referred to in this Cetalogue will be sent post tree on application.

I AMEN CORNER, LONDON, E.C. 4. AND AT BATH, NEW YORK \& MELBOURNE 



\section{UNIVERSITY OF CALIFORNIA LIBRARY}

\section{BERKELEY}

Return to desk from which borrowed.

This book is DUE on the last date stamped below.

\section{DEC 8 1947}

4Jan'5 $5 . B C N$

108pros!LU 


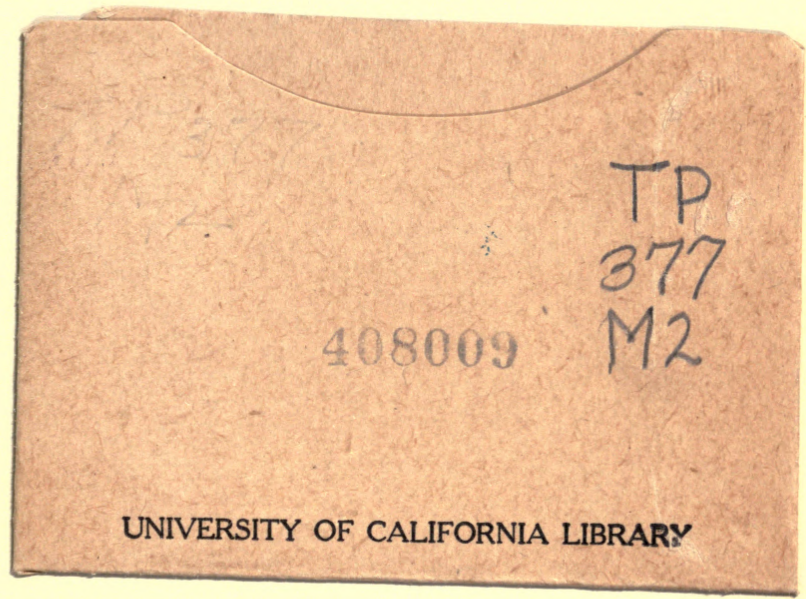


